SERVIÇO DE POS-GRADUAÇĀO DO ICMC-USP

Data de Depósito: 18 de Fevereiro de 2003

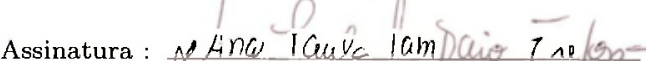

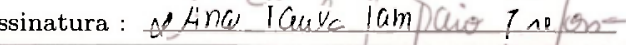

\title{
Técnicas de Segmentação de Imagens Aéreas para Contagem de População de Aves
}

André Guilherme Ribeiro Balan

Orientador: Prof. Dr. João do Espírito Santo Batista Neto

Dissertação apresentada ao Instituto de Ciências Matemáticas e de Computação - ICMC-USP, como parte dos requisitos para obtenção do título de Mestre em Ciências, na área de Ciências de Computação e Matemática Computacional.

USP - São Carlos

Fevereiro de 2003 
A Comissão Julgadora:

Prof. Dr. João do Espirito Santo Batista Neto

Prof. Dr. Ronaldo Fumio Hashimoto

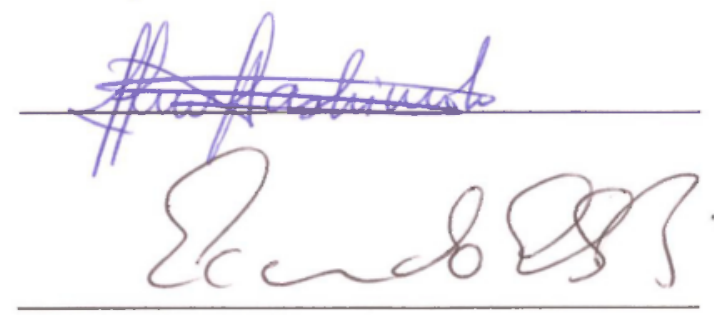

Prof. Dr. Evandro Eduardo Seron Ruiz 
A Densis pela vida

( aos mens pais Antonio ana. pelo amor: carinho apoio. 


\section{Agradecimentos}

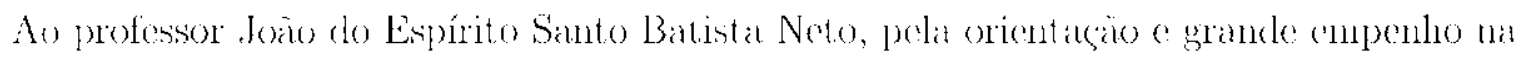
roulizaçäo cleste traballho

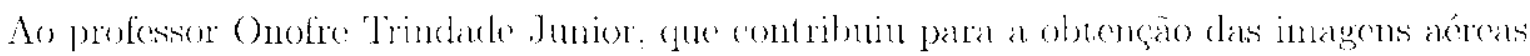
utilizaluas:

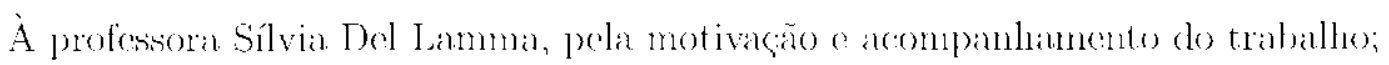

Ao CNP'e pelo apoio financeriro;

E a todos os mous amigos o fandiatres pelo companheirismo e incentivo. 
() monitoranento biológico de determinadas espócios de aves representa una fonte impor-

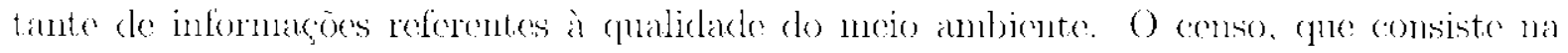
contagen don indivíluos do uma populaçäo é una das principais variáveis desto procosso.

Fin virtude deste contexto, o trabalho proposto nesta dissertaca tem como objetivo

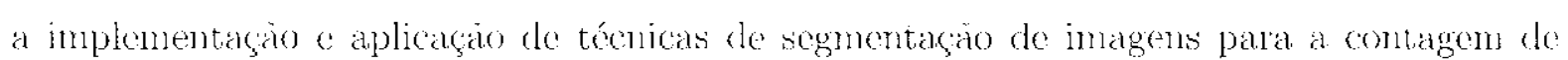

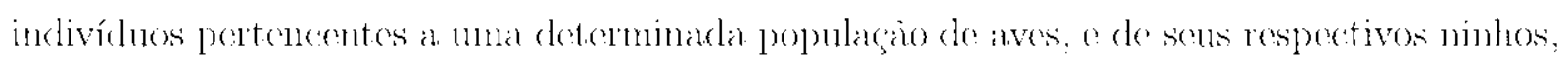

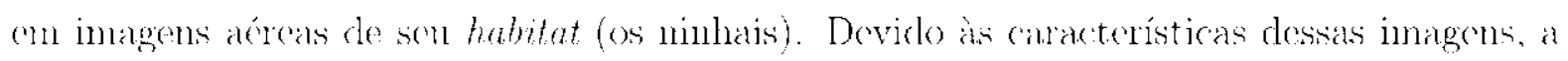
segmentaça bascada em textura é adotada como abordagem principal do projeto.

() método escolhido parat este estudo faz parte do conjunto de mótodos baseados em

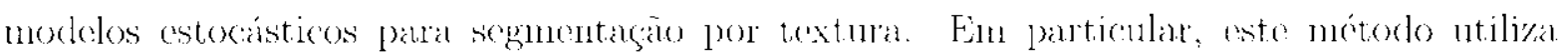
como modelo fundannental um Campo Aloatório do Markov (Markon Random Field).

Fista dissertacão apresenta os fundamentos cstatísticos da lécnica adolada, bem como

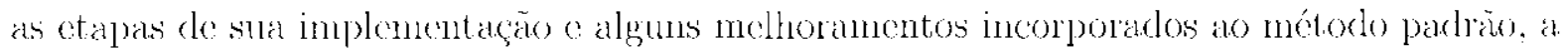

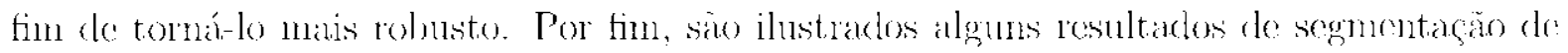
imagens to ninhatis. bem emo o de algumas imagens sintritias e imagens de modalidade médica. As imagens aéreas sio arlquiridas em parceria com orltro projeto cm curso no ICMC-USP': o Projeto ARARA (Acronaves de Reconhecinento Assisticlas por Rárlio o Altionomasis). 
The biological monitoring of ecetain speries of bircls reperesents an inportant sonece of in-

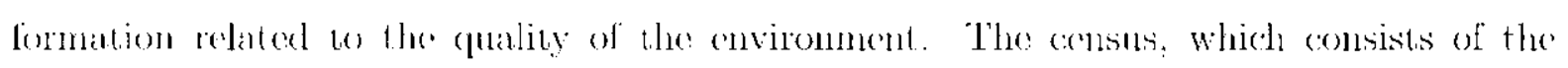
quantification of individuals, is one of the key factors of this process

On this context, the work proposed in this dissertation aims the implementation and employment of indge segmentation techniques for counting indivicluals of a specilic population

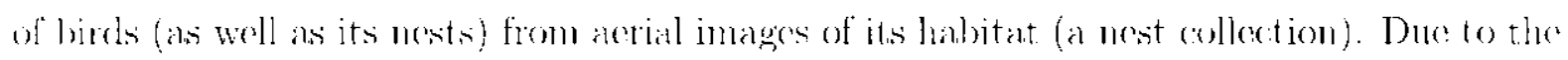

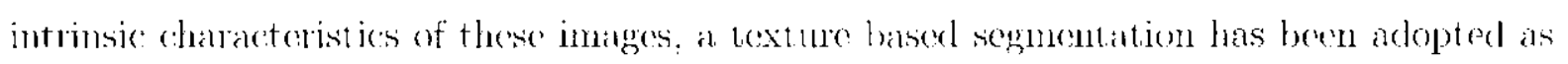
the main approach of the project.

The method chosen for this study is part of a broader set ol methods betsed on ranclom models lor lexture sognendation. In particular, this method is based on Markov Ramdom Finld (MRF).

This dissortation presents the statistical grounding for the adopted technigue, as woll as the stages involved in its implementation and some inprovements adeled to the shandand

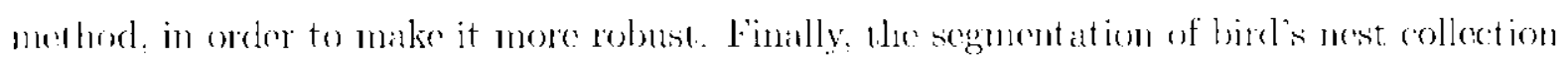
images is presented, as well as the results oblained with some medical and synthetic: textural images. The aerial images have bern accuired in partucrship with another project in course: in the 1O:NC-CSP: the AR ARA Project (Acronives de Reconhecimento Assistidas por Rálio a Antonomasis. 


\section{Sumário}

1 Introdıção 1

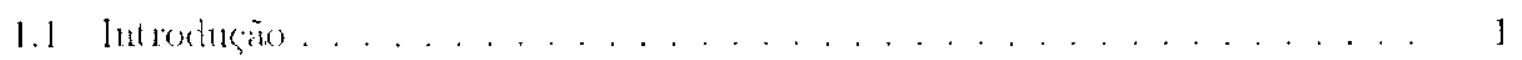

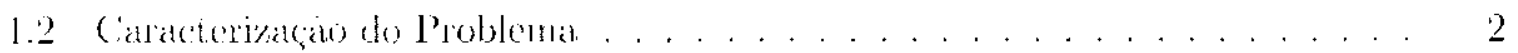

1.3 ()

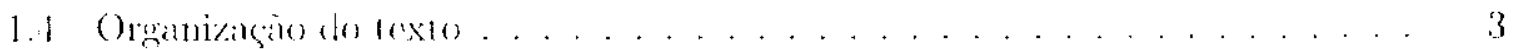

2 Segmentação de lmagens $\quad 4$

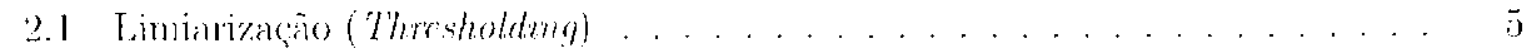

2.2 Mritodos barcados na detecrio de bordas . . . . . . . . . . . . . . . . . . . . 7

2.2.1 Algoritums de Enlare (Edge Linting) . . . . . . . . . . . . . . 9

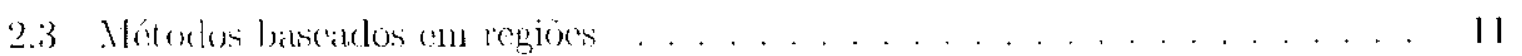

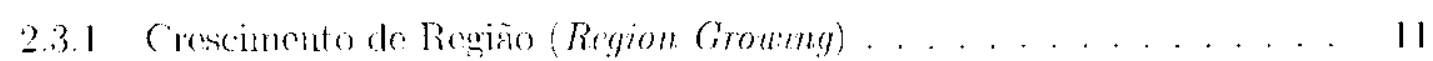

2.3 .2 Divisao e linsio (Splat and Merge) . . . . . . . . . . . . . 12

2.1 Vétodos bascados an lextuma . . . . . . . . . . . . . . . . . 1:3

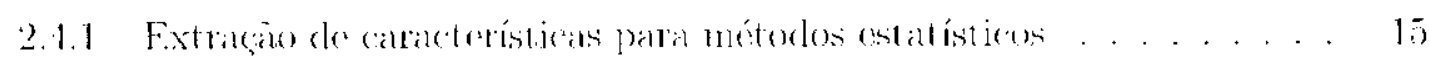

3 Métodos bascados em nodelos estocásticos para segmentação por textura 21

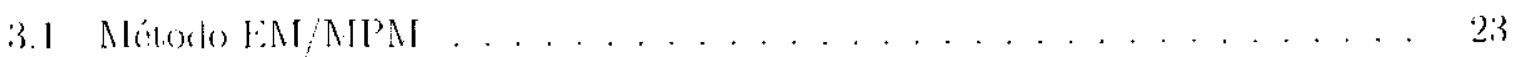

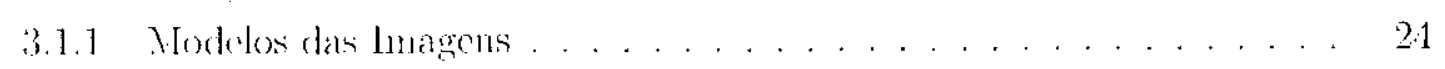

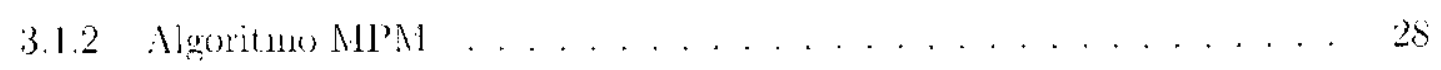

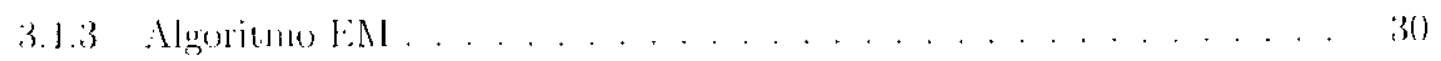

4 Implementação $\quad 32$

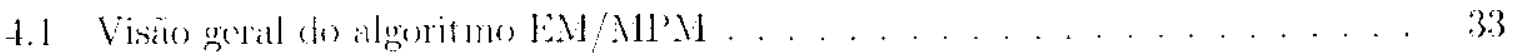

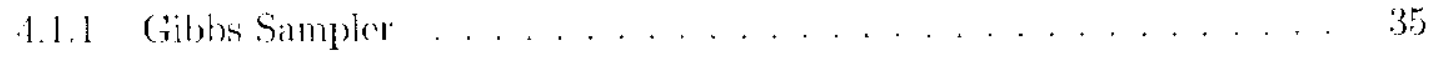

1.1.2 Retimando mona amostra de ma limerio donsidarle de probabilidade. 38 


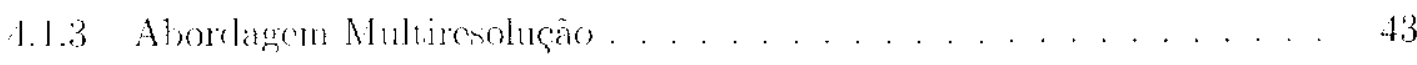

4.1 .4 Anneding . . . . . . . . . . . . . . . . . . . . 49

1.2 Contagrm do Regioes . . . . . . . . . . . . . . . . 50

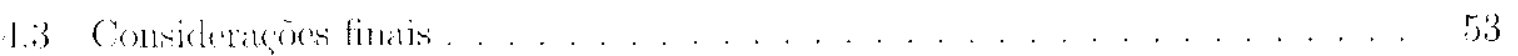

5 Testes e Resultados 54

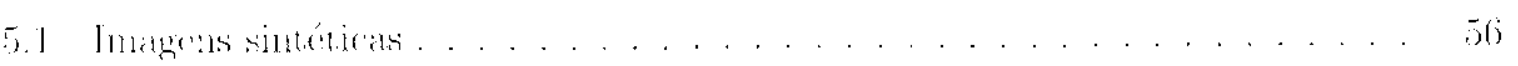

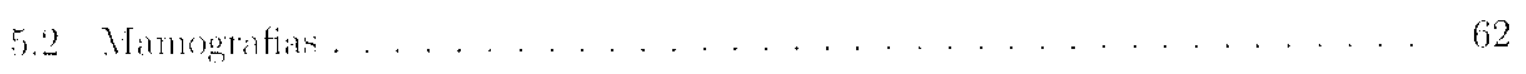

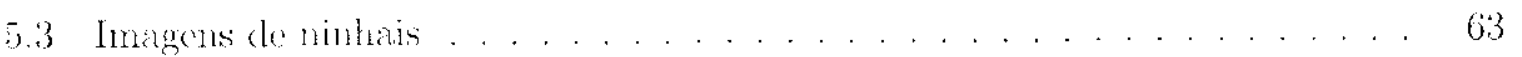

6 Conclusões $\quad 73$

$\begin{array}{lc}\text { Referências Bibliográficas } & 76\end{array}$ 
Capítulo

\section{Introdução}

\subsection{Introdução}

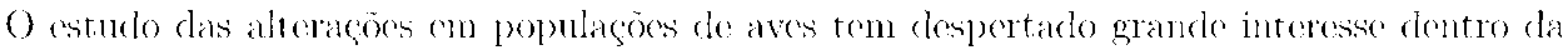
commidade científica. Através dele é possivel detectar eventuais distúrbios que possan estar ocorrendo no meio ambiente e. por isso, pode ser utilizado como monitorannento biológico $[\mathrm{T}, \mathrm{I}, \mathrm{L}, \mathrm{OS}]^{\circ}$

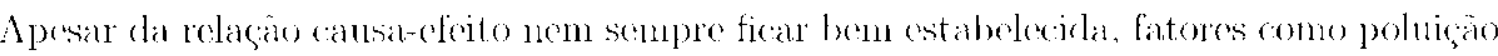
(cpoda de habiat podem ser justificativas para cstas alteraçós. Fstudos a longo prazo. como o monitoramento de determinadas regioes, săo necossários para quo so possa diferenciar as alteraģoes naturais dacpulas calusalas pela poluçäo o por ontros impactos.

Esse monitoramento onvolve a coleta sistemática de molidas o variáveis do processos ao longo do trmpo quándo (xiste uma razào para que eles sejam coletados e os procedimentos utilizados. O nonitoramento biológico se retere ao 1 so sistomático de organismos para de-

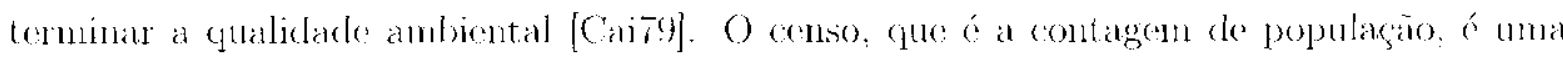
des estratégias mais utilizadas nos programas do monitoramento

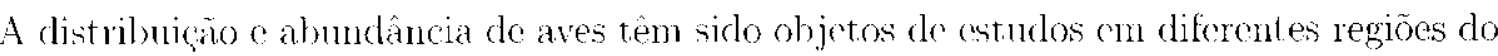
mundo. O grupo das aves tem sido mais estudado do que ounos porque est as são, geralmente, mais lacilnente visualizadas do que os demais animais e lambém, porque săo extremanemte sensived à combumingào ambiental. Dessa forma a resposta de suas commidades frente dis alteracoes amhientais poden ser excelentes indicadores dos efeitos biológicos.

É possivel utilizar a teenologia de procosiamento de imagens de forma a possibilitar on agilizar a tarofa de monitorancento. 


\subsection{Caracterização do Problema}

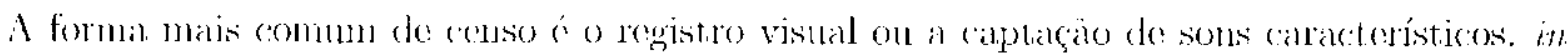

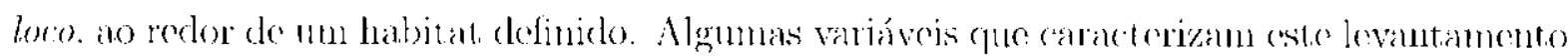
Siào:

- o tompo gation no registro;

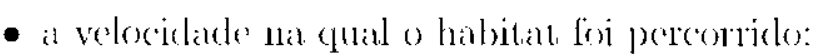

- a ćpoca con cure loi frito oregistro;

- as condiçoess climáticas:

- a experiencia do penquisarlor que doluon o registro.

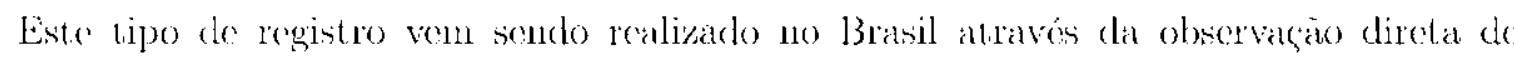
ninlads localizados nas principais áreas úmidas do país. Cm ninhal á definielo como uma

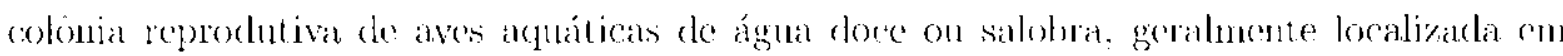
ávores ou albustos. A matioria clas espécios que se reproduzem nos ninhais não são residentes permanent es das árcas úmidas. mas migram para essas regiöes e ali permanecom durante todo

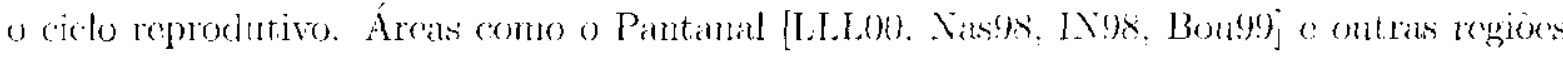

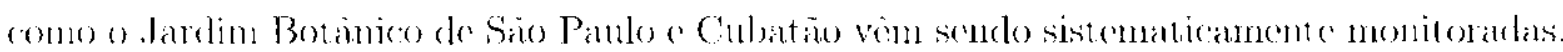

Dentre esses traballes, destaca-se o Projeto Ninhal realizado pelo Laboratónio de

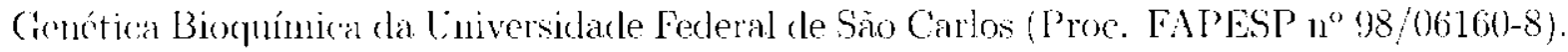

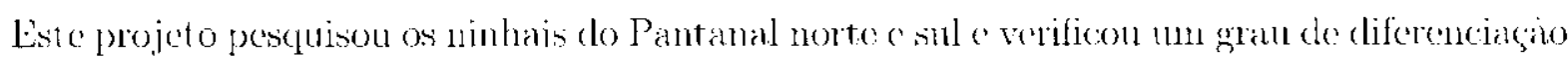
genética baixo entre as populaçoes do aves do Pantanal o chtre as populaçós da Anérica

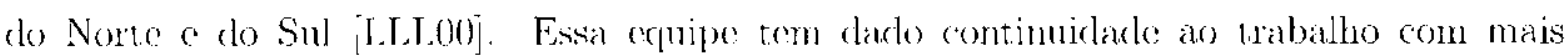
dois monques: a) contanimagà anbiental pola closagem de mercúrio nas penas dos filhotes

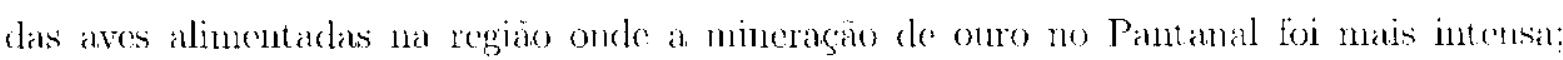

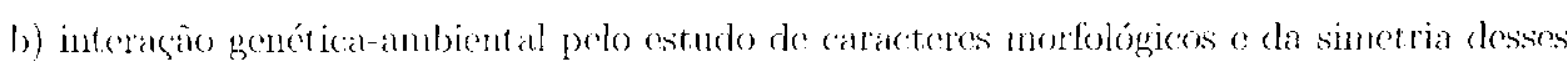

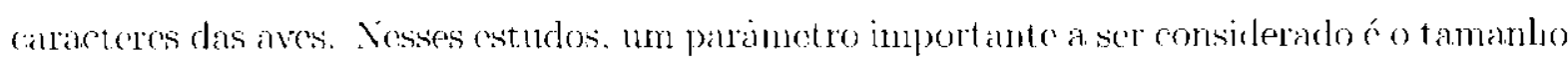
da populacaro. In grande intoresse da equipe deste projeto é ter o monitoramento das colonias reprodulivas lacilitado por um processo de contagem antomática de ninhos at ravés

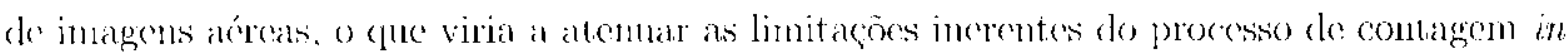
lero de claclos sobre a colomiat. 


\subsection{Objetivos}

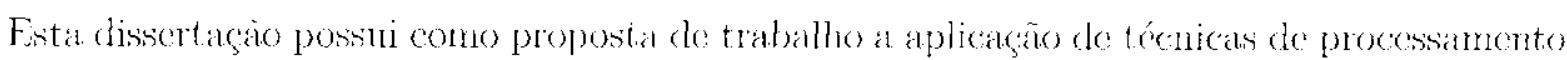
de imagens que permitam a segmentacäo de imagons áceas de nintais para cue seja possivel realizar a contagen automática de individuos $\% / O u$ ninhos existentes em deterninadas colonias. En funça da naturezal das indagens, a scymentagia por textuma é ardotada como abordagenn principal do projoto.

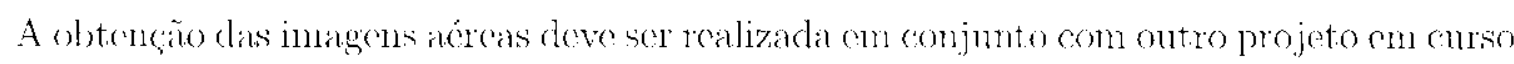
no ICMC-USP. O projeto ARARA, como é denominarlo, tem como objetivo a implomentagăo de aeronaves nào tripuladas em escala reduzida para a utilizaçäo no monitoramento agrícola

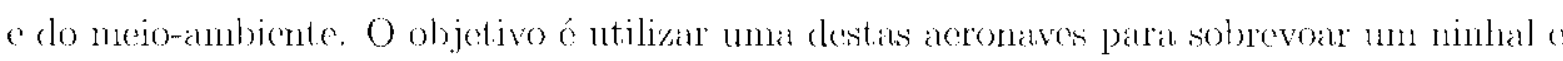

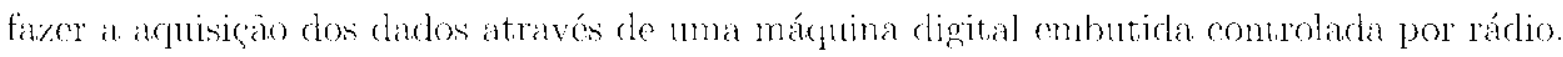

\subsection{Organização do texto}

Fsite documento está organizado om cinco capítulos. O segundo capítulo apresenta uma revisão dos prineipais métodos de segmentagâo de imagens encontrados na literatura. São

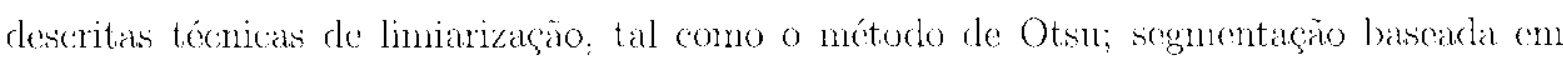

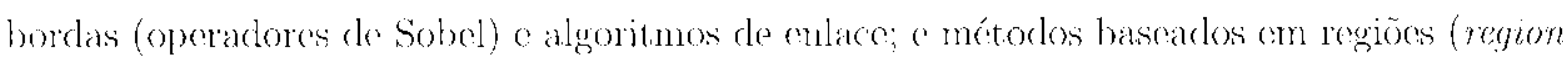
growing c split and merye). Também são abordados tópicos relacionalos à sognontacão

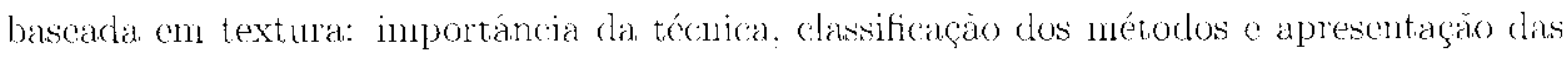

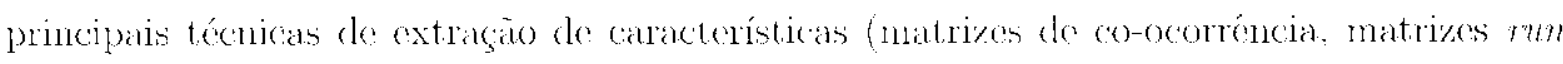
lemght, etce).

$O$ terceiro capitulo ć dedicado à segmentação de imagens por toxtura a partir rle modolos rotocísticos. Esse assunto tem sido recentemente foro do um grancle número de bescunisasi na área de processamento de imagens o, por apresentar resultaklos saltisfatórios na maionin

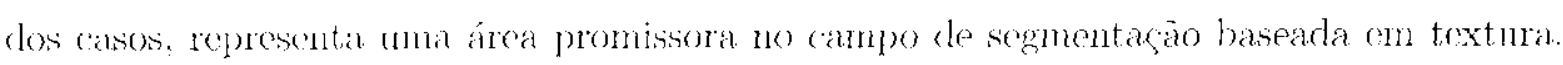
Em crpocífico, ć apresentado o método de segmentagăo FM/.MPM que utiliza como modelo principal um Campo Aleatório de Markov (Markov Random Fichl).

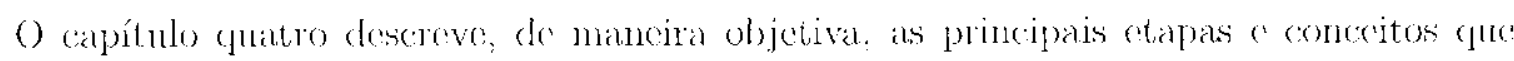
conduzen à implementagào do algoritmo de segmentaçăo FM/MPM e des um algoritmo de contagom de regiöes conexas, para ser aplicado sobre as imagons segmentarlas.

Finalmente no capitulo cinco, săo apresentados on principais resultados obtidos con o

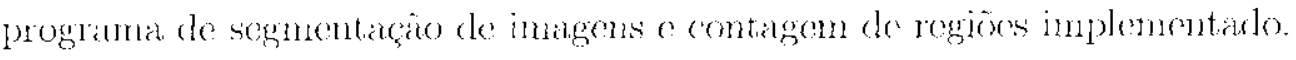




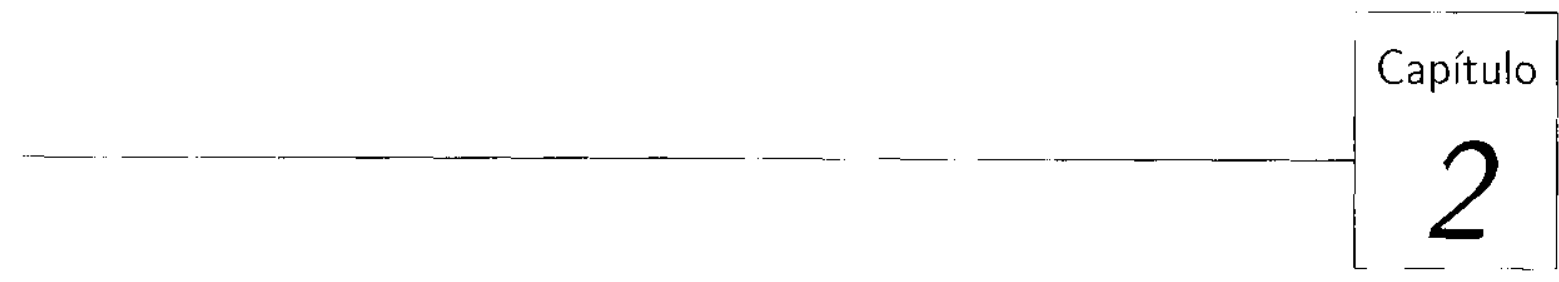

\section{Segmentação de Imagens}

Segnentação é un processo que consiste na subdivisão de una imagen em regiöes distintas. levando-so em consideraça duas propriedades básicas das imagons om tons de cinzal des-

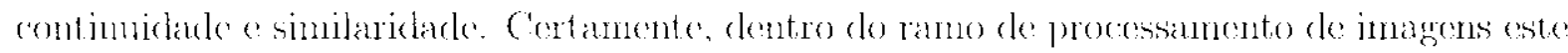

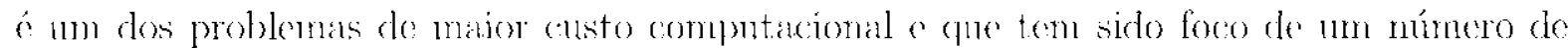
pescruisas calda vo' mintor.

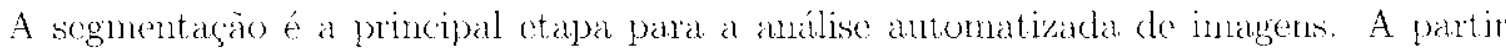

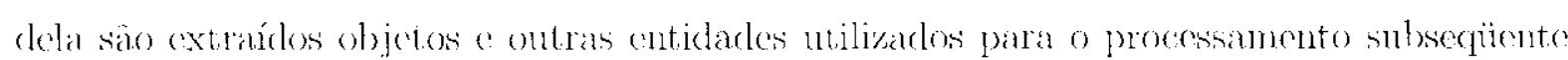

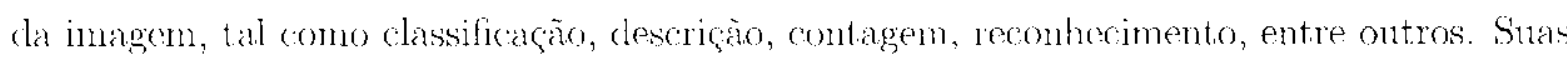
aplicaçoes estendem-se para os mais variados tipos de imagens: inagens médicas, innagens aéreas, imragens de radar, imagens de agroculturas, rurais, entre outras.

O princípio da segmentaça foi introduzirlo no início do século XX per alguns psicólogen alemães (Khler, Wertheimer e Kofftka) [Fac93]. Eles mostraram que o sistema de visão humana realiza agrupanentos baseados na proximidade, similaridade e continuidade das

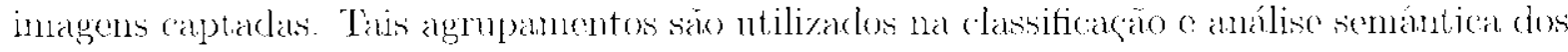

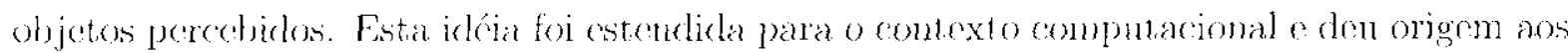
primeires algoritmos de segmentagào de imagens.

O ideal da segmentação é que cada regiāo obtida no resultado esteja diretancnte rela-

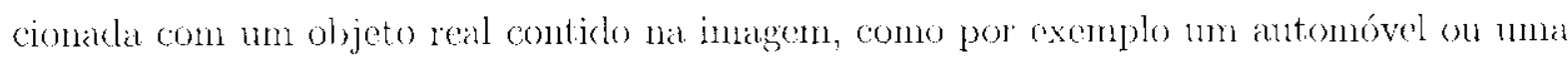

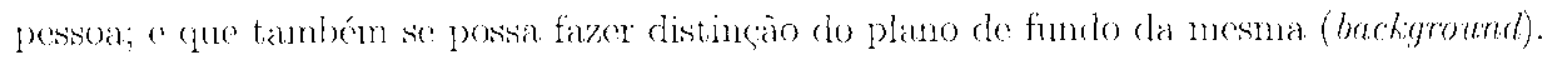

Existom ma literatura diversas taxonomias para dassificação dos mótodos de segrnentação de inagem. Neste estudo será considerada a mesma taxonomia adobada por Gonzales

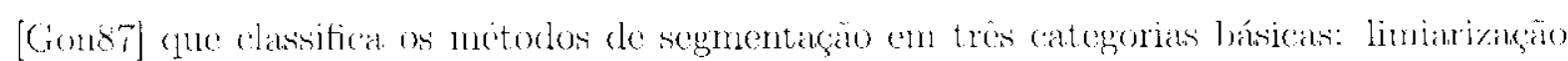


(thresholding); segmentacão baseada em bordas; o segmentaça baseada en regioxs. Recentemente várias ontras categorias são levadas em considemaçăo. Dentre elas estão os mótodos

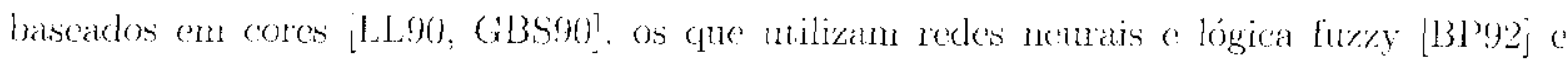

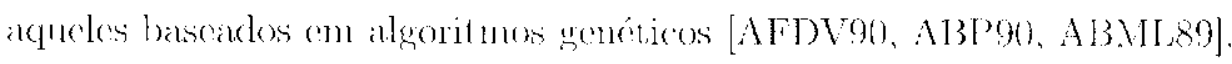

\subsection{Limiarização (Thresholding)}

A limiariagão co ométodo mais simples e intuitivo do segmentacão do imagens. Basicamento todos os pixols que rutăo dentro de uma faixa de intonidado são classificarlos como pertencentes a unna mesma regiano. Enn sua forma mais geral a liniarizaģa podo ser descrita matematicanume (o)mo:

$$
S(i, j) \ldots h \text { se } T_{k-1} \leq f(i, j)<T_{k} \text { piria } \quad h:=1,2, \ldots, m
$$

onde $S(i, j)$ é a função resultante, $f(i, j)$ é a função original (imagem), $T_{0}, \ldots, T_{m}$ são os valores de limiarização (thresholding) e m é o número de classes distintas a sorem aplicadas à inatgenth.

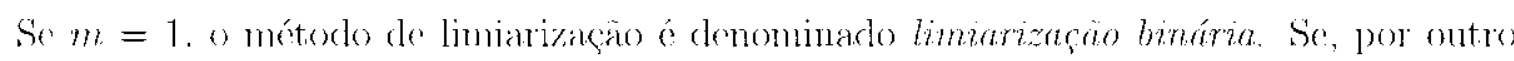
liado, $m>1$ o método é descrito como limiarização multi-modal.

A limiarizaga é geralmente aplicada a imagens que possuem áreas homogeneas sob un

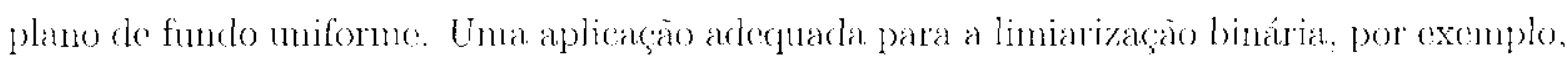
scria a extração de texto da imagem digitalizada de mun página.

Existem várias técnicas para se determinar os valores de corte $T_{0} \ldots T_{m}$. Cima delas é a própria seleção manual. baseada no mellor resultado obtido após o ticsto com vírios

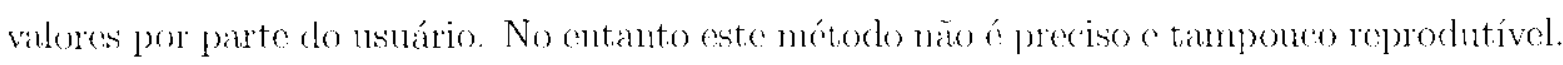
Dontre as técnicas antomáticas, a mais tradieional, e tamben a mais intuitiva bascia-se na detreção dos pontos de mínimo do histograma da imagom (vales) [SSWC88]. O histograma é una função que inclica o nível de onomencia de um deteminado nível de cinza dentro da inagem (ou, para inagens coloridas, o nível de ocorrencia de cak cor pertencente ao sistema utilizaklo). F́ cocrente pensar qur para os valores do cor (nivel de cinza, por exemplo) ondo esta função aprescnta níveis míninos (o que caracteriza a ausencia desta cor na imagem), há una barreira que separa objetos da imagenn com níveis de cinza distintos. Sondo assim, on valores $T_{0}, \ldots, T_{m}$ serào os pontos de mínimo do histograma dit imagem. A desvantagem desta técnica reside no fato de que muitas vezes os vales são longos ( planos, tornando a escolha do limiar uma busca arbitrária. Também, é possivol que os vales assmmam valores

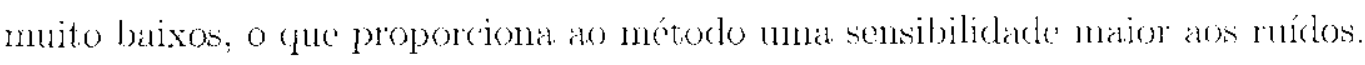


A figura 2.1 ilustra um histograma bimodal (histograma que possui apenas um ponto do mínimo local e dois picos). O limiar $T$ foi selecionado a partir do único ponto de mínimo da funç̧io.

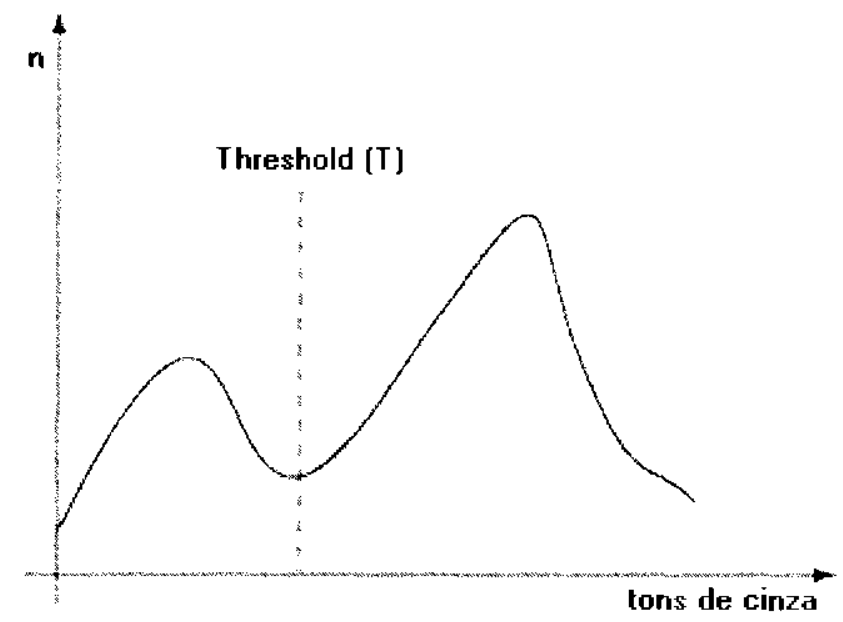

Figura 2.1: Seleção de threshold otimizado para unn histograma binodal

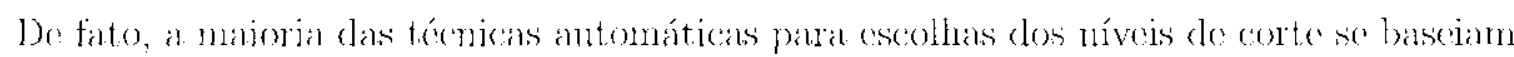
no histograma. A técnica de Otsu [Gons7], por cxemplo, é conhecida cono a mais eficionte o confiável delas. Fla se basela na escolla do valor do corte que maximize an mediela de variánela

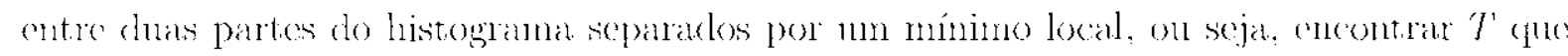
minimizo a funçầ

$$
f(T)=q_{1}(T) \sigma_{1}^{2}(T)+q_{2}(T) \sigma_{2}^{2}(T)
$$

onde:

- q1 $(T)$ é o número de pixels cuja intensidade é menor que T;

- ${ }_{22}(T)$ o número de pixcls com intensidado superior a $T$ :

- $\sigma_{1}^{2}(T)$ variancia dos pixcls cuja intentidade é menor que $T$;

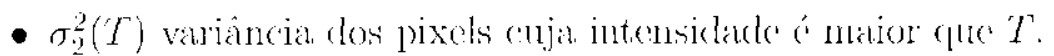

Embora eficiente, o método de Otsu é extremannente custoso do ponto de vista com-

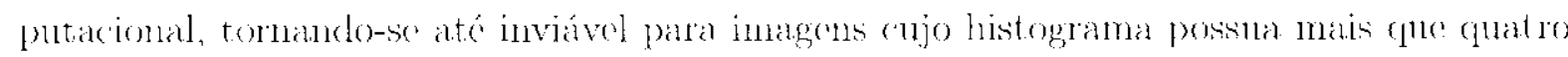
mínimos locais. Uma ontra altemativa ó denominada (Otsu recursioo. Nesta técnica, o método de Otsu simples (para duas partes apenas do histograma separados por um mínimo 
local) é aplieado succsivinnente à imagem. sendo que a cacla iteragăo parte da imagem já segmentada é desconsiderada, aplicando-se novamente o método para os pixels restantes.

1 partir da sovera andepuada dos liniares $T_{0}, \ldots, T_{m}$, também é possivel ancontrar as

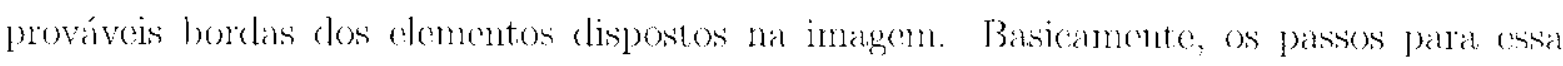

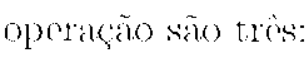

- varrer a inagem f por linhas o deteminar una matriz anxiliar $f_{1}$ tal que

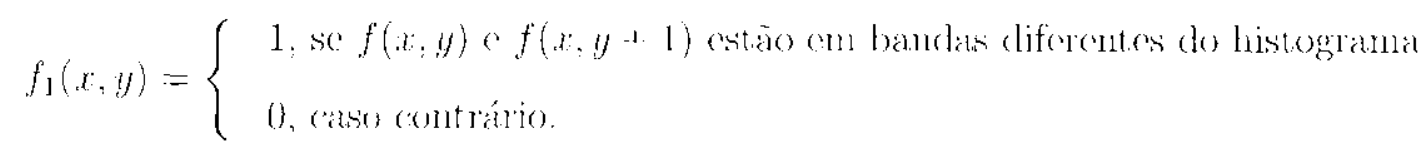

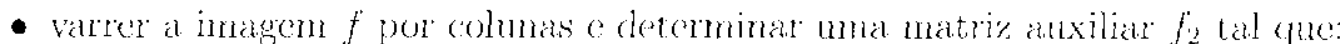

$$
f_{2}(x, y)=\left\{\begin{array}{l}
1, \text { se } f(x, y) \text { e } f(x+1, y) \text { cstão em bandas diferentes do histograna } \\
0, \text { caso contrário. }
\end{array}\right.
$$

- determinar a imagem resultante g(x,y) através da relagão:

$$
g(x, y)=\left\{\begin{array}{l}
1, \text { so } f_{1}(x, y)-1 \text { on } f_{2}(x, y)=1 \\
\text { 0. caso contrário. }
\end{array}\right.
$$

\subsection{Métodos bascados na detecção de bordas}

Os métodos de sogmentagăo bascados na detecyão de bordas envolvem basicanente a locali-

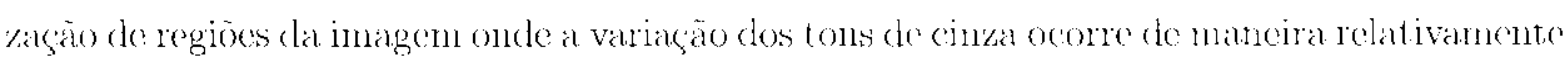

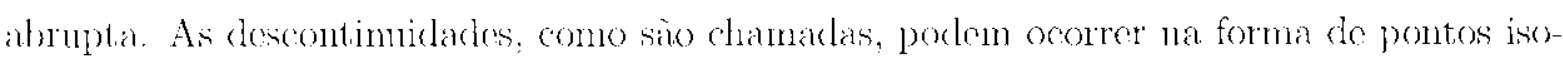
lados. linhas, segmentos on curvas e. a partir delas, são fomados os contornos, ou bordas, dos objetos contidos na imagem.

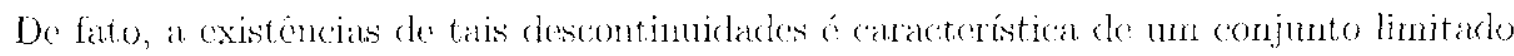
do imagens. En muitas dolats, a transição de una regiào para ontra oeorre de maneira tão sutil que tornam a aplicação dos métodos de deteceño de bordas ma opção inviável.

Após a deteçäo das descontinnidades segue-se, geralunente, a aplicaça de algum mótodo capar de concetar tais fragmentos a gerar contomes que estejam associados com os contormos reais clos objetos. Fstres métodos são donominados algoritmos de cralace (edge lanking alyonthms) e na maioria das voges cles fazem uso das ténicas de pereurso em gratos.

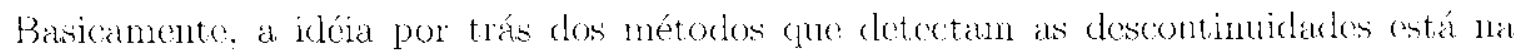

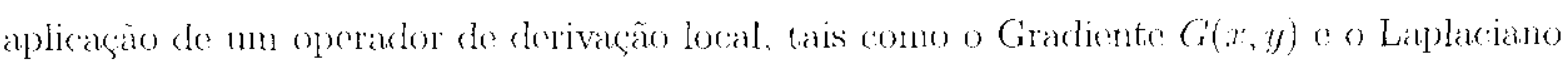
$L(x, y)$, que são operadores de derivada de primeira e segunda ordem, respectivamente. 
A imagem digital esimplesmente uma função do chas variáveis $x$ e y. So tomarmos como análise a prineira derivada desta funcăo. podemos facilmente cncontrar as transiçoes. visto que para as regiós de niveis constantes da magem a dexivada será zero e para as descontimblates a derivada deveri assumir ma valor pexitivo on negativo. Do mosno modo. o sinal da segunda derivada pode ser utilizado para se distinguir quando a transição está ocorrendo de um tom escuro para um tom claro on vice-versa.

A figura 2.2 ilustra o comportanento da primeira e da segumda derivada para dois ti-

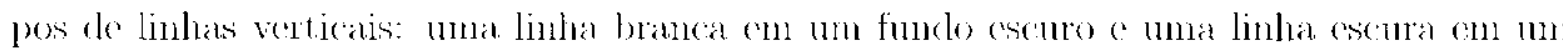
funclo branco. Embora a figura ilustre apenas uma amostra unidimensional da funçào é fácil estender o exemplo para duas dimensões.

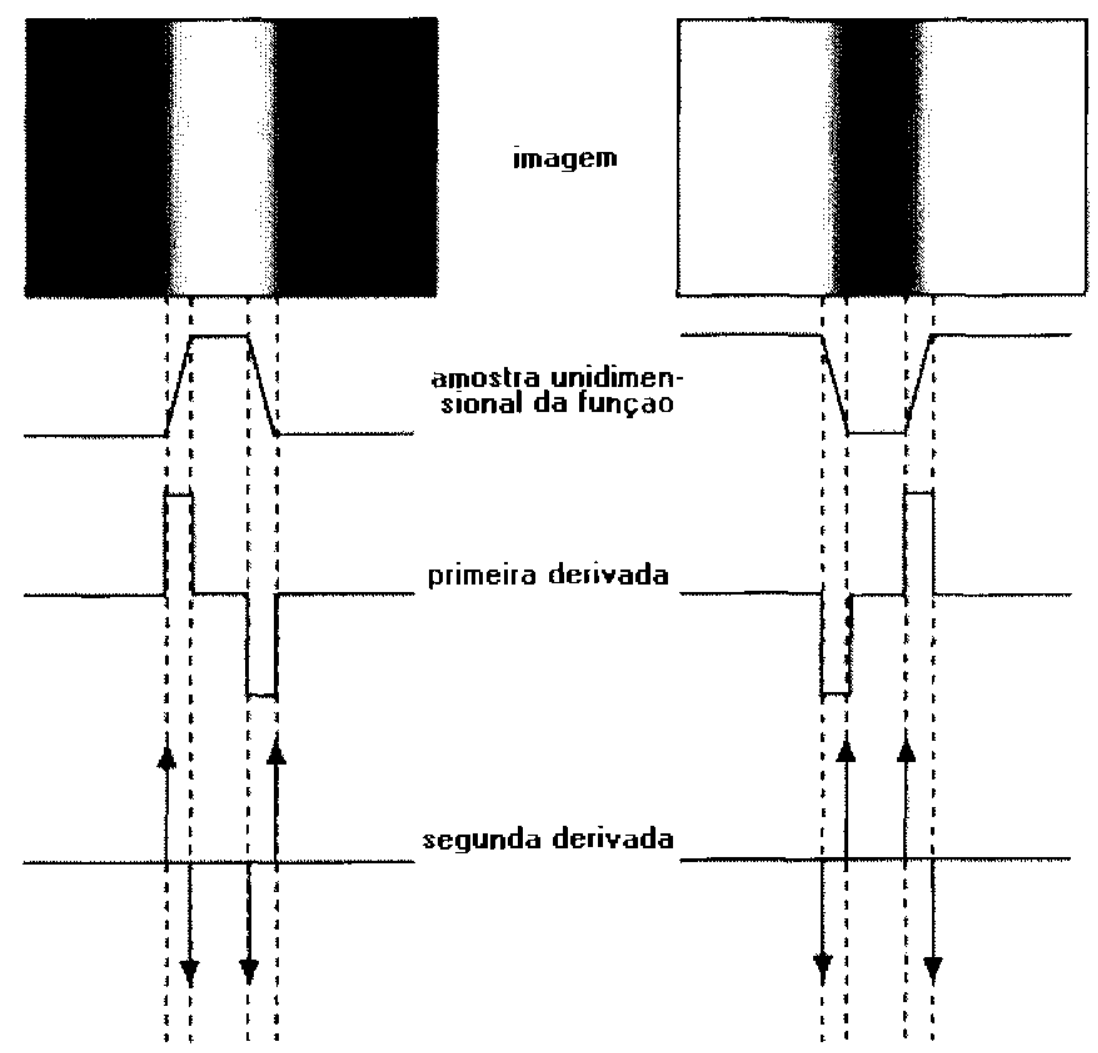

Figura 2.2: Primesira e segunda derivada de una anostra unidimensional de ma imagen $f(x, y)$

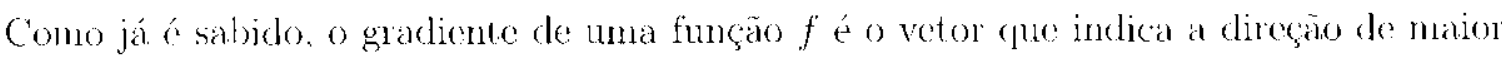

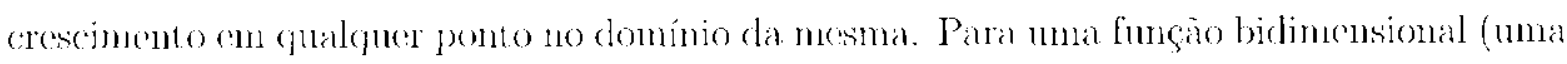
imagem por ex(mplo), o gradiente é definido da seguinte maneira:

$$
\left.G^{\prime} f(x, y)\right]=\left[\begin{array}{l}
G_{r} \\
G_{;}
\end{array}\right]=\left[\begin{array}{c}
\frac{\partial f}{\partial x} \\
\frac{\partial g}{\partial y}
\end{array}\right]
$$


A tarefia de deteçăo de contornos recuer apenas a informagăo da norma do velor gladiente. que. por convenicheia, ś simplesmente referenciada como gradiente. Fla é derinida por:

$$
\left.G^{r} f(x, y)\right]=\left[G_{, j}^{2}-G_{y,}^{2}+1 / 2\right.
$$

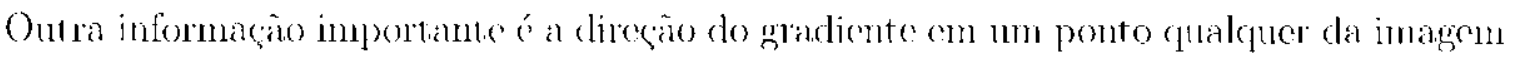
$(0(x . y))$. Ela ó utilizada para concetar os contormos obtidos através do gradicnte é obtida la segrinte mancira:

$$
\theta(x, y)=\arctan \left(G_{x}^{2} /\left(C_{y}^{2}\right)\right.
$$

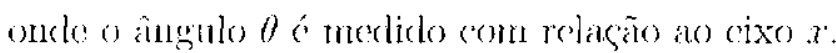

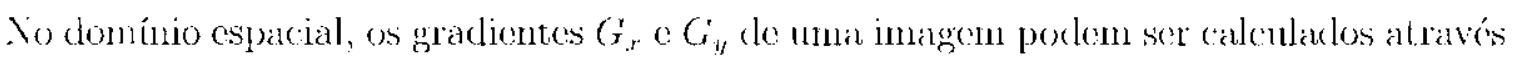

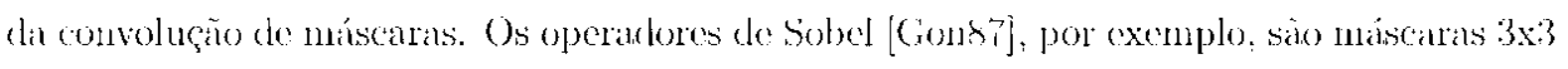

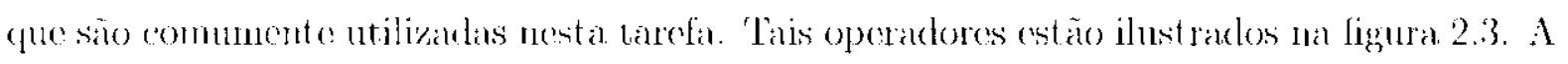
liguma 2.1 ilustra un exemplo da aplicação destas máscaras. A imagem resulume cobtida

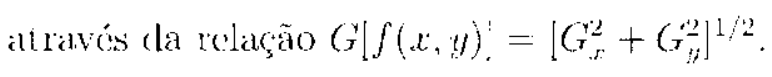

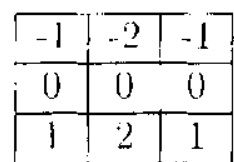

(a)

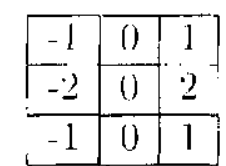

(b)

F“igura 2.3: (Operadores de Sobel. (a) máscara usada para computar $C_{x}$ : (b) mábcama usada para complutar $C_{t:}^{r}$

\subsubsection{Algoritmos de Enlace (Edge Linking)}

Comlorme já mencionado. os algorimmos de segmentagäo bascandos en borclas geralmente utilizam-se de mocanismos capazes de interligar os segmentos obtidos na fase inicial re de-

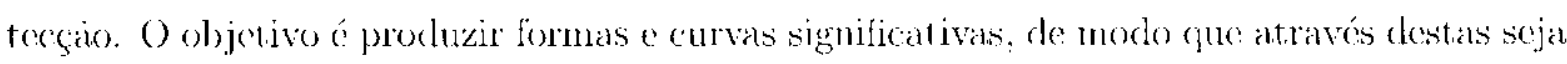

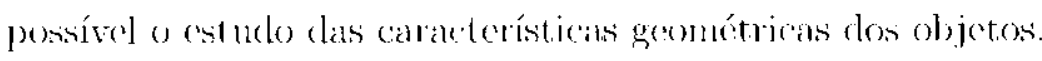

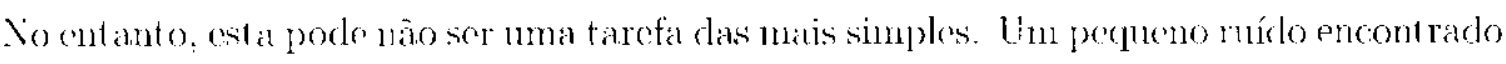
na imagem pode. mutas vezes. conduzir o algorituno à produçăo de comvas desconexas e insignificantes. impossibilitando a conexaro clos pontos.

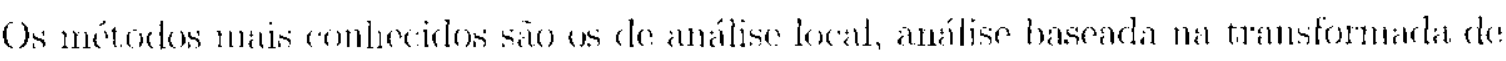
Hough o percurso em grafos :Fac03, Constj.

A análise local a a mais simples de toras. la consiste em analisal as características de

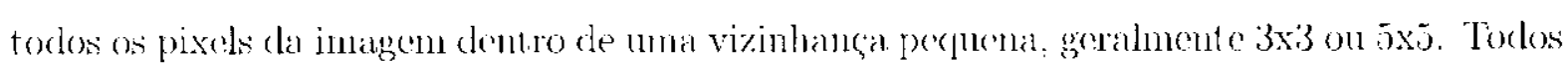




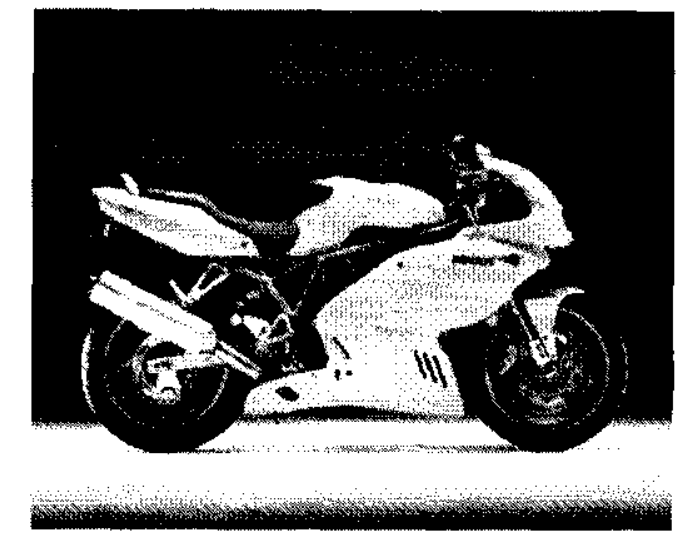

(a)

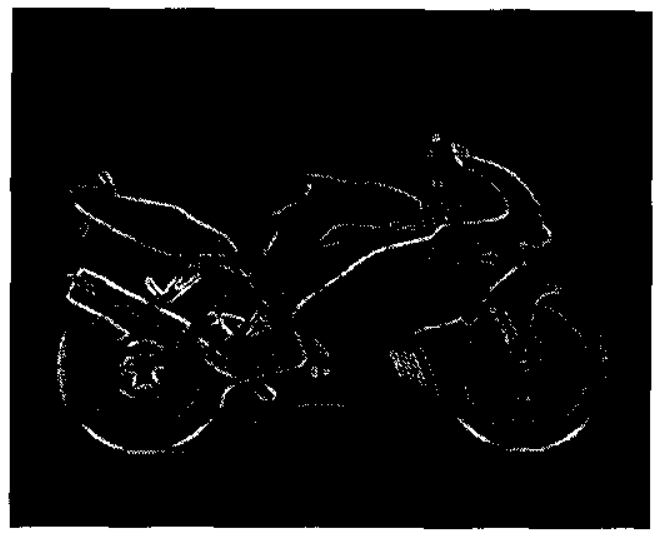

(b)

Figura 2.4: (a) inagem original; (b) imagem gradiente

os pontos que possuem características similares são conectados, formando uma frontcira do pircls que compartilham características en comum.

Neste mótodo, as cancterísticas principais de análise săo a intensidade o a diregão do gradiente da inngem. Como já foi dito ma segano anterior: a intensidade do gradiento é dada por $G \mid f(x, y)]$. Para se dizer que dois pixels vizinhos são similares na intensidade clos seus gradientes, basta verificar se $\left|G[f(x, y)]-G\left[f\left(x^{\prime}, y^{\prime}\right)\right]\right| \leq T$, ondo $T$ o urn limiar pré-etabelecido. Analogannente diz-se que dois pixels săo similares nas direçōes de sonsis graxlicntes se ${ }^{\prime} \theta(x, y)-\theta\left(x^{\prime}, y^{\prime}\right) \mid \leq A$, onde $A$ ć o angulo limite.

O método bascado na transformada de Hough é utilizado para encontrar curvas específicas dentro da imagem, tais como retas, circunferencias ou elipses. A idéia é uransferir a imagrm original do espaço cartesiano para o espaģo dos parinetros da curva procurada. O resultado desta operacũo irá mapear en um único ponto $p$, no espaço dos parametros, todos os pontos la inagem original pertencentes à curva cujos parâmetros são as coordenadas de p. Deste modo, para se detectar curvas específicas, basta procurar no espaço dos parànetros os pontos de maikr evidincia.

Os métodos de percurso en grafos são, em geral, bem mais complicados, porém possuem a vantagen de fornecer resultados satisfatórios em presença de ruídos [lac93]. Está ć urma técnica de análise global que consiste en representar segmentos de reta na forma de una cstrutura em grafoc, a partir desta ostrutura, encontrar caminhos de menor custo, fue repre?sentam contornos significativos na imagem. Facon [Fac93] o Gonzales [Gon87] apresentan im sostudo mais elaborado desta técnicá. 


\subsection{Métodos bascados em regiões}

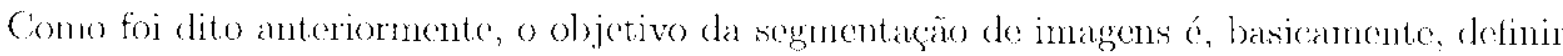
regiōes significativas dentro da imagem. Fncpunto os métodos de limiarização e os baseados m bordas resolvem este problemal encontrando diferenças nas tonalidades dos pixels on conjunto de pixels. os mótonlos baseados om regioes abordam a procura de similaridaics entiro os mesmos.

Os ténicas mais comlecirlas desta catogoria são denominalas Crescimento de Região (Region Growing) o Divisão e Fusão (Split and Merge).

\subsubsection{Crescimento de Região (Region Growing)}

Como sugere o próprio nome, o objetivo deste métorlo ć expandir pequenos grupos de pixels cm regiōes maiores. A partir de um conjunto inicial de pontos (somentes), agrega-se a cada $u$ m deles novos pixels vizinhos que contenham propriedarles similares, tais como cor, textura on nivel de cinza. Un critério simples de agregaçào para novos pixels ć o módulo da diferenca entre os tons de cinza dos pixels em questäro, on seja, we este valor for menor que nu doterminado limiar (T), entäo o novo pixel ó agregado à região, caso contrário, náo.

Embora o método de Crescimento de Regiäo seja bem simples, dois problemas surgem de inediato. Săo des: a) como selecionar "sementes" que devidamente reprosentem as regiöns de interesse ( b) qual critério de agregaça melhor se arlapta ao tipo do imagem gue está se utilizancko. O primeiro prohlema está freqüentemente associado à natureza da imagem. Por exemplo, en uma aplicaçào que utilize imagens geradas por dispositivos infravermolhos a comum que os objetos de interesse sojam mais reluzente que os demais, sendo assinn conjumlo de sementes seria o un conjunto de pixels enja tonalidade se aproxime mais da cor branca.

A seleçâo do critério de agregaçào a se utilizar diz respeito näo somente ao problema em (fuestá, mas também ao tipo de imagem disponível. Por exemplo, a análise do fotografias ohtidas por satólitos pode tirar grande proveito da utilizagăo de cores.

A conectividade da vizinhanga também é outro fator que deve ser levado em consideração. Os tipos nais commns utilizados são a vizinhança de quatro unidades cn forma de cruz. (blorkerity nezhborhood on virinhanga 4-conectada) a a de oito vizinhos em forma de bloco

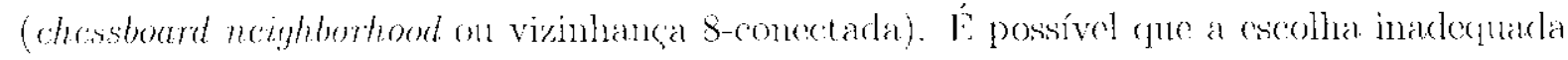
(lo tipo de vizinhanca conduza a produçào de um resultado erroneo dependendo da aplicação. Por exemplo, so os contornos de regioes dentro da imagem que se deseja segmontal

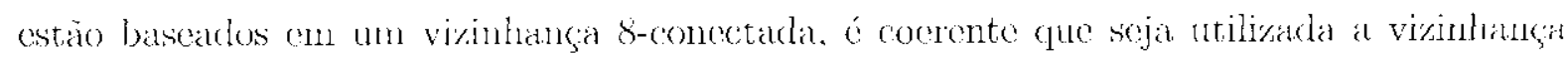

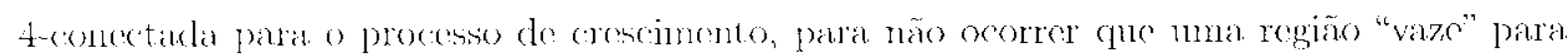


dentro de outra regiäo adjacente, conforme ilustrado na figura 2.5. Por outro lado, se ó conhecido que a imagem possui apenas contornos de vizinhança 4-concctada, o método de crescinento de região pode utilizar a vizinhlanı̧a 8-eonectadla sem problemas.

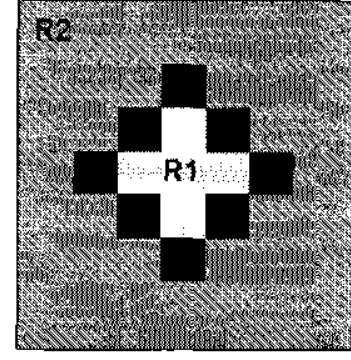

(a.)

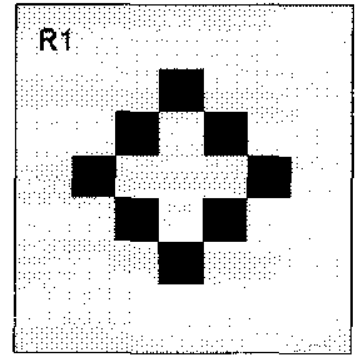

(b)

Figura 2.5: Inagens com contomos 8-conectados (a) crescimento 4-conectado: (b) crescimento 8-concetado

Critérios adicionais que agilizam a conversão e melhoram o resultado obtido por este

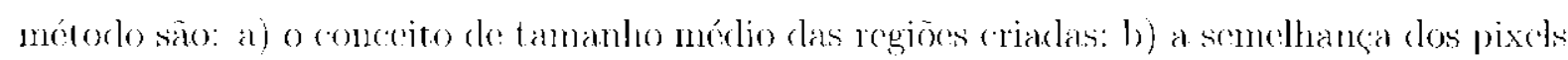

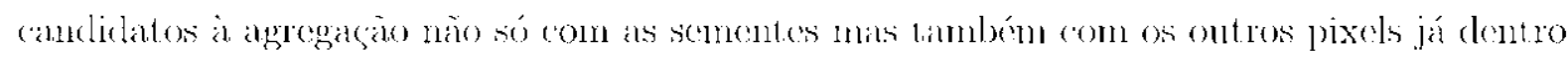

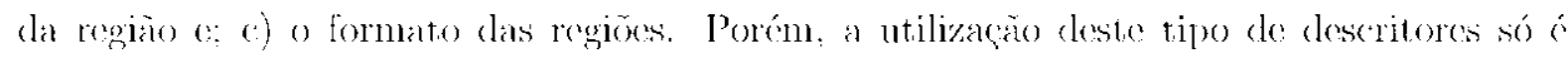
possível quando a natureza do resultado a scr obtido já estiver, pelo menos, parcialmente modelado.

\subsubsection{Divisão e Fusão (Split and Merge)}

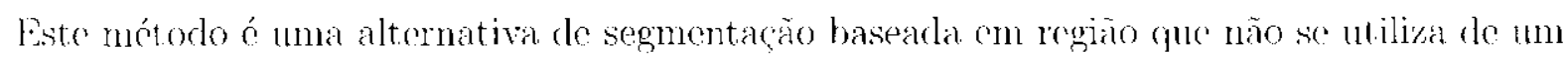
conjunto inicial de pontos (sementes) para a resolnção do problemal [Gons7]. Lile constitui una combinaçào de outros dois métodos já conhecidos: o Split e o Merge.

No escluema do Divisão e Fusão a imagem original ó particionada recursivamente a partir de scu todo, o as novas partiçós criadas podem ser ocasionalmente fundidas.

O método atua cm torno de uma proposição pré-estabelecida $P$. Cima região $R$ é particionada em gulatro novas regioes (quadrantes) se, e somente se, a proposição $P(R)$ for falsat @ por outro lado. duas regiöes $R_{1}$ o $R_{2}$ sĩo fundiclas quando $P\left(R_{1} \cup R_{2}\right)$ for verdadeira. $P(x$ exemplo, a proposição $P(R)$ pode ser verdadeira guando todos os pixels de $R$ liverem intensidades iguais. Ou, algo mais flexível, quando a variancia entre as intensidlades deste pixcls estiver abaixo de un limite pré-estabeleciclo $T$ (vale lembrar que so a variância é zero, todos os pixels tem intensidaxles ignais). Concluindo, o algoritmo se resume nos seguintes passos: 


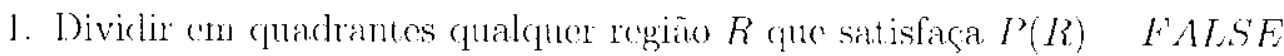

2. Fundir culaisquer regions arljacentes $R_{1}$ o $R_{2}$ que satisfacan $P\left(R_{1} \cup R_{2}\right)=T R U E$

3. Parar enando náo mais houver rogions que possan ser divididas on fundidas

Jnar representagà conveniente das regiöes neste nótodo pode ser feita através da täo

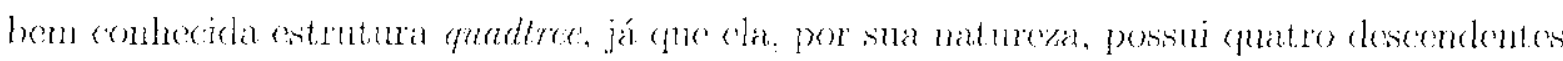
para carla nó. A figura 2.6 ilustra $14 m$ exomplo do particionamento do uma imagem. bem como a estrutura quadrece associada a ola.

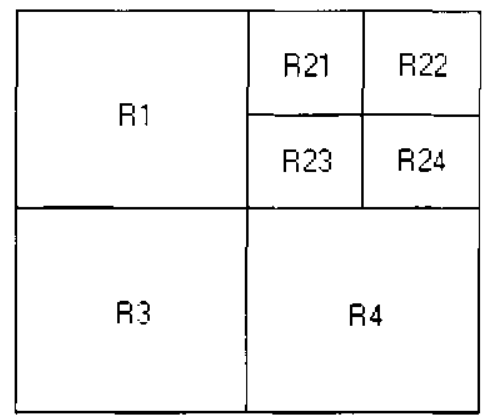

(a)

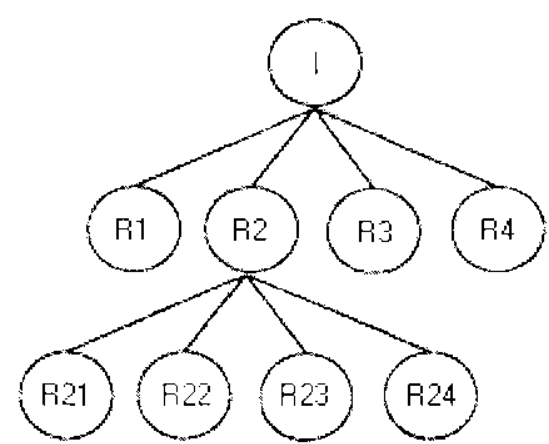

(b)

Figura 2.6: (a) intagem particionarta: (b) (juadtreo correspondente

Unar variação ben comm deste métorlo foi proposta por IHorowitz e Pavlidis om 1974

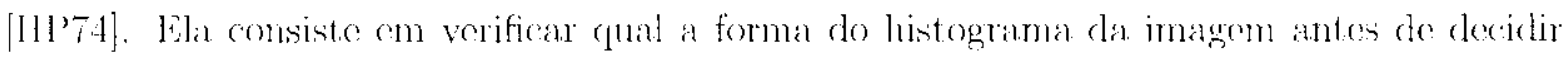

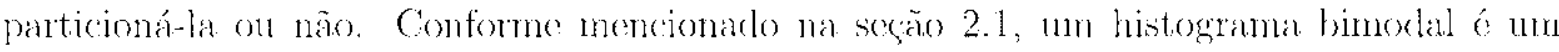
histograma que possui aponas dois picos (pontos néximos locais) e um ponto de minumo

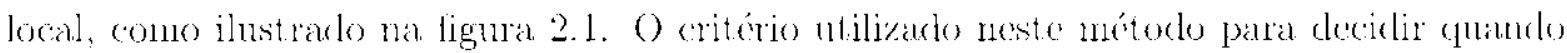
particionar a inlagem, ou $14 m$ quadrante, consiste em verificas so o histograma da mesma ó ou nà̃o bimodal. Em caso afimativo, aplica-so ì imagem do quadrante uma operaçäo do limiarizaçäo (thresholding) pelo método do ()tsu, on. caso contrário, particiona-se a 111 esma em novos quadrates.

\subsection{Métodos baseados em Textura}

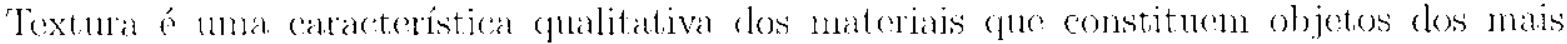
variados tipos, sejayn cles naturais ou sintetizados por algum processo industrial. Fmbora ben conhecirla o implicitamente intuitiva, na área de processamento de imagens a deliniçä desta característica náa possuri, do fato, uma versão formal e bem estabelecirla. Vários 


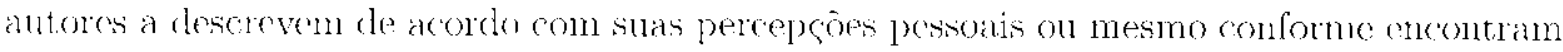
para ola utilidade cm suas aplicaçoes. A sicguir são apresentadas alguns cxomplos:

- "Trxinra é um al ributo que representa o aranjo espacial dos tons de cinza clos pixeli em unna regiaio." [IEE) $(0]$.

- "Textura se refere à repetição de elementos básicos da imagem chamalos textels. A distribuiçáo dos textels porle ser perióxlica on aleatória. Texturas naturais geralnenente

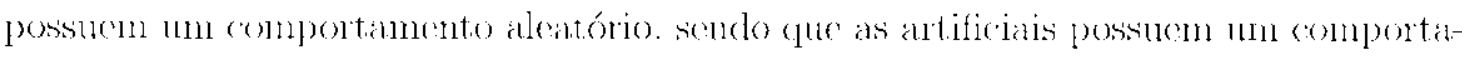
mento perióxlico e detemninístico." [Ja193]

- "Padroes que caracterizan objetos em uma cena saio chamades texturas." [.Jah933.

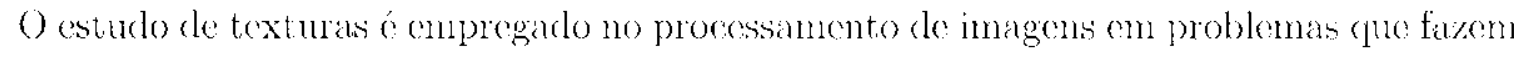

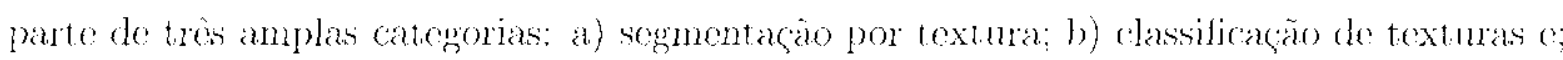
c) síntese de texturas. Conformo Van Gool o Todd R. Reed [G1)085, RB393], a chassificacaio dos métodos de segmentaça por textura ocorre da seguinte foma:

- Métorlos estatístiros;

- Métodos bascados em modelos o

- Mótodos cstruturais

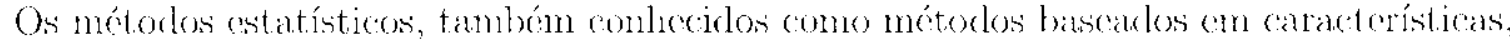

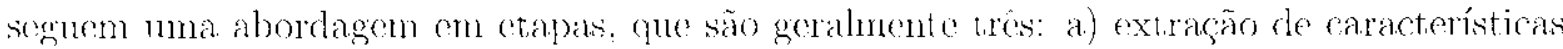
las texturas; b) seleção ou reduçào do número de características (aso haja um númoro muito grande delas e: c) utilização do um algoritmo de scomentagăo. A grande desvantagem destes

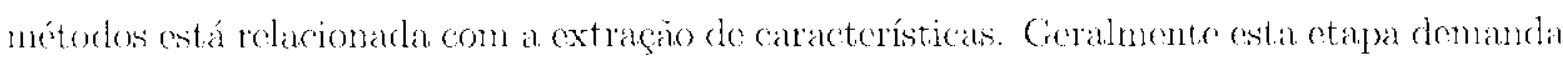
grancle guantidarle de processamento e grande quantidade de memória para armazenar as estruturas utilizadas [Son99].

A abordagem estrutural é empregada na clasisticaçäo e scomontaçăo de imagens que

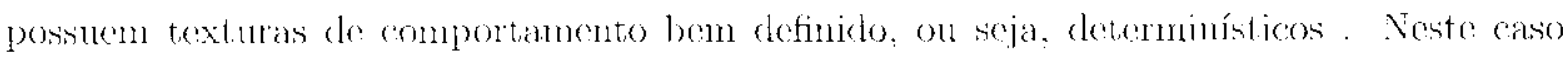
das săo compostas por um arranjo repetitivo de olementos estruturais denominados textels. Alguns exemplos doste tipo do textura estão ilustrados na figura 2.7 (a-d) [Brofít. Visto que a maioria das texturas encontradas cm objotos do mundo real nawo possuen este tipo do comportanenco (figuma 2.7 (d-o)), a utilizaño dos métolos estruturais abrange um conjunto limitako de problemas. Deste modo tais técnicas não scrán abordadas neste cstudo.

Os métodos basoados na utilizaçăo de modelos constitum una categoria cuja utiliza-

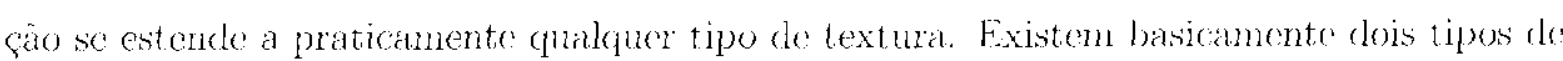




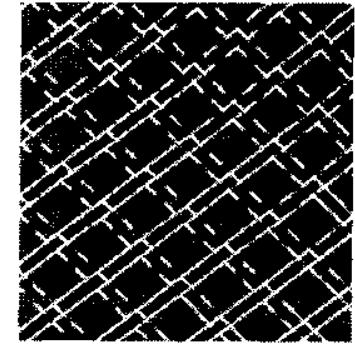

(a)

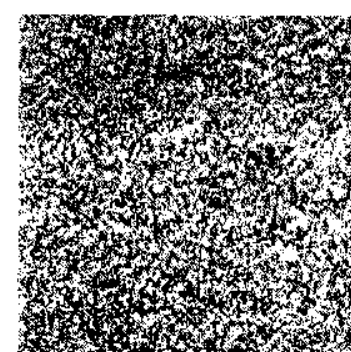

(e)

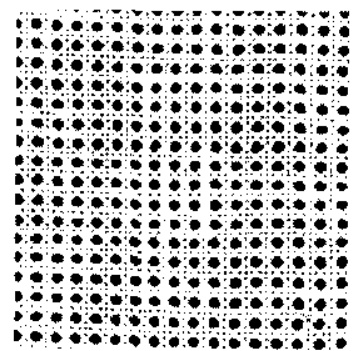

(b)

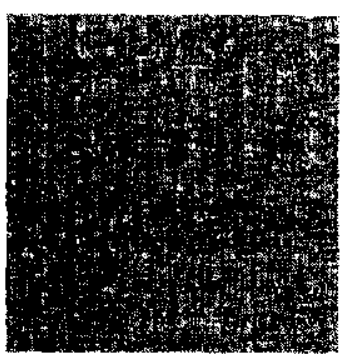

(1)

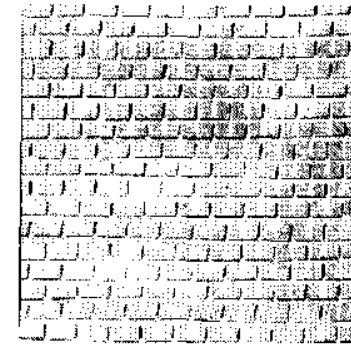

(c)

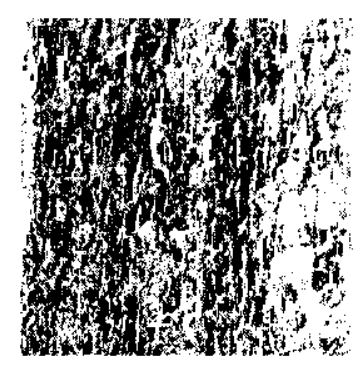

(a)

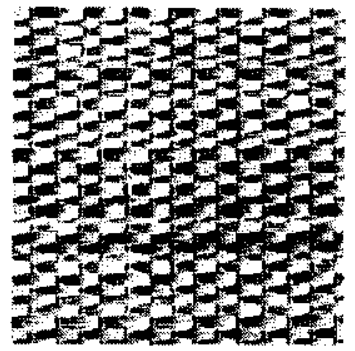

(d)

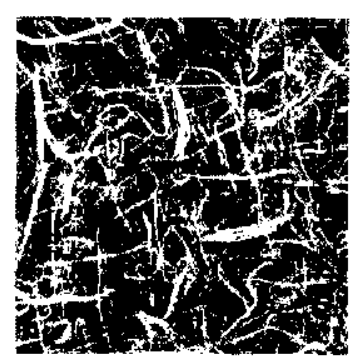

(h)

Figura 2.7: Exemplos de texturas cxtraídas do álbum de Brodatz [Bro66] (a)-(b) texturas de comportamento determinístico; $(c)$-(d)texturas de comportamento aleatório

modelos utilizados nesta abordagem: os modelos Fractais e os modelos Estocásticos [R[393]. A utilizaçăo de métodos estocésticos para morlelagem de imagens em algoritmos do segmentagio ó uma área inportante e de rápirlo crescimento. Isto ó reffetido pelo grande número de aplieacoes que atnalmente fazen uso desta técnica. Por este motivo esta abordagem será descrita om urn capítulo exclusivo (Capítulo 3). A próxina secão descreve as técnicas mais conhecidas para extração de características utilizarlas nos métodos estatísticos.

\subsubsection{Extração de características para métodos estatísticos}

Matrizes de co-ocorrência

As matrizes de co-ocorrência, também denominadas matrizes SGI.D) (Spatial Gray Level Dependence), são una ras mais populares fontes de características para texturas i[RB393]. Lsta aloorlagem consisto em computar matrizes intermediárias de uma imagem digital om tons de (inza e. a partir clestas, oxtrair características e funçoes utilizadas nas etapas subseqüentes do processamento.

Dado uma inagem $f$ com un conjunto discreto de tons de cinza I, define-se a matriz $P_{d, q}(i, j)$. Cada demento $(i, j)$ desta matriz é un numero inteiro que indiea quantas vezos un pixel de nível de cinza i aparece distante de un pixel de intensidade $j$ por uma clistancia 


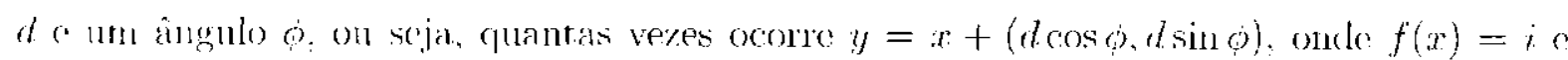
$f(y)=j$. Considere o exemplo da figura 2.8 .

$$
\begin{aligned}
& \begin{array}{|l|l|l|l|}
\hline 0 & 0 & 1 & \frac{1}{0} \\
0 & 0 & 1 & \frac{1}{2} \\
0 & 2 & 2 & \frac{2}{3} \\
\hline 2 & 2 & 3 & 3 \\
\hline
\end{array} \\
& \text { (a) Inlagen } \\
& \text { (inl lons do: } \\
& \text { (inza } \\
& P_{1,0}=\left[\begin{array}{llll}
4 & 2 & 1 & 0 \\
2 & 4 & 0 & 0 \\
1 & 0 & 6 & 1 \\
0 & 0 & 1 & 2
\end{array}\right] \quad I_{1, \ldots} \quad\left[\begin{array}{llll}
2 & 1 & 3 & 0 \\
1 & 2 & 1 & 0 \\
3 & 1 & 0 & 2 \\
0 & 0 & 2 & 0
\end{array}\right] \\
& \begin{array}{lll}
\text { (b) Matriz de co- } & \text { (c) Matriy de co- } \\
\text { ocomencia } & \text { para } & \text { ocorrencia para ingulo }
\end{array} \\
& \text { immulo } 00 \mathrm{~d}=1 \quad 135^{\circ} \text { e } d-1
\end{aligned}
$$

Figura 2,s: Excmplo de matrizes de co-ocorronciat

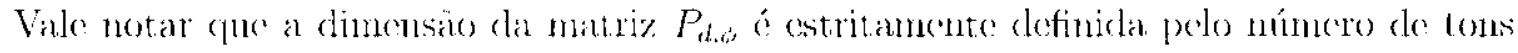

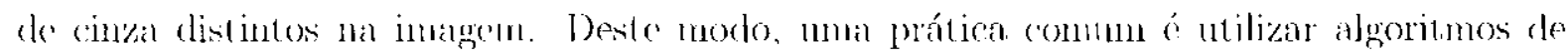
quimlizaço sol, a imagem que se está trabalhando para se reduzir a quantidade de tons de cinza.

A cualidade das característ icas a serem extraídas depende do número de matrizes com-

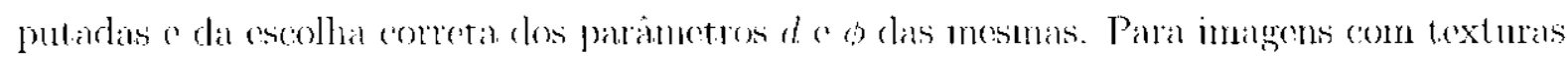
refinadas ó neressário que sejam criadas marizes com paranetros de pequenos valores. geralmente 1 on 2. Por ontro lado, para textmas mais grosseiras contuma-se ntilizar valores maiores para $d$.

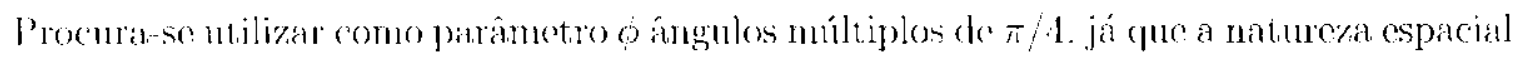
la imagem indu\% ao cák (nlo mais simplificarlo nas direcous vertical. horizontal e nas diagonais.

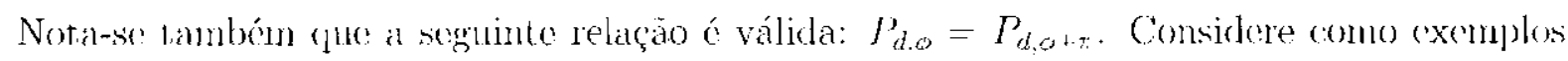
as segumbes matlizes:

$$
\begin{gathered}
I_{d, 4 n=}=\{\{((k, l),(m, n)) \in D:(k-m=d, l \cdot n:=-d) O R(k-m=-d, l-n= \\
\text { d), } f(k, l)-\cdots, f(m, n) \cdots \cdot j\}_{1}
\end{gathered}
$$

(')

$$
\left.I_{a, 0:}^{\prime}=\mid\{((k, l),(m, n)) \in L):(k-m-0,|l-n| \cdot d), f(k, l)=i, f(m, n)-j\right\} \mid
$$


onde $D$ representa o produto cartesiano $f \mathrm{x} f$ e $\{\ldots\} \mid$ denota um operador de cardinalidade.

Diversas sào as características passíveis do extraçăo em uma matriz de co-ocorrencia Haralick [Har 79] proposes 14 delas, porm as mais comuns o utilizadas na literatuma sion 5 :

1. Energia

$$
\sum_{i, j} P_{d, \phi}^{2}(i, j)
$$

2. Fintropia

$$
\sum_{i, j} P_{d, \phi}(i, j) \log _{2} P_{t, \phi}(i, j)
$$

3. Contraste

$$
\sum_{i, j}|a-b|^{k} \Gamma_{d, i, j}^{\lambda}(i, j)
$$

1. Homogeneidade

$$
\sum_{a, b ; a+b} \frac{P_{d, b}^{\lambda}(i, j)}{|a-b|^{k}}
$$

5. Probabilidade máxima

$$
\operatorname{lind}_{i, j} P_{i, j}(i, j)
$$

A idéia é caracterizar o contcúdo de cada matriz a partir destes descritores. Os dois

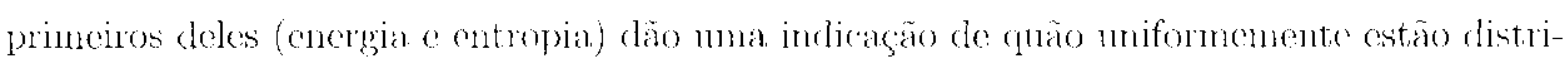
buídos os elementos da matriz e, consequientemente, glual o comportamento da textura en relaçáo à sua periodicidade. O descritor seguinte (contraste) analisa os valores da matriz com cinfase nos clementos mais distantes da diagonal, on beja, on pontos cujos níveis de cinzar pessuen maior distingăo entre sj, o gue vale como indicador do nível de contratste da texturi. O descritor "homogeneidado" possui a mesma tendencia, porém, com sentido inverso. E, por fim, o descritor "probabilicladle máxima" indica clual o maior elemento de $P_{d, \phi}(i, j)$.

A grande clesvantagem da utilização das matrizes de co-ocorrencia na extração de carac-

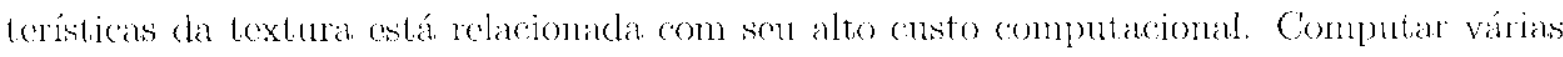
matrizes de grandes dimensoos nem sempre ó uma alternativa factível. Também, a escolha dos parametros $d$ e 0 depende muitar vezes de um conhecimento prévio acerca da qualidarce

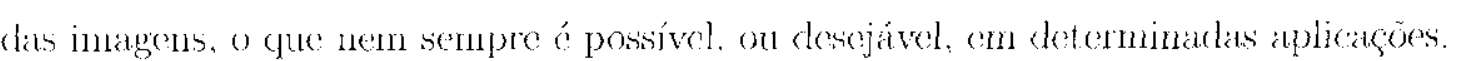




\section{Método Run-Length}

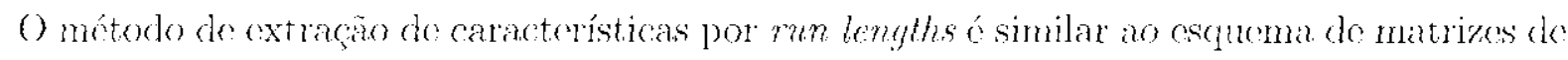
(o-ocorrencia. () objetivo é também extrair aracteristicas descritivas de texturas a partir de matrizes anxiliares, computarlas a partir da imagem digital original (em lons de cinza).

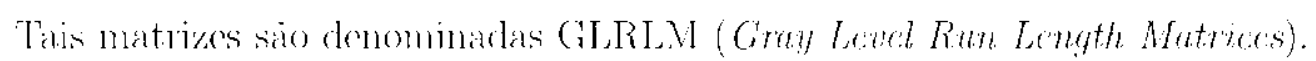

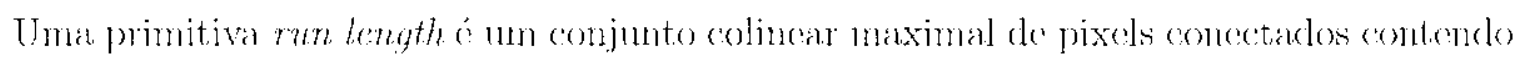
todos o mesno tom do cinza. Tais primitivas poclen ser caracterizados basicamente pelo sen comprimento, sua inclinaça a o o sem tom.

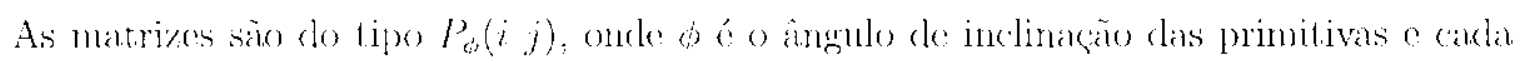
clemento ( $j$ ) inclica o número do vezos que mun juinitiva de tom de cinza $i$ e comprimento $j$ ocorre dentro da imagem. Geralmente várias matrizes säo computadas para diversos ângulos,

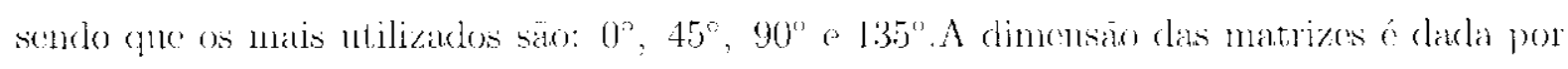

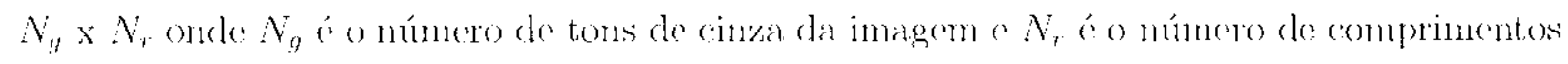

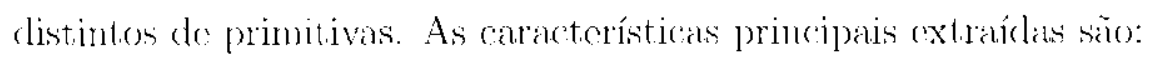

1. Fnfase (no primitivas comtas

$$
\frac{1}{k} \sum_{i, j} P_{\phi}(i, j) j^{2}
$$

2. Finfase on primitivas longas

$$
\frac{1}{K} \sum_{i, j} \frac{P_{i}(i, j)}{j^{2}}
$$

3. Uniformielade do nível de cinzal

$$
\frac{1}{K^{\prime}} \sum_{i}\left(\sum_{j} P_{\phi}(i, j)\right)^{2}
$$

4. Eniformidade do comprimento

$$
\frac{1}{K} \sum_{j}\left(\sum_{i} I_{i}(i, j)\right)^{2}
$$

5. Porcentagem das plimitivas dentro da magem

$$
\frac{K}{\sum_{i, j} j H_{b}(i, j)}
$$


onde $K^{\prime}$ o o número total cle prinitivats dentro da inangem.

O major motivo para a utilizaçăo das GLRLM's para extraça do características ó o fato

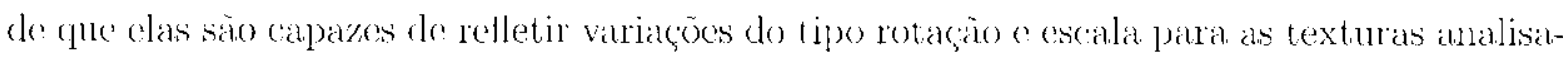

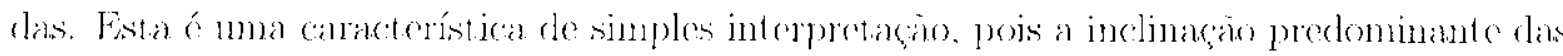
primitivas está dirctamente relaciomada ao comportamento direcional da textura. Qualouer rotaço aplicala sobre a mesma será refletida nas malrizes. A ascala da textura, por sua ve\%, tem relaça direta com o tamanho móndio das prinitivas.

Estre mátodo também possin a desivantagem do alto custo computakional. As primitivat

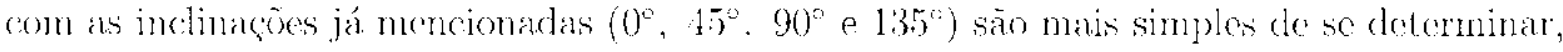
porém, prinitivas com angulos intermediários requerom um esforço adicional. Muitas vezes

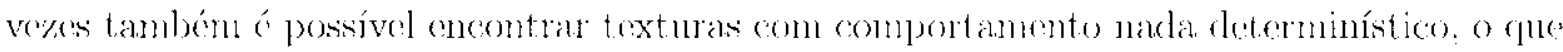
toma aste método mona aplicanion invińvel.

\section{Autocorrelação}

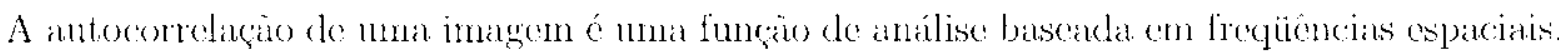
É possivel, a partir dela, determinar algumas características importantes da textura tais como tammaho das primitivas (primitivas grandes - textura grosseira, prinitivas pequenas - textrua fina) eperiodicidnde das mesmas. Textmas finas sa caracterizarlas por altas frequencias espakias, enquanto que texturas grosseiras possuem baxas frequincias. So as prinutivas

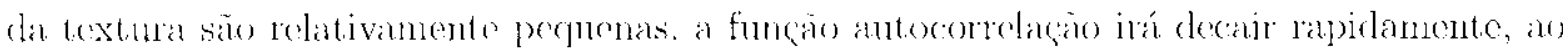

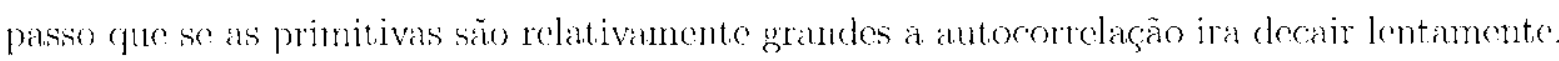
A periodicidade das primitivas é evidenciada cuando a antocomelaģo dimimi o anmenta periodicanente.

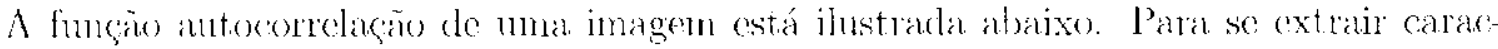
teristicas úteis referentes à textura ó necessário computar a funcuár para cliforentes valores de $p$ e q analisar o comportanento da lungio $p$ e q săo as dimensons de unla sub-janela definida dentre da jamela principal da innagent.

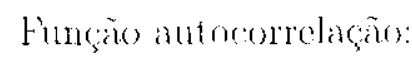

$$
\Theta_{f f}(p, q)=\frac{M N}{(M-p)(N-q)} \frac{\sum_{i}^{M-p} \sum_{j-1}^{N-q} f(i, j) f(i+p, j+q)}{\sum_{j-1}^{M} \sum_{j-1}^{N} f^{2}(i, j)}
$$

\section{Análise da energia do espectro de Fourier}

A transformada de Fourier descreve uma inagem através de suas freqübncias espaciais. A partir do uma análiso sistomática do resultado desta funço (no opprogo das frecuibucias) ó 
possivel também extrair caracteristicas tais como a espessuma a direcionalielaxle da toxtura. A idéla ó calcular a energia da transformada em regioes pro-detinidas como por exemplo, au longo de cunhas on anéis, conforme ilustraklo na figura 2.9. o utilizar estes valores como carnctoristicous.

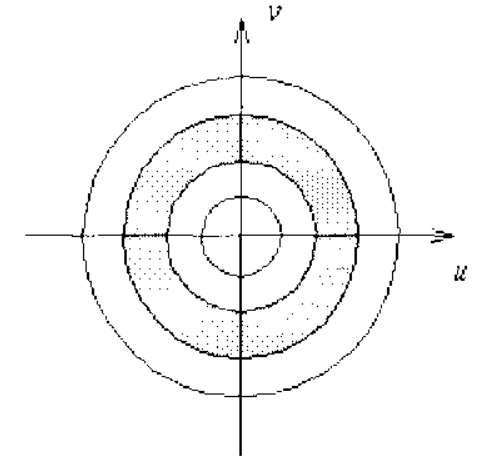

(a)

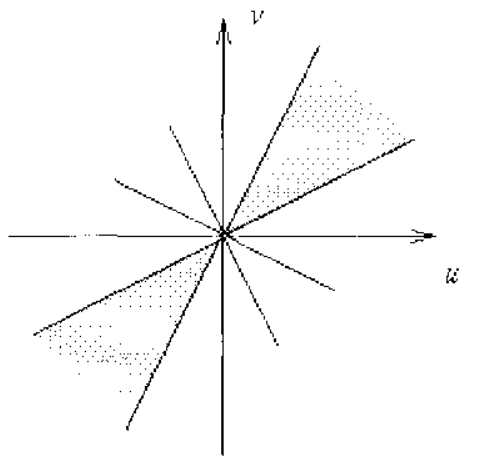

(b)

Figura 2.9: Fxtraço de características a partir da transformada de Fourier (cspaço das frepüencias) (a) energia ao longo de ancis; (c) energia ao longo de cunbas

Caractónticas avaliadas a partir do ancis (fig. 2.9-(a)) refletem a copessura da textura. Energia alta monéis do mo granclés característico de texturas finas presença de altas

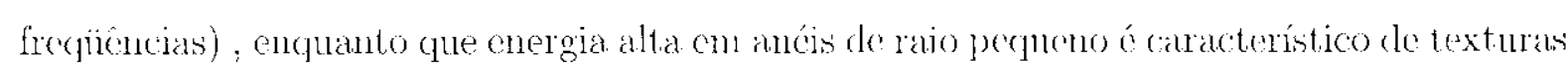
grosseiras e esparsas (presenga do baxas froüencias). As caracteristicas provenientes da

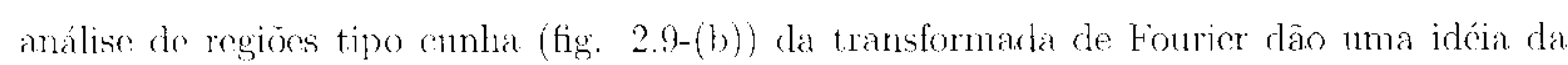
direcionalidado da textura. Caso esta possua um comportamento direcional com ángulo $\phi$,

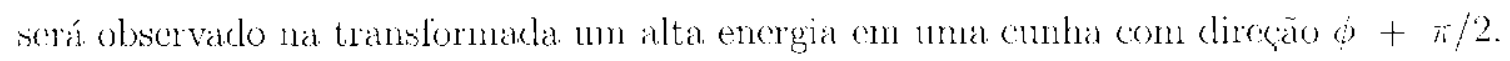




\section{Métodos baseados em modelos estocásticos para segmentação por textura}

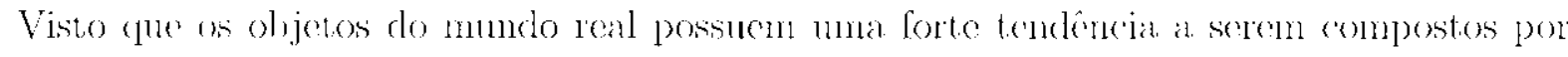
matcriais cujas texturas possurm comportamentos aleatórios, é razoável para uma aplicaçăo de segmontaçăo caracterizan as regióes da imagen como sendo campos aleatórios bidimensio-

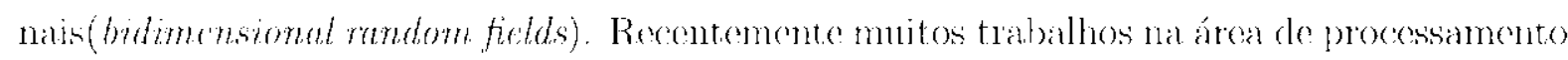

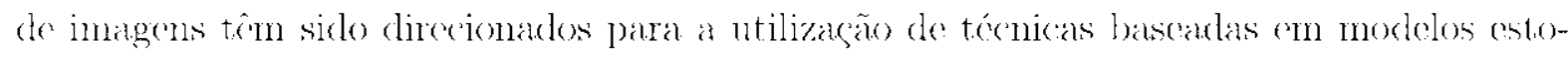

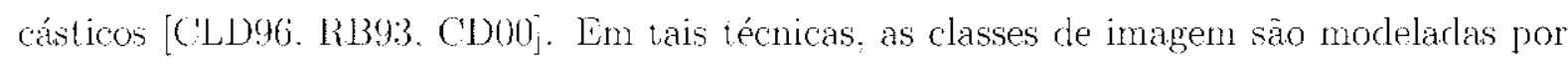
campos aleatórios co problena de segnentaçäo ć proposto cono un problema de olinizaçăo estatínticiol

Comparale com as ténicas anteriomente discut irlas os métodos baseados em modelos stocásticos freqüentemente fornecem um resultado mais preciso para a tarefa de segmentaça por toxtura. Do fato, vários modelos já conhecidos poden ser empregados na síntese: de texturas que mito so aproximan diafuelas encontratas om objetos do mundo real. Geralmente os mótodos desta categoria são cmpregados cuando se deseja segnentar imagens contendo textumas mais complexas. Isto nom semple ó possível, ou. na maioria das vezes tomarse un processo de custo muito alto quando se está eno questäo a utilizagäo das técni-

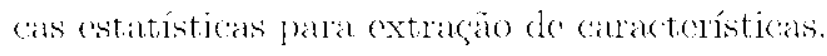

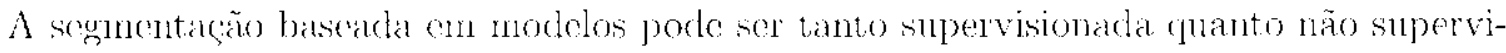
sionada. Na abordagem supervisionada os parâmetros dos modelos são obtidos a partir de
} 
um conjunto de treinamento gorado a partir de imagems já segmentadas da mesma natureza, ao passo que na aborclagem não-supervisionada tais parametros devem ser estimados ao curso do processo, diretanente atravós apenas da imagem observada. O escuema mas

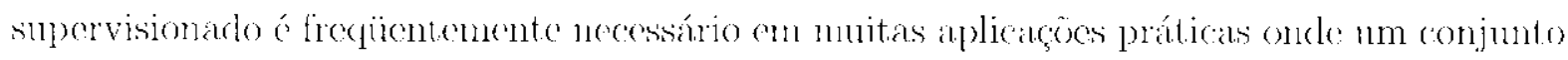
de treinamento nào está disponível (por (xemplo, gllando se tem apenas uma inagem para segmentar ou quando se doseja um sistema completamente autónomo).

As abordagens nâa supervisionadas sino modeladas como um problema de dartos incompletos (incomplete data problem) onde a imagem a ser segmentala să os dados observados; 0 resultado que se deseja obter, geralnuente denominado mapa de classes on campo de rótulos: sào considerados os dados ausentes e; os parâmetros do modelo constituem um ítem a ser doterminalo. A implementaço desta abordagen segue un padrão commun clividido

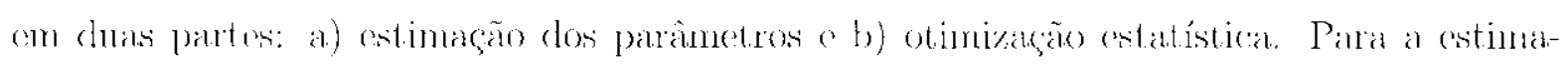
(ão cle parânetros os algoritmos iterativos conhecidos são: FN (Expectation-Marimization); SEM (Stochastic Estimation-Maxmization) e ICE (Iterative Conditional Estimation). Para.

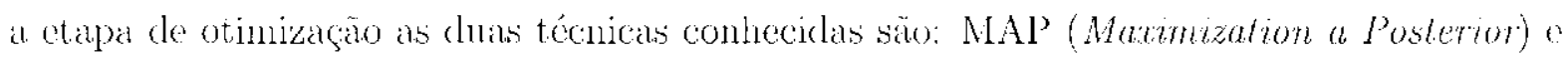

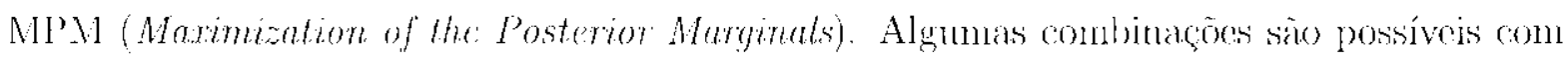
astos conjuntos de métodos. Giondana e Pieczynski [GPY7]: por exemplo, apresentam um estudo sobre a combinação ICM/MPM. Mary Comer, Edward Delp e S. Liu [CTO0), CJD96] apresentam estudos a resultados obtidos com o métoclo FM/MPM.

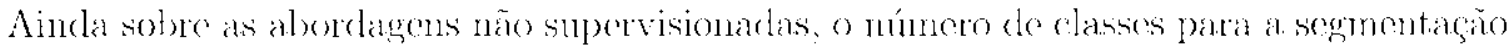

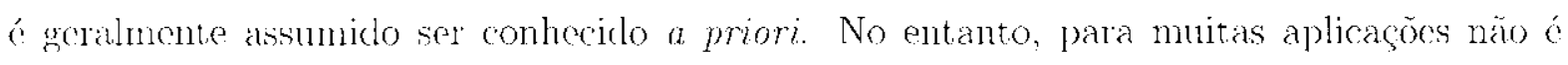
possível o conhecimento de antemão deste paranetro. Fste problemá é conhecido como problema de valiclacio de conjuntos (chuster validation problem) e cmbona tenham siclo propostas algumas estratégias para resoluçäo do mesmo, ainda hoje cle não possui uma solugào formal. Vamos supor neste estudo que o número de classes ó um paranetro conhecido.

Os Campos Aleatórios de Markov (Markov Random f'ields - MlRF’s) mostram ser

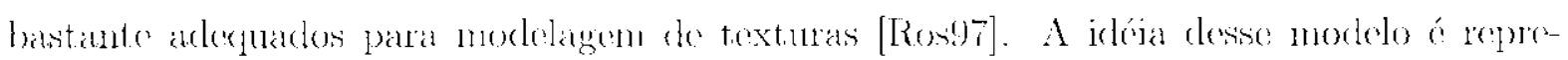
sentaly una imagem através da capture de caracteristicas locais, deteminando para cata. pixel a dependencia de sura intensidade em relaçào às intensidades de seus vizinhos. Esta dependencia é expressa em termos de uma distribuiça de probabilidado condicional dodinida acera da intensidade de carlat pixel. Caso esta clistribuigäo seja definicla como unna distri-

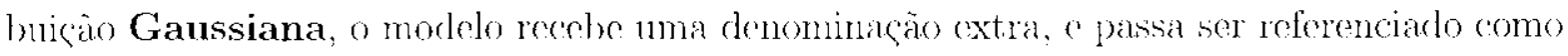
G.MRF's (Guassian Markov Random Fields)

Alguns outros modelos também sào conhecidos. porém a grande malioria das anplicaçócs faw

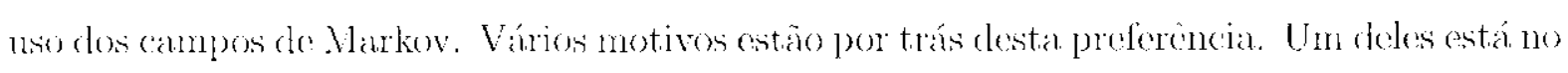
fato de que praticanente qualquer femomeno de contexto nstocástico pode ser representado 
a partir do modelo Markoviano. Alóm do mais de perrnite a moclelagem de características complexas com o uso de relativamente pouces parámetros. Un brove estudo anerca dos demais modrelos pode ser encontrado em [Rosy7]. Säo eles: nodelo de Gibs, moxdelo de Ising,

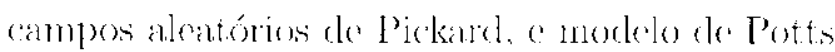

\subsection{Método EM/MPM}

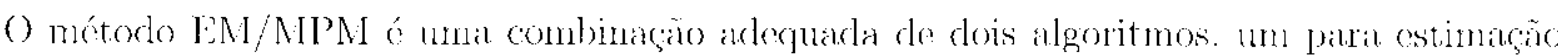
de parametros e outro para otimizaço cstatistica. Os resultados obtidos con este método

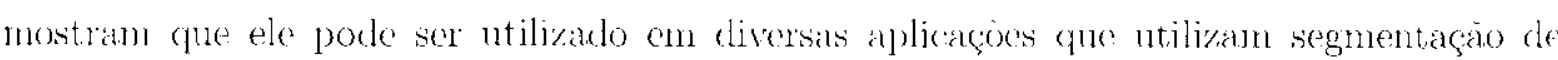
inlagens bascalala cont trotum.

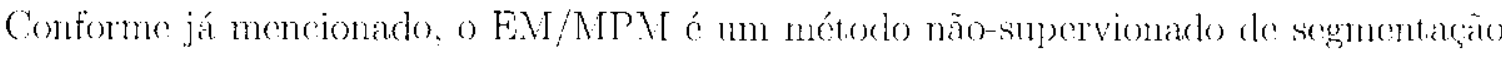
do imagens. Nesta teonica é utilizado um modelo estatístico para a imagem observada (em tons de einza) e 1 m campo alcatório de Markov para o mapa de classes (futuro resultado

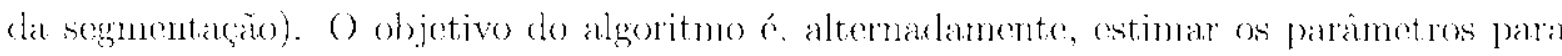

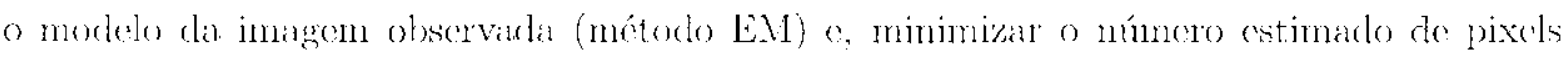
(assificados erroneamente no mapa de classes (método WPM).

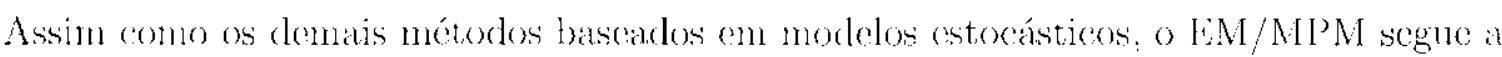

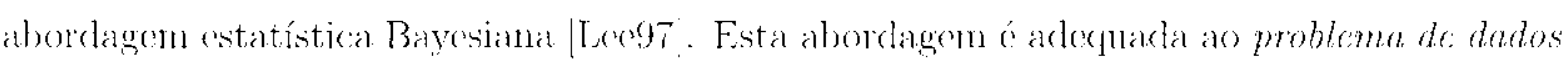
meomplefos, meneionado anteriormente. no sentido do que, primeiranuente, algumas "supo-

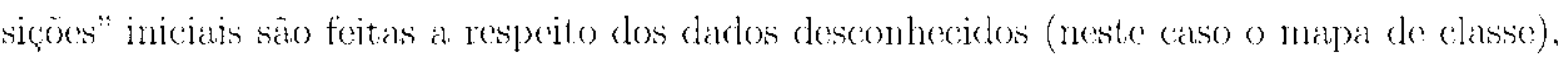
c, a medicla que novos daclos väo sendo adquiriclos, estas supesteges văo sendo alteradas de modo a gerar as informagoes cotrelat. Mais precisamente, a aloordigem Bayesiana para

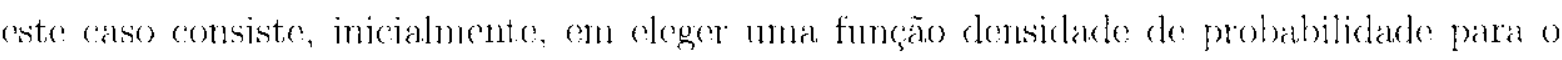

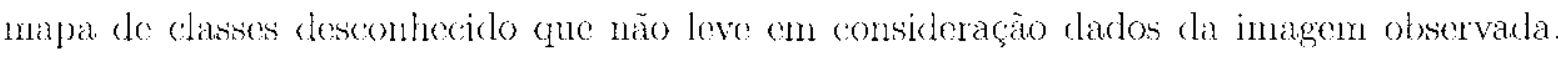

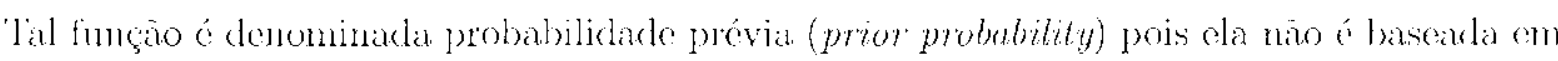

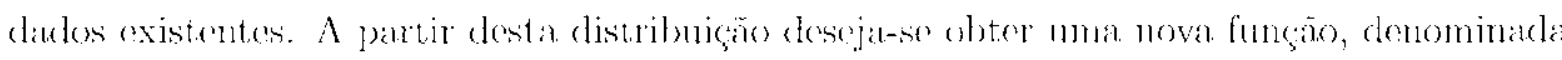
probabiliclade posterior (posterior probability). A probabilidade posterior, neste (aso), ( umal funça de custo que indien o quäo correto cstá o mapa de clasbes atual em rolaça ao resultado esperato, en vista da imagem observada.

O tano combecido teorema de Bayes postula que a probabilidade postorior á proporcional à probabilidarle prévia vozes uma ontra funç̄o denominada função de verossimilhança (likelihood function). Um bom esclarecincento a resperito desta funçà pode ser encontrado

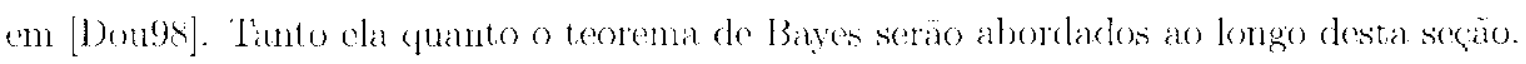

Algumas notacoos serio utilizadas a soguir para a descrigio do mótorlo F.M/MP.M o dos modelos estocásticos utilizados. Süo clas: 
- X - o mapa de classes (ou campo de rótulos)

- $Y$ - a imagem obsorvadia

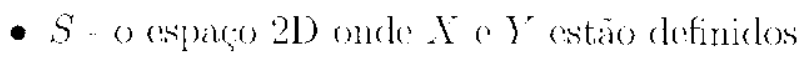

- $N$ - múmero de pixcls em $S$

- $x=\left(x_{1}, r_{2}, \ldots, x_{N}\right)$ - ralização de $X=\left(X_{1}, X_{2}, \ldots, X_{N}\right)$

- $y=\left(y_{1}, y_{2}, \ldots, y_{N}\right)$ - realização de $Y=\left(Y_{1}, Y_{2}, \ldots, Y_{N}\right)$

- $\Omega_{x}$ - espaco das possiveis realizacoes de X

- $\Omega_{y}$ - copago das possíveis realizaçoes de $Y$

- L - Ninnero de clasises pram segmentada

\subsubsection{Modelos das Imagens}

Conforme moncionado, no método EM/.MPA é utilizarlo um canpo aleatório de Markov

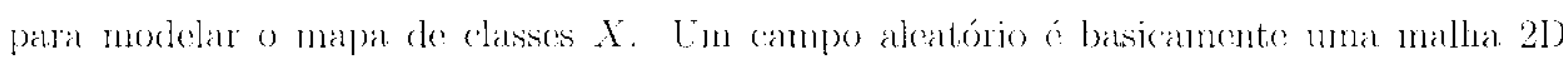

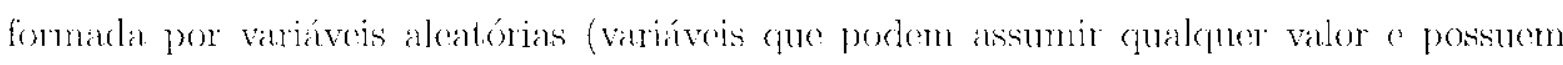

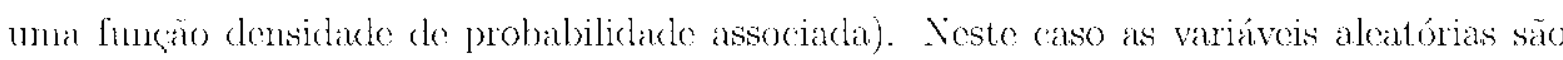
$\left(X_{1}, X_{2}, \ldots, X_{N}\right)$ o o valores que clas podem assumir säo os valores assorialos a carla classe $\{1,2, \ldots, L\}$. Cm ampo aleatório de Markov á um campo aleatório onde a probabilidade

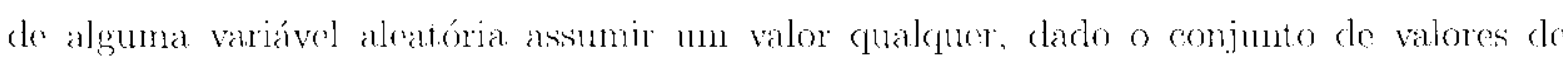
todas as variávois do campo, ó igual a probabilidade desta mosma variável assunir un valor qualquer dado apenas os valores das variáveis definidas dontro de unn sistema de vizinhança. Fommalizando:

$$
P\left(X_{i}=x_{i}, x_{j} j \in S\right)=P\left(X_{i}=x_{i} \mid x_{j}, j \in \eta_{i}\right)
$$

onde mi é conjunto de pixels vizinhos de $i$, dado um sistema de vizinhança pré-estabolecido.

O encuema de vizinhanģis para os campos de Markoy segue o escuema da labola ilustrada na figuma 3.1. A vizinhand 1-conectada, em relaçăo a pixel "x" é obtida tomando-se apenas os valores "1" da tabela, o neste caso. o campo é denominado de princira ordem. Para um

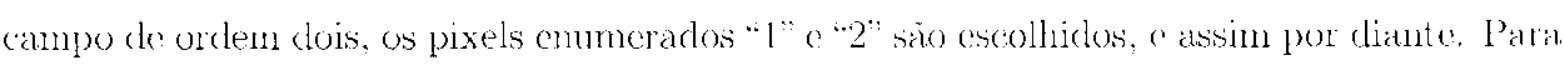
o método EM/APM en particular é utilizado um campo de ordem um, mas nada impede quo algutus testos sejam feitos para ordems maiores. 


\begin{tabular}{|l|l:l|l|l|}
\hline 5 & 4 & 3 & 4 & 5 \\
\hline 4 & 2 & 1 & 2 & 1 \\
\hline 3 & 1 & $x$ & 1 & 3 \\
\hline 4 & 2 & 1 & 2 & 4 \\
\hline 5 & 4 & 3 & 1 & 5 \\
\hline
\end{tabular}

Figura 3.1: Estruluras de vizinhanças para os campos aleatórios de Markov

Un conceito importante, anda relacionado com a vizinlanga utilizada no ranpo, é u

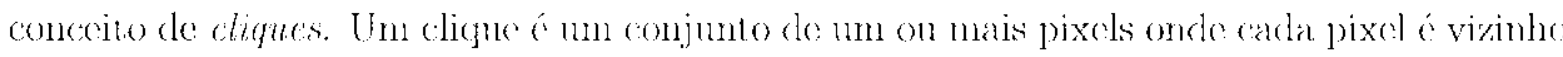
de todos os demais do conjunto (daxto um sistema de vizinhanga). Por exemplo, para a vizinhança de quatro pixels (ordem um) os cliques possíveis são o conjunto de todos os pixcls individuais mais o conjunto das duplas de pixels adjacentes na vertical mais o conjunto de duplati adjacentes na horizontal. conforme ilustraklo na figma 3.2. O conjunto de toclos on

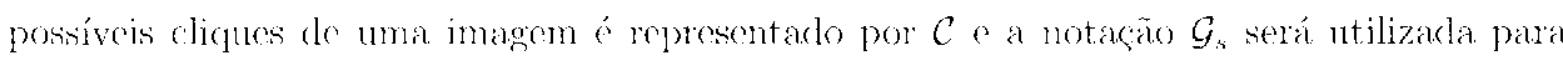
referenciar o conjumto de pixels vizinhos do pixel s. darla a vizinhanca estabelecida.

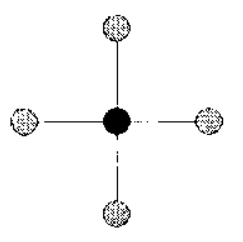

(a)

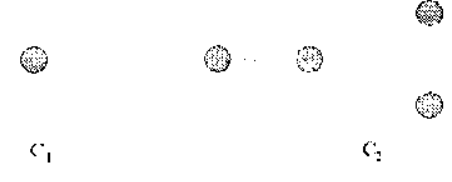

(b)

Figura 3.2: (a) Vizinlança de primeira ordem; (b) cliques correspondentes

() conceito fundamental a respeito dos cumpos aleatórios de Markov está no teorema de Ilammersley-Chifford [Best.1] que diz que a probabilidade conjunta $p\left(X_{1}=x_{1}, X_{2}=\right.$ $\left.x_{2}, \ldots, X_{N}=x_{N}\right)$ de um campo de Markov, ou simplesmente $p(x)$, é equivalente à muat distribuiçăo de Gibbs, on scija:

$$
p(x)=\frac{\exp (-U(x))}{z}
$$

onde zé unna constante de nomalizaçào e $U(x)$ é o somatório de alguma função potencial $V_{c}(x)$ dependente dos chiques da inatgent, on seja:

$$
U(x)=-\sum_{i \in c} V(x)
$$


O fundanento desta fómula assume um papel importante dentro do método de segmentaçăo pois ela representa a probabilidade prévia (prior probability) a ser utilizada dentro do paradigma bayesiano. O modelo proposto por Mary L. Comer e Lelward Del] [CDO(o],

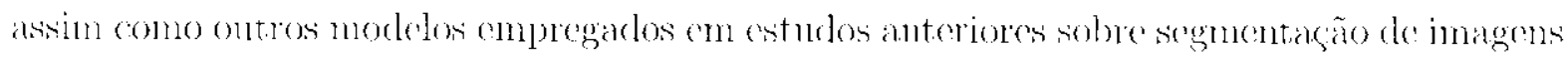
[LD89, KDH8s, Pâj) 92], utilizan a seguinte funçăo $U(x)$ :

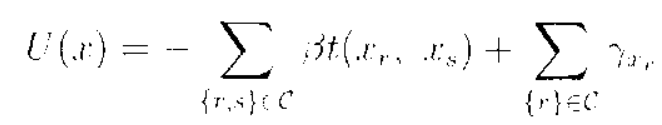

onde

$$
t\left(x_{r}, x_{s}\right)= \begin{cases}0, & s e, x_{r} \cdots x_{s} \\ 1, & \text { se }, x_{r} \neq x_{s}\end{cases}
$$

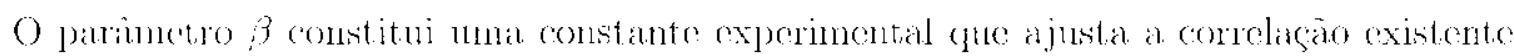
entre pixels vizinhos do modelo e por isso é denominala parâmetro de interaçäo espacial. O conjunto de valores $\left\{\gamma_{k}\right\}$ corresponde aos parámetros que regem a utilizaçăo clos clicpues

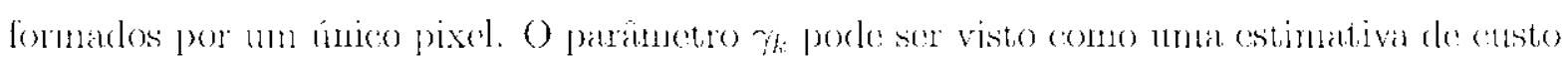

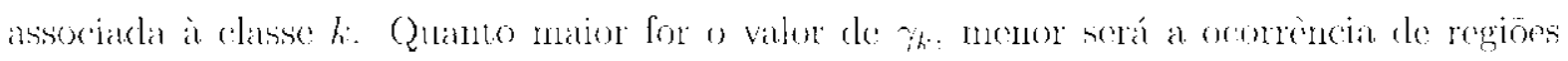
darpucla classe. O capítulo 4 aborla de maneira mais específica a infuéncia exereida polo parimetro de iteraçāo espacial $\beta$ e pelo conjunto de parametros de custo $\left\{\gamma_{k}\right\}$.

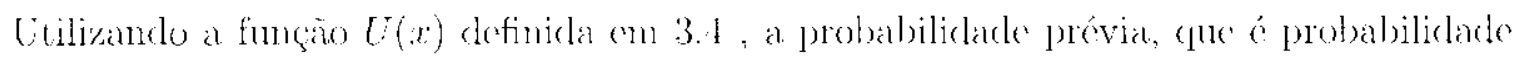
conjunta do campo aleatório do Markov, corresponde a:

$$
p(x)=-\frac{\exp \left(\sum_{\{r, s\}<c} \beta t+\left(x_{r}, x_{r}\right) \cdots \sum_{\{r\}<c} \gamma_{x_{r}}\right)}{z}
$$

O objetivo desta seçăo, (que descreve os modelos para o mélodo de segmentaçĭ̌ EM/MP.M,

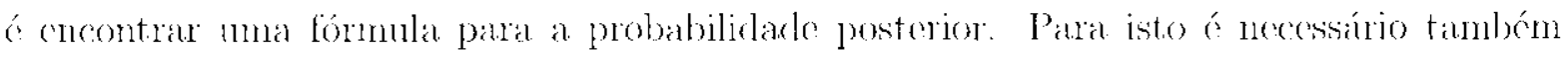
assimir um modelo para a imagem obscrvada $Y$. Do mesmo modo, cste modelo será uma. malha $2 \mathrm{D}$ de variáveis aleatórias $\left(Y_{1}, Y_{2}, \ldots, Y_{N}\right)$.

Inicialmente é coerente pensar que. (le alguma forma, a intensidade de canda pixol cla

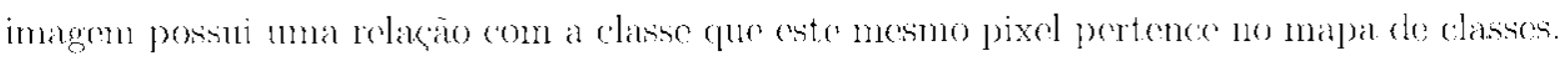
Isto sugere que para cada variável aleatória do moxklo de $Y$ scja associada uma funçäo densidade de probabilidade do tipo $f\left(Y_{r}=y_{r} \mid X_{r}=x_{r}, \theta_{x_{r}}\right)$, que indica a probabilidade de un pixel $r$ ter intensidade $y_{r}$, darlo que este pixel pertence is classe $x_{r}$ no mapar de 


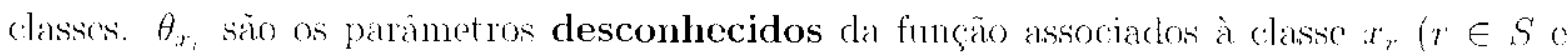
$\left.x_{r} \in\{1,2, \ldots, L\}\right)$

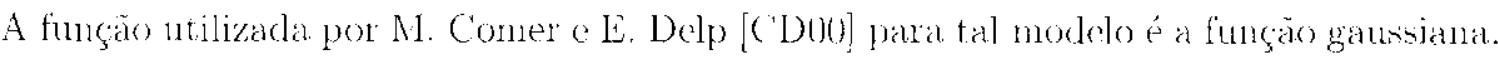

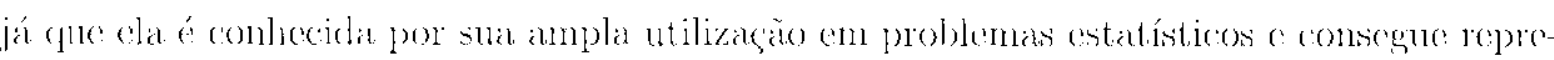

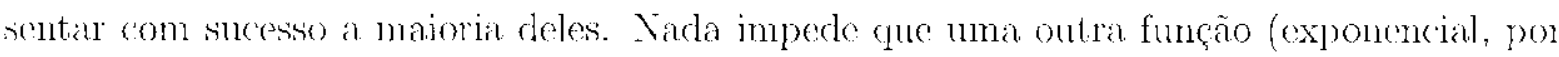
exemplo) seja (xperimentada. Neste estudo vamos também supor a utilização de gámssianas. Deste modo:

$$
f\left(Y_{r}-y_{r} \mid X_{r}-x_{r}, \theta_{r_{r}}\right)=\frac{1}{\sqrt{2 \pi \sigma_{x_{r}}^{2}}} \exp \left(-\frac{\left(y_{r}-\mu_{r_{r}}\right)^{2}}{2 \sigma_{r_{r}}^{2}}\right)
$$

Conforme dito anteriomente, a probabilidade posterior é proporcional à probabilidade pré-

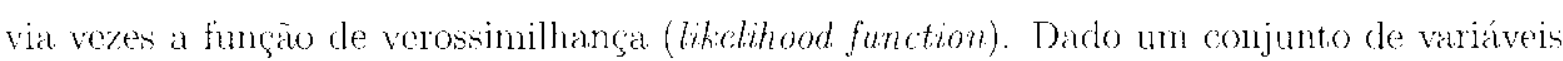

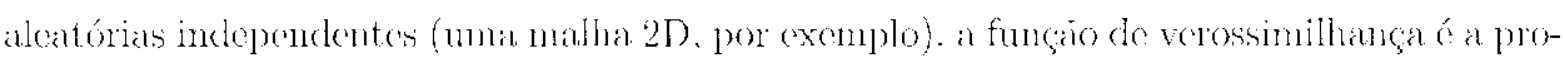
babilidate conjunta do sistema, obticla através do produtório das probabilidades das variáveis [Doug8]. No caso da inragem observada $Y=\left(Y_{1}, Y_{2}, \ldots, Y_{N}\right)$, a função de verossimilhança $L(0 \mid X, Y)=f(y \mid x, \theta)$ será

$$
\begin{gathered}
L(\theta \mid X, Y)=\prod_{r=1}^{N} f\left(Y_{r}=y_{r} \mid X_{r}=n_{r}, \theta_{r_{r}}\right) \\
=\prod_{r=1}^{N} \frac{1}{\sqrt{2 \pi \sigma_{r_{r}}^{2}}} \exp \left(-\frac{\left(y_{r}-\mu_{x_{r}}\right)^{2}}{2 \sigma_{r_{r}}^{2}}\right)
\end{gathered}
$$

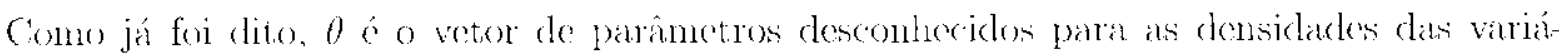
veis $\left(Y_{1}, Y_{2}, \ldots, Y_{N}\right)$. Ele possui $L$ posiçoos da seguinte forma: $\theta=\left[\mu_{1}, \sigma_{1}^{2} ; \ldots ; \mu_{L}, \sigma_{l}^{2}\right]$. () objetivo do método EM ó estimar iterativamente cites valores.

Neste ponto, com base no teorema de Bayes e utilizande ats couacoes 3.7 a 3.5 , 6 possível

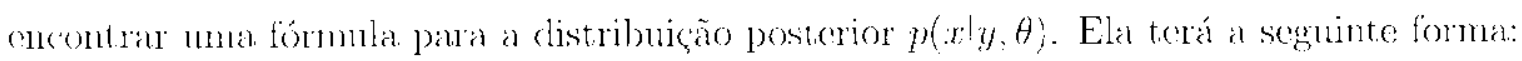

$$
\begin{aligned}
& p(x \mid y, \theta) \cong f(y \mid x, \theta) p(x)=\prod_{r=1}^{N} f\left(y_{r} \mid x_{r} . \theta_{x,}\right) \operatorname{xp}\left(\sum_{c \in c} V_{c}(x)\right) \frac{1}{z}= \\
& =\left[\prod_{r=1}^{N} \frac{1}{\sqrt{2 \pi \sigma_{r_{r}}^{2}}} \exp \left(-\frac{\left(y_{r}-\mu_{x_{r}}\right)^{2}}{2 \sigma_{r_{r}}^{2}}\right)\right] \exp \left(\sum_{\{r, 4\}<c} \beta t\left(x_{r}, x_{s}\right)-\sum_{\{r\} \in C} \gamma_{r}\right) \frac{1}{z}=
\end{aligned}
$$




$$
=\frac{1}{z}\left[\prod_{r-1}^{N} \frac{1}{\sqrt{2 \pi \sigma_{x_{r}}^{2}}}\right] \exp \left(-\sum_{r=1}^{N} \frac{\left(y_{r}-\mu_{x_{r}}\right)^{2}}{2 \sigma_{x_{r}}^{2}}+\sum_{\left\{r_{r}\right\} \boldsymbol{C}_{C}} \beta t\left(x_{r}, x_{s}\right)-\sum_{\{r\} \in C} \gamma_{x_{r}}\right)
$$

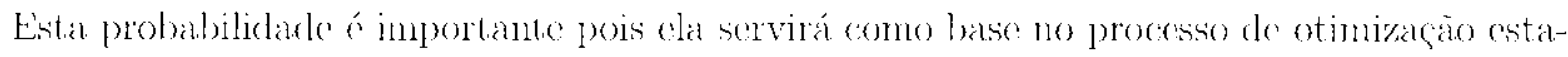
tística. Naximizar o valor desta funço significa cncentrar o mana de classes $X$ (on imagem segmentada) mais provável, dada a imagem a ser segmentada $Y$ : ou : cru outras palavas, minimizar o numero de pixels nal classificakos en $X$. Como já foi clito, os algoritmos

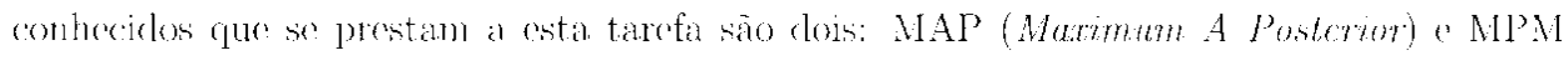
(Marmization of the Posterior Maryinals). O primeino deles (MAP) visa a maximizacaio direta da funçăo $p(x, y, \theta)$ enquanto o outro procura maximizar as marginais desta distribuição: $p(x), y)$.

De fato, o método WPN é o mais inficado para a segrnentadaro. O algoritmo MAP associa um custo constante para todas as segmentaçōes incorretas sem levar em conta o número de pixels mal classificados, ou seja, os pixels cuja classificação diferem da segmentiaçäo verda-

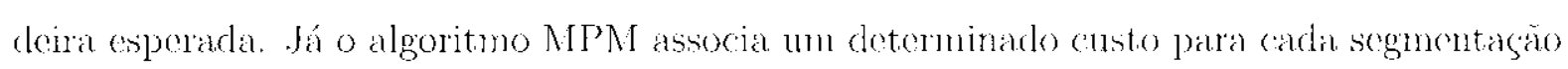

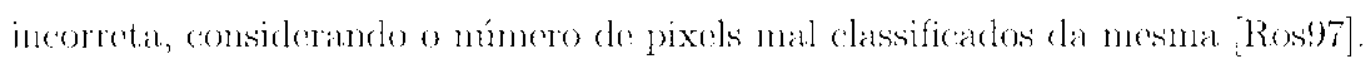

Infelizunente, tanto para o método MAP quanto para o MPM, não ó possível gerar uma amostra direta de $X$ a partir da probabilidade posterior $p(x \mid y, \theta)$, mas é possível que ela seja aproximada iterativanente utilizando, por exemplo. o método Cabbs Sampler [( (a92].

\subsubsection{Algoritmo MPM}

Vamos assumir inicialmente que os parametros do vetor $\theta$ já sä́o conhecidos. O algoritmo MP X ú utilizado para realizar a scomentaça da imagen bascacla em uma tarefa de otimiza-

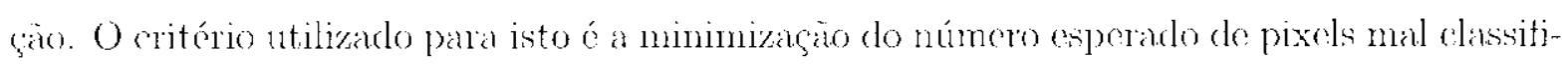
cardos. Conforme foj comprovado por Jeff A. Bilmes [Bilgs], minimizar este valor é expivalente a maximuar a distribuigào marginal $p\left(X_{s}=k \mid Y=y, \theta\right)$ para todo $k \in\{1,2, \ldots, L\}$ e para Lodo $s \in S$. Portanto, para concontrar una estinaçäo MP'M de $X$ é necensário oncontrar para calas $s \in S$ o valor de ha que maximize:

$$
p\left(X_{h}=k \mid Y=y\right)=\sum_{r \in \Omega \Omega_{i, \infty}} p(x \mid y, \theta)
$$

onde $\Omega_{k, s}=\left\{x: l_{s}=k\right\}$. 


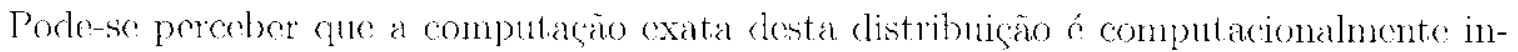
viával. Se fixarmos o pixel s como sendo da classe $k$ e variamos todos os pixels restantes obteremos inúnumas combinagoes para o mapa $X$. comespondente a espago $\Omega_{k, s}$. F. por isso

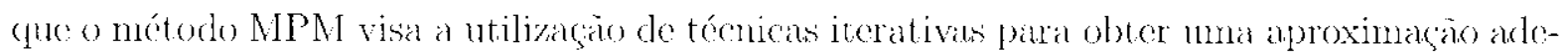

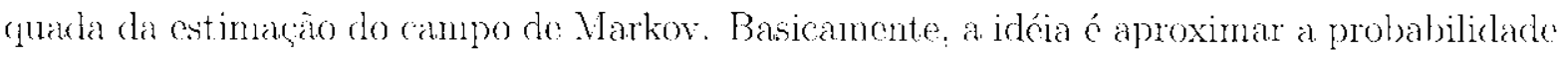
$p\left(X_{s}=k Y=y\right)$ para cada $s \in S$ e $k \in 1,2, \ldots, L$ da seguinte mancira:

- utilizar o Gibbs sampler para gerar uma cardeia de Markov $X(t)$, discreta no tempo. (que comvirja con distribuiça para un campo aleatório com probabilidade $p(x \mid y, \theta)$;

- aproximar a densidado marginal $p\left(X_{s}=k \mid Y=y, \theta\right)$, que deve ser maxinizada, cono sendo a fração de tempo em que a cadeia de Markov passa no estaclo k no pixel s, para cadia s c h:

Para una carleia de Markov X(t), gerada utilizando-se o Gibbs sampler, há um total

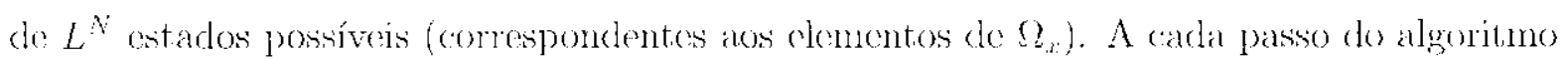

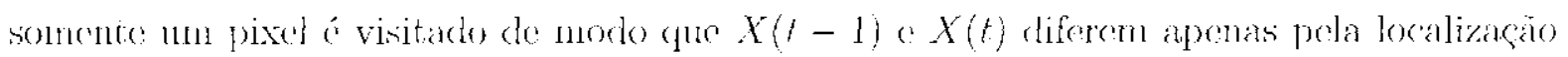
de un pixel. Em uma posição do tempo qualquer t, o estarlo de $X(t)$ em um pixels $s$ coresponde à variável alcatória $X_{b}(t)$. Considere at $\in S$ como sendo o pixel visitarlo no tempo t. O estado de $X_{q}$ (t) ó deterninado gerando-se um valor aleatório com distribuição (le probabilidade $p\left(X_{q t}=k_{i} Y=y_{,}, x_{r}(t-1), r \in \mathcal{G}_{q t}, \theta\right)$.

So a sequïncia $\{q 1, q 2, q\}, \ldots\}$ contém cada pixel $s \in S$ com frequència tendendo ao infinito, então para una configuraçăo $x(0) \in \Omega_{X}$ :

$$
\lim _{i, \infty} p(X(t)=x \mid Y=y, x(0))-p(x \mid y, \theta)
$$

para cada $x \in \Omega$. Deste modo, a cadoia de Markov converge em distribuicaio a um campo alcatório com probabilidade $p(x \mid y, \theta)$, on soja: $p(x \mid y . \theta)$ é a distribuição linnite para a cadeia. de Markov.

Para formalizar a aproximaça da densidade marginal $\nu\left(\mathrm{X}_{s}=k, Y=y, \theta\right)$ considere primeiramente a seguinte fulunção:

$$
\alpha_{k, b}(t)= \begin{cases}1, & \text { se } X_{s}(t)=h \\ 0, & \text { se } X_{s}(t) \neq h\end{cases}
$$

Sendo assinte so $T_{s}$ o o múmero de visitas an pixel s realizadas polo Gibbs sampler então a 
al)roximagào ocorre da segninute maneira:

$$
p\left(X_{s}=k \mid Y=y, \theta\right) \approx \frac{1}{T_{s}^{\prime}} \sum_{i=1}^{T_{s}} a_{k, s}(l) \quad \forall k, s
$$

\subsubsection{Algoritmo EM}

O) algoritmo EM [Bilg8, DIRTT. Wus3, RWst] é um método de estimação do paránctros (quo so cncaixa no esquema geral de estimazăo por máxima-verossimilhança e é aplicado an problemas onde parte dos dados nive sajo conlecidos, ou seja, em problemas de dados incomplotos.

Dentro do contexto de segmentaçào de imagens o objetivo do método EM é estimar os paràmotros $\theta$, do modelo utilizado para a imagem observada $Y$. Conforme foi visto, estes parametros sâ importantes no processo de otimizaga realizado pelo algoritmo MPM.

Os métodos de estimagäo baseados no escuema de máxima-verossimilhance proeuram. como o próprio nome diz, maximizar a função de verossinilhança [Dougs]. Como esta funçäo ó definida a partir de um produtório, a larefa de otimizaçäo da mesma se torma mais simples

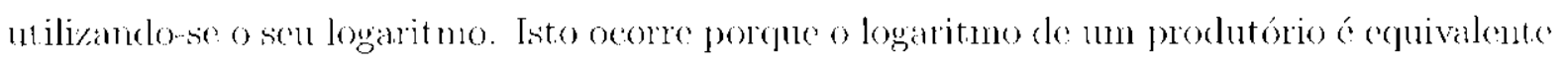
a. um somatório de logaritmos.

Para um problema comum, que não possui dados ansentes, bastaria simplesmente que a função de verossimilhança fosso maximizada. Porcm, com a cxistencia de darlus ausentess, 0 gue se procura a a maxinizaga do valor esperado desta funcaio [Colgr].

O método F.M c cssencialmente um algoritmo iterativo de olimização que converge para ımo máxino local da funçào de verossimilhança. Fm cada iteraça são realizados dois passos: determinaço do valor esperado e maximizaçá

Seja $\theta(p)$ o conjunto de parânetros estimalos na itcracão $p$. chtão o primeiro passo do algoritmo é compunar a seguinte funçăo:

$$
Q(0, O(p-1))=E \log f(y \mid \cdot x, \theta) \mid Y^{\prime}=y \cdot \theta(p-1)
$$

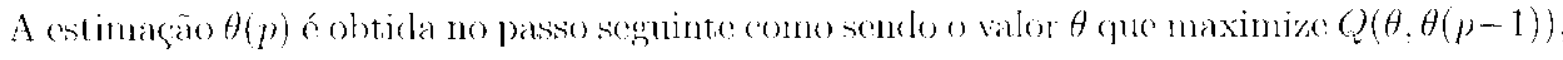
oll soja. clue satisficka:

$$
Q(\theta(p), \theta(p-1)) \geq Q(\theta, \theta(p-1)) \quad \forall \theta \in \Omega_{0}
$$


Substituindo (3.7) en (3.13), diferenciando, igualando a zero o resolvendo para $0(p)=$ $\left.\mu_{1}(p), \sigma_{1}^{2}(p) ; \ldots ; \mu,(p), \sigma_{l}^{2}(p)\right]$ obtém-so:

$$
\mu_{k}(p)=\frac{1}{V_{k}(p)} \sum_{s=1}^{N} y_{s} p\left(X_{s} \ldots k Y=y, 0(p-1)\right)
$$

$$
\sigma_{k}^{2}(p)=\frac{1}{N_{k}(p)} \sum_{s=1}^{N}\left(y_{s}-\mu_{k}(p)\right)^{2} p\left(X_{s} \quad k Y=y_{0}(0(p-1))\right.
$$

onde

$$
N_{k}(p)=\sum_{s-1}^{N} p\left(X_{s}=k \mid Y=y, \theta(p-1)\right)
$$

para $k-1, \ldots, L$

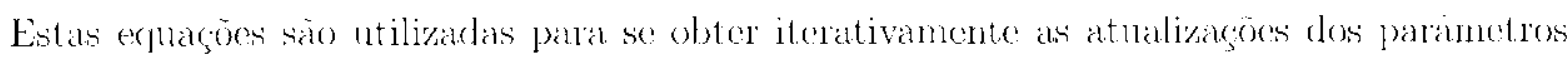
conticlos 10 vetor $\theta$ (módial e variância para cada classo). 


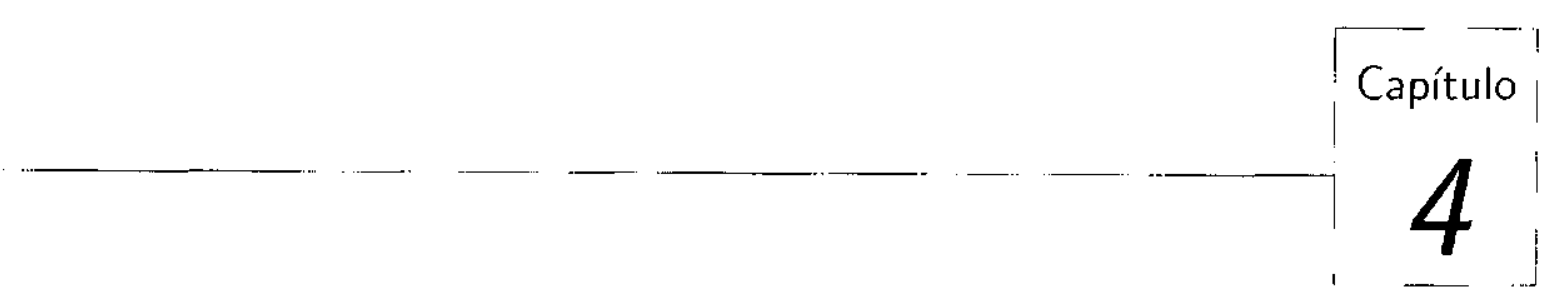

Implementação

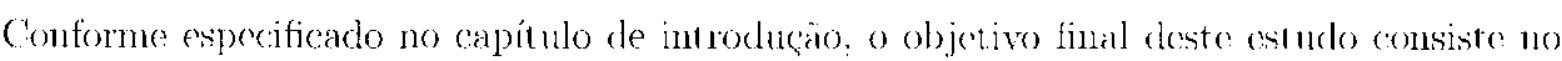

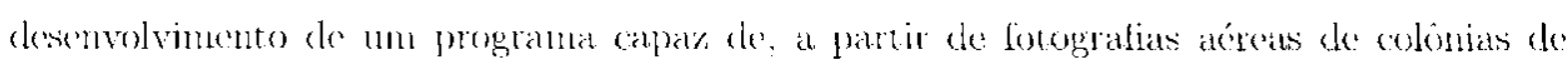

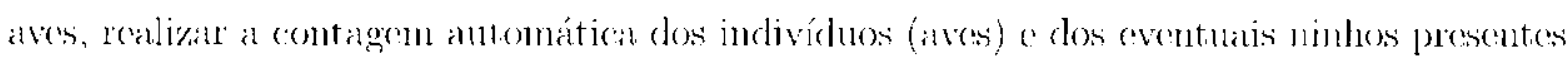
nestas imagens. Para isso, é necessário que este programa seja constituíclo. basicannente de: $10 m$ algoritno (apaz de segment ar as imagens o outro para a contagens das regiöes obtidas.

As imagens utilizarlas ap)resent am características que sugerem fortemente a aplicagio de

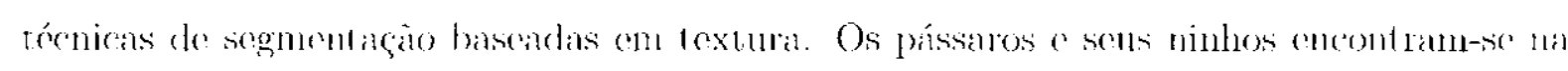
maioria das veres sobre as copas das árvores. Deste nodo as fotografias são compostas basicanonte pela imagem dos indivíduos, dos ninlose e de cobertura florestal.

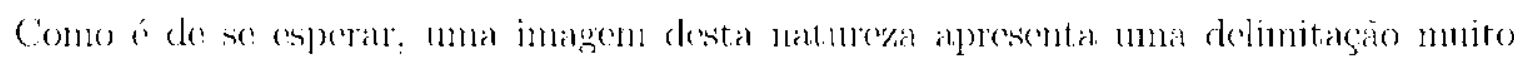

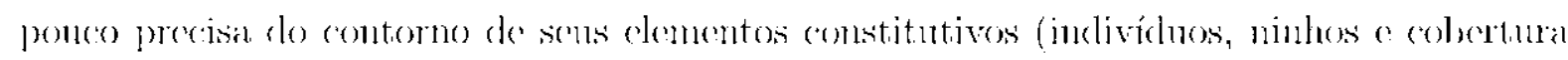
florestal). Os ninhos. por cxemplo, quando visíveis, cneontrun-se bem difundiclos cm meio a folhagem das ávores, o que afasta a possibilidaxle do se enpregar alguma técnica bascada mat delecerio de bordas.

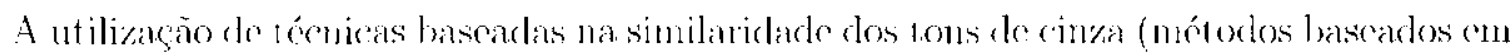
regiăo e limianizaço) taubém representa una solucio inaclequada an problema pois nenhum dos elementos hásious das imagems possui como calacterística predominante a similaridade

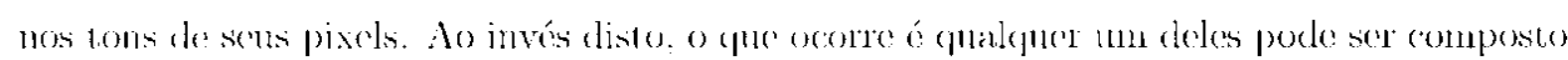

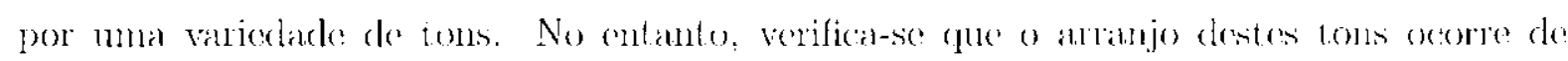
maneira diforente en cada clemento.

Fstas afinmagoes reforçan a idcía de que a utilizaça de texturats no processo de seg-

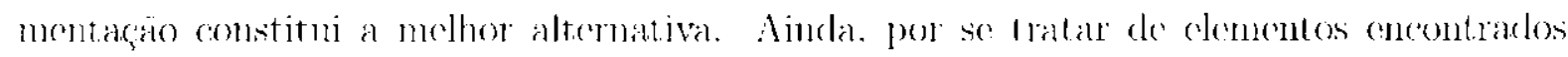




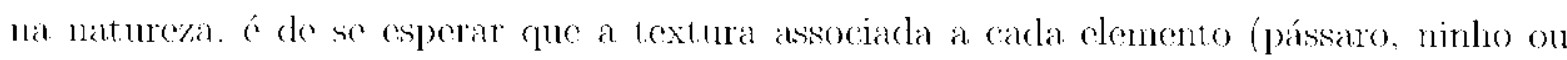
cobertura florestal) apresente comportamento ponco determinístico. on seja, aleatório.

Com base nestas aracteristicas. a analisando os resuluados obtidos em diversos estudos voltados para segmentaço baseada em textura, o nótodo escolledo para segmentar as inatgens loi o método E.M/.MPM, apresentarlo no capítulo 3. Para a contagem do númoro do regions conexas. cue representam os objetos obtidos na etapa de segmentação, foi utilizado num método iterativo bascado no algoritmo de precuchimento por alagancento (Flood Fill) $[11130(j \mathrm{j}$.

Este capitulo desereve, de maneira objetiva as principais olapas e conceitos que conduzem à implenentaça do algorino de segmentação EM/MPM e do algoritmo de contagem de regiós. Outras duas lécnicas foran incorporarlas an EM/ MPM tornando-o mais robusto.

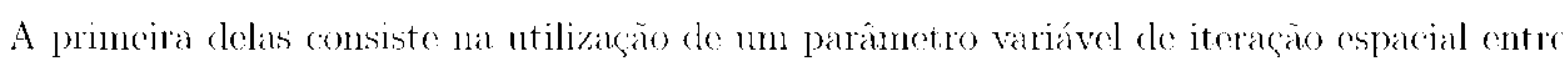
os pixels do mapa de classo (técnica denominada Annealing) e a ontra refore-se à utilizargão de una abordagom multi-resolução. Fstas duas técnicas lambém serào discutidas neste capítulo.

\subsection{Visão geral do algoritmo EM/MPM}

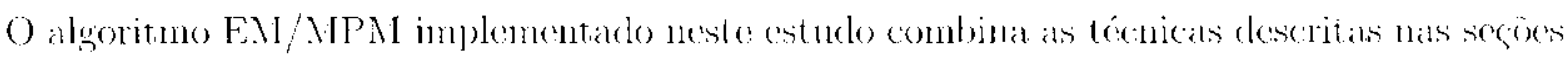

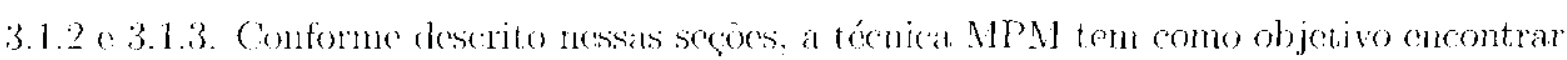
um mapa de classes que possua um número mínino de pixcls mal classificados (pixels cuja

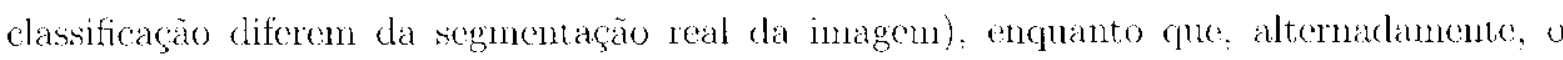

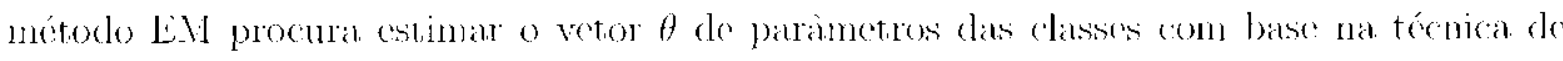
stimngäo por máxima verossimilhatuça.

P’ara se ter uma visăo geral deste processo, considere inicialmente? um vetor $\theta$ cscolhido arbitrariancente e clenominado $\hat{\theta}(0)$. A partir de $\theta(0)$ o algoritmo MP.M é executado pela

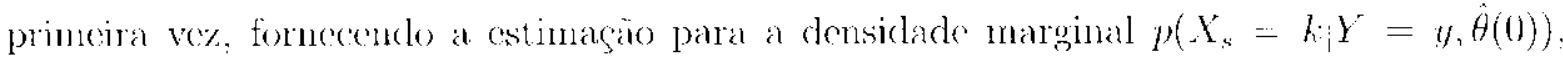
conformo especificado em 3.12. Fste valor estimado da marginal ć utilizado nas cquaçoes 3.15 e 3.16 para se obter a primeira estimaçáa do velor 0 ou seja $\theta(1)$. Esta nova ostinaçá é

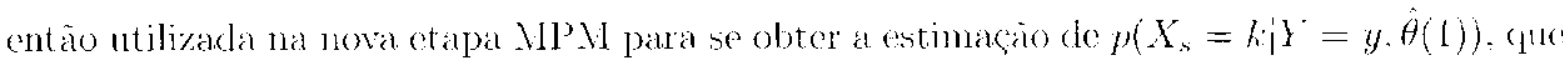

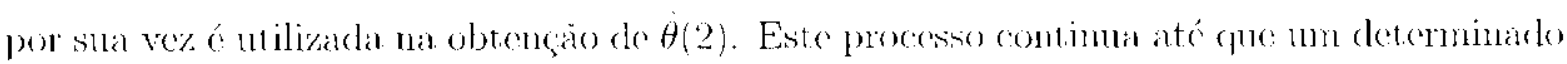
eritério de parada seja atingido. Tal critério ó abordado mais adiante ainda nesta seção.

En cada performance do algoritmo MPM é gerada uma cadeia de Markov $X(t)$ que converge en clistribuição para un canpo alcatório com probubilidade $p(x \mid y, \theta)$. Os clementos

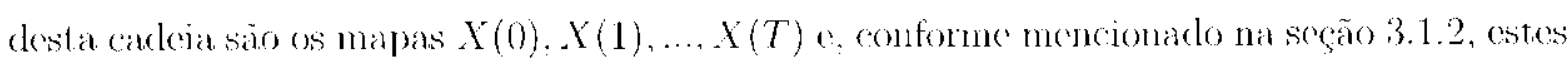
clementos so diferem apenas pela classificaçano do um pixel. Ao logo do processo LM/MPM, 
várias destas cadeias são geradas, formando o conjunto $X(1, t), \ldots, X(P+1, t)$, para algum $P>=1$. $\Lambda$ geracio da cadeia $X(p, t)$ comesponde ì perfornanoe do estágio $p$ do algoritmo EM/MPM a a estimaçáa do velor A obticla durante o estágio pé representada pola variável alcatória $(-(p)$.

Considerando estas novas notagöes é possived descrever de uma maneira um ponco nais específica o procosso en questâo. O algoritmo inicia com una estinabão $\theta(0)=\theta(0)$ para

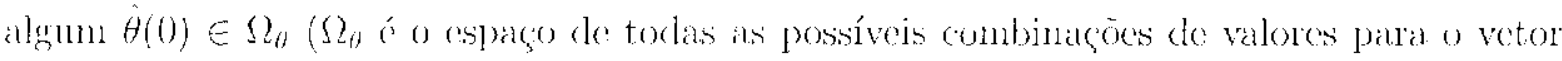
$\theta) . \Lambda$ primeira adein de Markov $X(1, t)$ á gerada utilizande o procodimento descrito ma sçà 3.1.2. Nesta cadeia, o estado de um determinado pixel qt no monento t cortresponde ¿ notaça $Y_{q}(t)$ e e determinado a partir de uma mostra retirada da funçäo densidade do

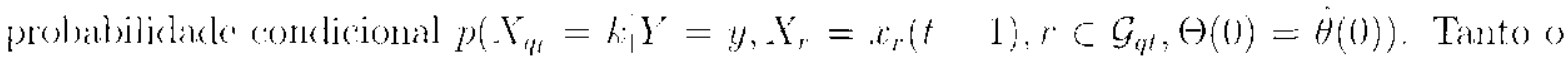

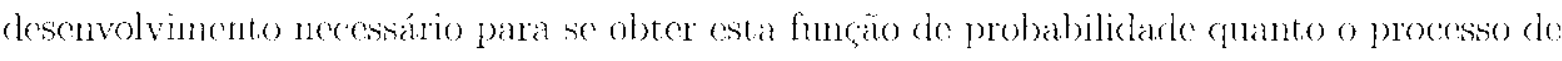
amostragem será visto com mais detalhes nas próximas seçoes.

Depois de cala pixel ter sido visitado $T_{1}$ vezes durante o estagio $p$ do processo, para algum $T_{1}>1$, o valor aproximado da densidade marginal $p\left(X_{s}=h: Y=y,(-(0)=\hat{\theta}(0))\right.$ é

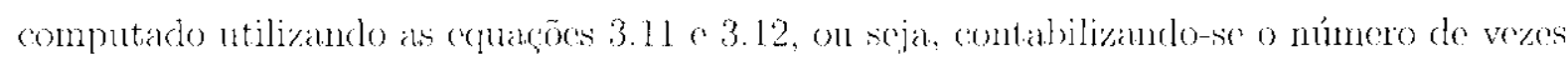
que o pixel s foi classificado como sendo da classe $k \mathrm{~cm}$ relação ao númcro total de visitas gue este pixal receber. Formalizando:

$$
p\left(X_{s}=k \mid Y=y,(\theta(0)=\hat{\theta}(0)) \approx \frac{1}{T_{1}} \sum_{t=1}^{T_{1}}\left(x_{k, n}(1, t)\right.\right.
$$

oncle

$$
a_{k, s}(1, t)= \begin{cases}1, & \text { se } X_{s}(1, t)=k \\ 0, & \text { se } X_{s}(1, t) \neq k\end{cases}
$$

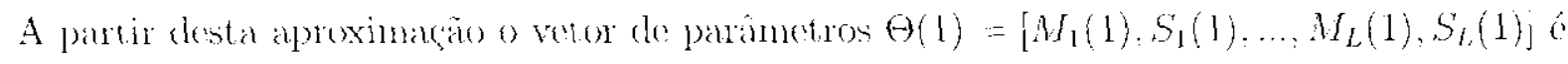
computado utilizado as equaços 3.15 e 3.16 conforme a aprestentado a segur:

$$
M_{h}(1)=\frac{\sum_{s=1}^{N} y_{s} p\left(X_{s}=k ! Y=y \cdot \Theta(0)=\hat{\theta}(0)\right)}{\sum_{s=1}^{N} p\left(X_{s}=h: Y=y, \Theta(0)=\hat{\theta}(0)\right)}
$$

(') 


$$
S_{k}(1)=\frac{\sum_{*-1}^{N}\left(y_{s}-M_{k}(1)\right)^{2} p\left(X_{*}=k \mid Y=\eta \cdot \Theta(0) \cdots \theta(0)\right)}{\sum_{s=1}^{N} p\left(X_{s}=k \mid Y=\eta, \Theta(0)=\dot{\partial}(0)\right)}
$$

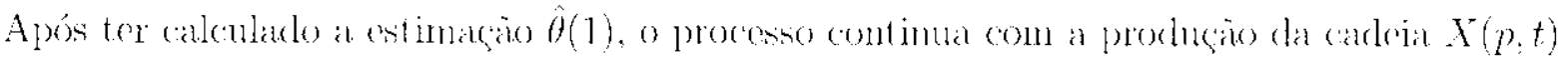

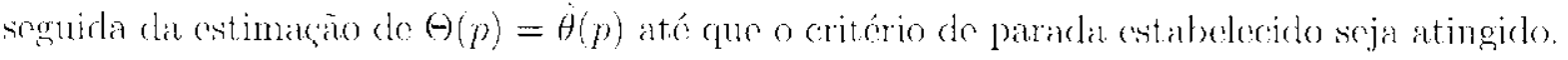
Nosta implenentaçăo o processo será finalizarlo quando un número predeterminado $l$ ' de estágios for atingirlo.

O algoritmo pode, entaino, ser resumirlo da seguinte maneim:

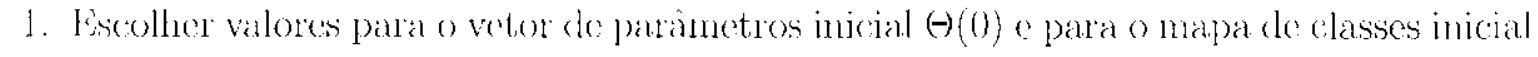
$X(1,0)$;

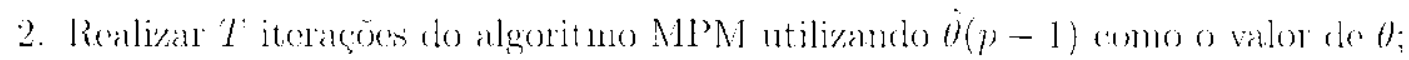

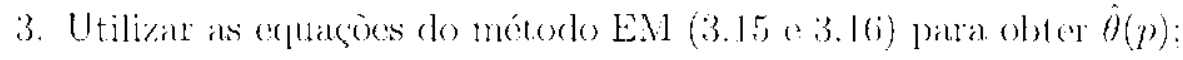

4. Repetir os ítens 2 o: 3 para $P$ estrigios.

A segmentaçio final ó obtirla executando o algorit mo MPM pela última vez com a estimagao de $\theta$ obtida no estágio $P$, ou seja, $\dot{\theta}\left(P^{\prime}\right)$. A execução desta etapa final irá produzir

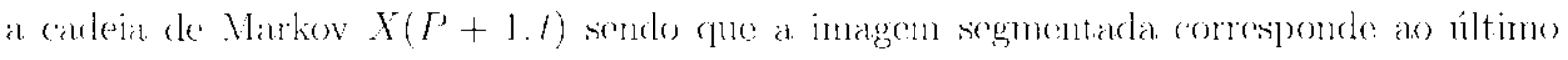
clemento destan cardela: $X(P, 1, T)$.

\subsubsection{Gibbs Sampler}

O algoritmo Gibbs Sumpler corresponde a módulo fundanental da implementagäo do algo-

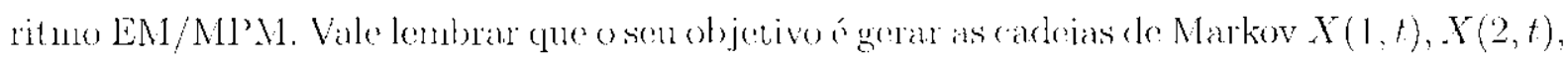
$\ldots, X\left(I^{\prime}+1, t\right)$, discretas no tempo, que convirjam em slistribuicão para un canpo alcatório

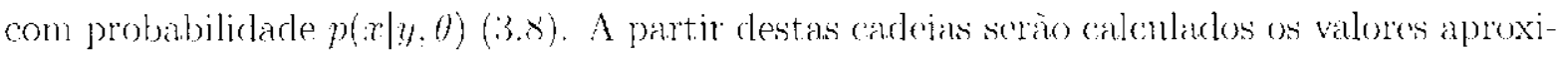

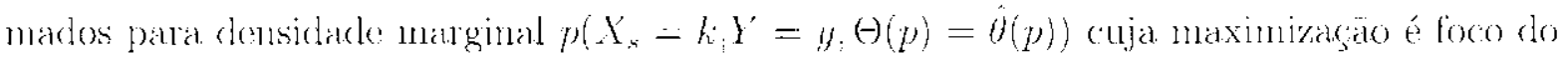
algoritno MPM (Mutimization of the Posterior Marginals).

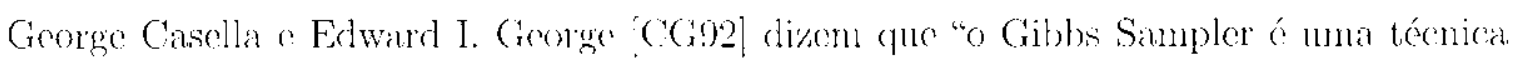
para geração indireta de variáveis alcaiórias de uma determinarla distribuiçäo marginal sem

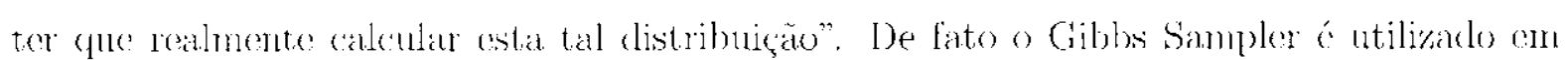

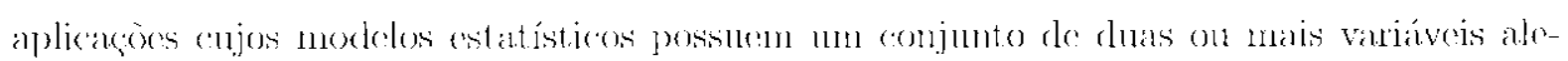

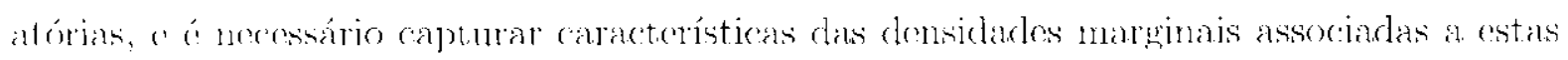


variaveis. A maneira mais intuitiva para se alcancar este objetivo seria calcular diretamente o valor das marginais. Ocorre que dependendo função de probabilidade conjunta do nordelo, a computaçäo exala dias probabilidades marginais se torna uma tadrefa inviável, conno por

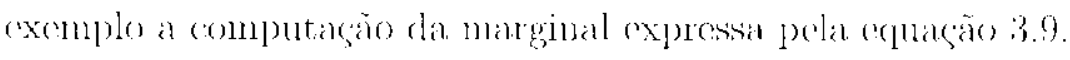

Para comecar a comprender o algoritmo Gibbs Sampler considere primeiro mm modelo com duas variaveis aleatórias $A$ e $B$ e sua respectiva densidade conjunta $f(A=a, B-b)$.

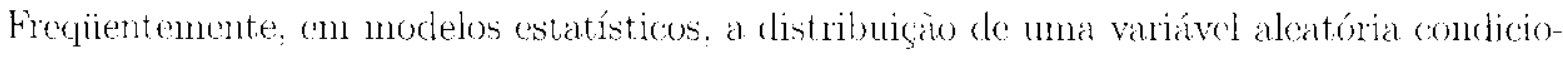

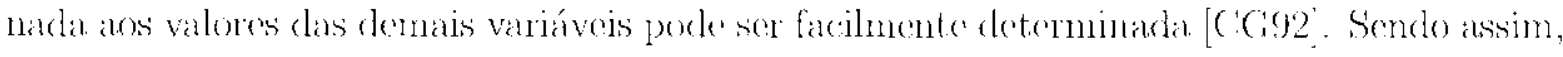

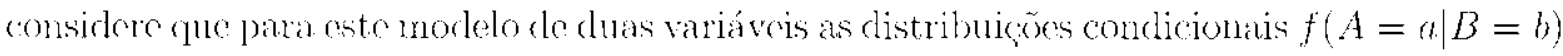
c $f(B=b \mid A=a)$ são conhesidas. A técnica utilizada pelo Gibbs Sampler consiste em gerar amostras alternadas destas funçoes condicionais, sendo que man amostra de mua determi-

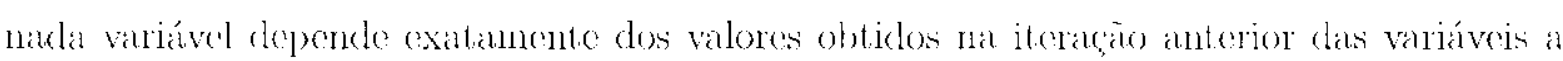
qual da se encontra condicionata, o que caracteriza uma andeia do Markov. Sondo assinn. para cste modelo do duas variáveis a seguinte cadeia seria gerada:

$$
B_{0}=b_{0}, A_{0}=a_{0}, B_{1}=b_{1}, A_{1}=a_{1}, B_{2}=b_{2}, A_{2} \cdots a_{2}, \ldots, B_{k}=b_{k}, A_{k} \cdots a_{k} .
$$

O valor incial da carleia, $3_{0}$, deve ser definido como 1 m valor aleatório encquanto que os valores restantes são obticlos iterativanente da scrguinte mancira:

$$
\begin{gathered}
A_{i} \sim f\left(a ! B_{i}=b_{i}\right) \\
B_{i} \sim f\left(b ! A_{i-1}=a_{i-1}\right)
\end{gathered}
$$

A geração da carleia 4.1 é denominaxla "amostragom de Gibbs" (Gibbs sampling) e a medida que o múmero de elementos desta carleia anmenta $(k \rightarrow \infty)$ a distribuiçăo associada a $A_{k}$ converge para $f(a)$. Sondo assim, é possível determinar as características desejáveis desta marginal ou até mesmo obter aproxinaçōes de seu valor.

Dentro do contexto do processo EM/NPM a cadeid de Markov $X(p, t)$ é gerada de maneira análoga. Nesta segão será ntilizada apenas a notação $X(t)$.

Considere agora o modelo utilizade para representar o mapa de chases $X$, descrito na seção 3.1.1. Trata-so de un Campo Aleatório do Markov (Markov Random Field) formado por $N$ variáveis aleatórias $X_{1}, X_{2}, \ldots, X_{N}$ que corresponklem ans pixels do mapa. 'Também

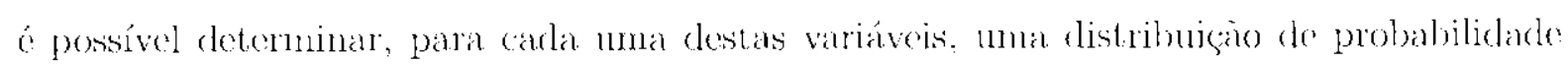
condicionada as demais variaveis do modelo. Valo lembrar que una das caracteristica dos 


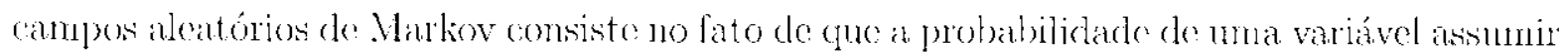
cleteminado valor condicionada aos valores assumidos pelas demais variáveis correspondo à probabilidade condicionala apenas aos valores das variáveis virinhas. Sondo absinn, a funçäo

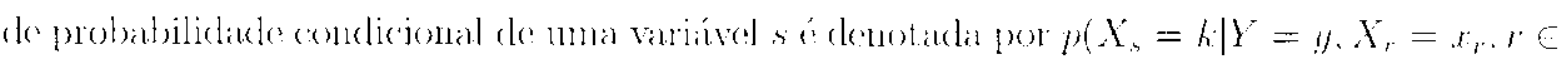

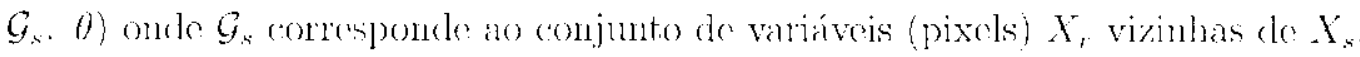

Para se gerar ma cadeia $X(t)$. o Gibbs Sumpler "visita" a cada iteração somerto um

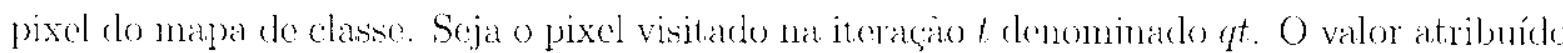

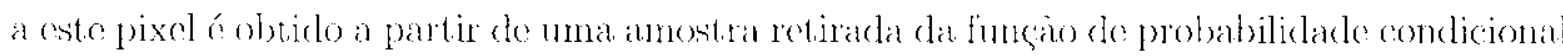
associada a ele, on seja, $p\left(X_{y}=k \mid Y=y, X_{t}=r_{r}(t-1), r \in \mathcal{G}_{q t}\right.$. $\left.\theta\right)$. Observe que parase geral esta amostra säo utilizados apenas os valores das variávejos vizinhas obtidos na iteraçăo

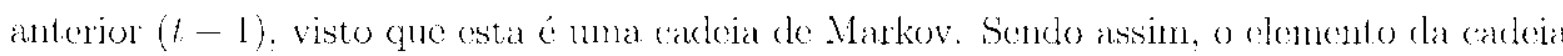

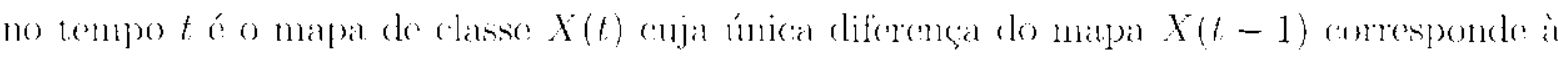

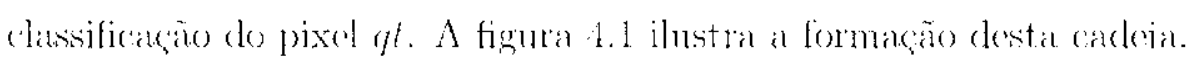

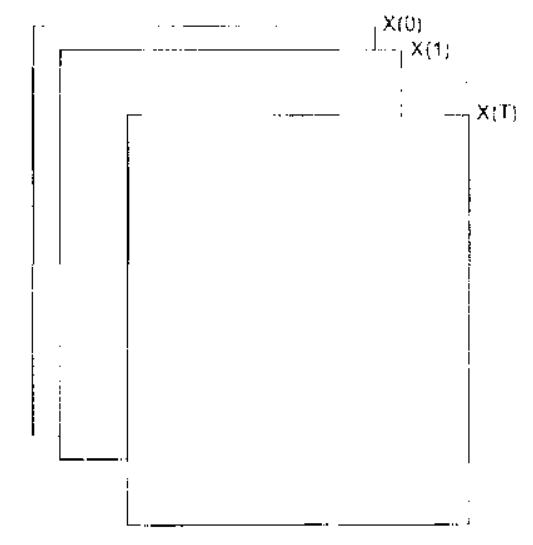

Figura 4.1: Caxleia de Markov gerada pelo Cabbs Sampler.

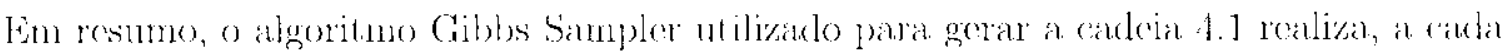
iteraçüros os seguint es passos:

- Escollar um deteminado pixel cla inagen:

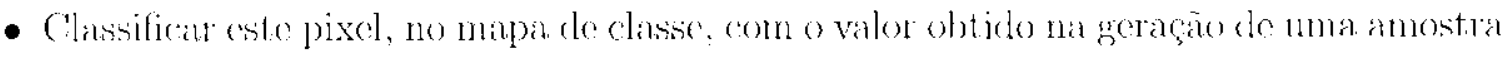

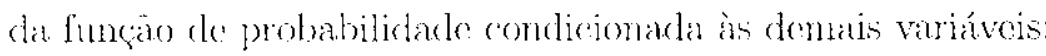

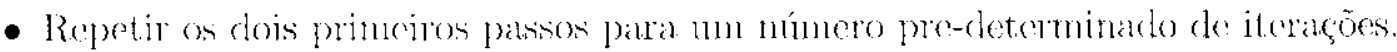

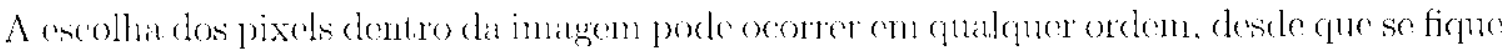

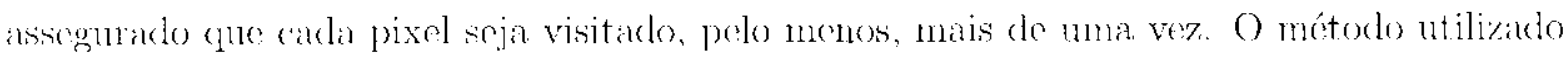
nesta inplementação, e tambóm o mais intuitivo, consiste con escolher seqüencialmente oy

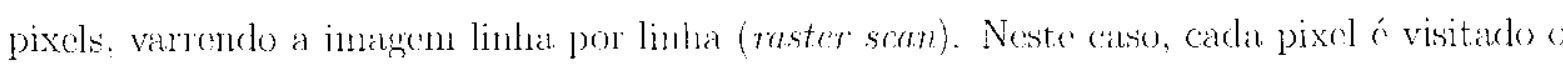


mesmo número de vezes, ou seja, $T_{1}=T_{2}=\ldots=T_{N}=T$. Togo, $T$ representar o número de veres que o mapa de dasse foi percorrido polo algoritmo. Outra maneira de se percomer a imagem encontra-so ilustrada na figura 1.2 . Trata-se de uma técnica recursiva para percurso

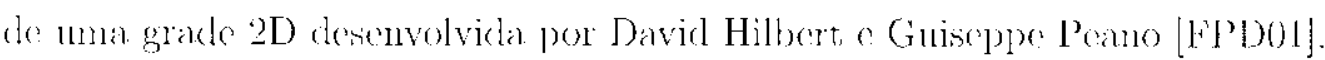

Vale também citar (que uma caraterística importante do algoritmo Gibbs Sampler comsiste no fato de cle pode ser implementado de modo que sla execnçăo se torne paralela. on seja. ovalor de duas on mais variáveis aleatórias pode ser calculado ao mesmo tempo.

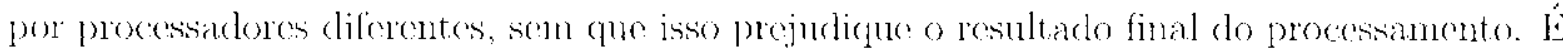
do so aperar, portanto, que este tipo de implementaço proporcione uma volocialade substancialmente maior na geração de cadeias de Markov, sendo esta volocidade dirctannento proporcional à capacidade de paralelismo do ambiente utilizado. Ln exemplo de imple-

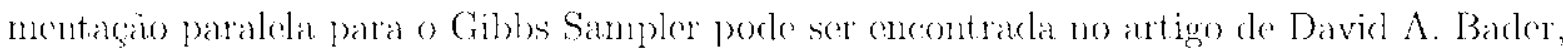

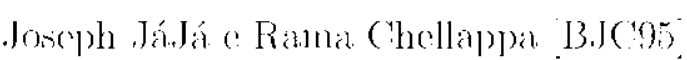

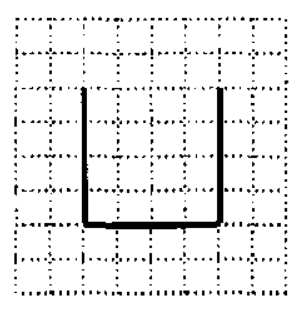

(a)

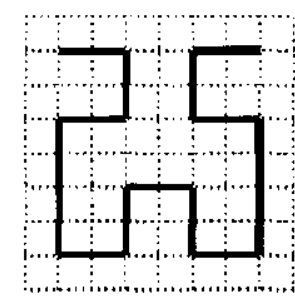

(b)

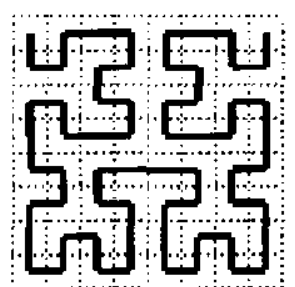

(c)

Figma 4.2: Percurso do imagem pelo método Hilbert-l'eano. (a) início; (b) sstágio intermediário; (c) resultado

\subsubsection{Retirando uma amostra de uma função densidade de proba- bilidade}

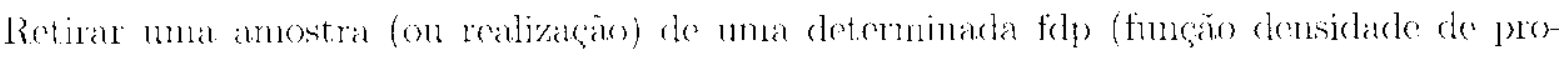
babilidade) significa atribuir um valor a uma varível aleatória, discreta ou contínua, cujo comportanento é descrito pela fdp em questão. Un conjunto significativanente grande de amostras deve, portanto, apresentar caracteristicals suficientes para descrever os paranetros (da. $\left.\mathrm{fl}_{\mathrm{p}}\right)$.

Diversas são as funçōes de probabilidade utilizadas para se descrever uma determinada variável aleatória. Dentre elas as mais conhecidas säa

- distribuiça uniforme: 
- distribuicaro exponencial:

- distribuiçäo geomótrica:

- distribuigrio normali;

- Clistribuiçá de poisson:

- distribuliçäo gamal.

- distribuicáo beta.

$\Lambda$ clistribuicão uniformo é a mais simples de toclas pois ela atribui um valor constante do probabilidade para todos os elementos do dominio. Ela é utilizada, na maioria dos casos. como base para a geragão de anestras de outras distribuiçoes. Por este motivo, a maioria

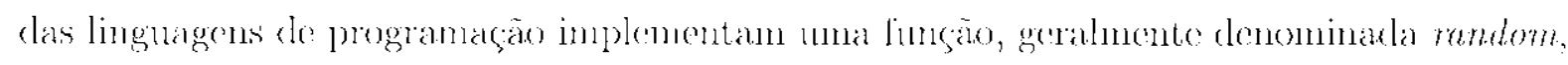
para a geracano de valores aleatórios com distribuição uniforme.

Para sc gerar uma anostra de uma fdp contínua $f(x)$, a partir da distribuiçáo miforme o necossário, primeiramente, definir duas funçóses: (1) a funçäo acumulada $F(x)$ $\int_{\infty}^{x} f(x) d x \quad(2)$ (2) a funçno inversa da acumulada $F^{-1}(x)$. Valo lembrar que $\lim _{x \rightarrow \infty} F(x)=1$

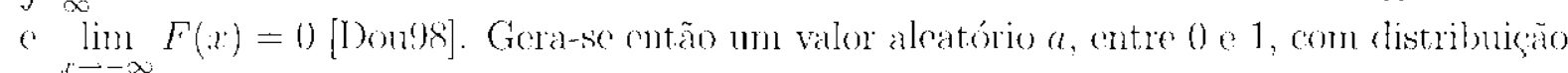
do probabilidade uniforme a aplica-so este valor à funcão inversa $F^{-1}(x)$. O valor obtido $v=F^{-1}(a)$ corresponde à amostra com distribuiço de probabilidade $f(x)$. A ligura 4.3 ilustra o prexesso de obtençäo de uma amostra retirada de distribuição normal.

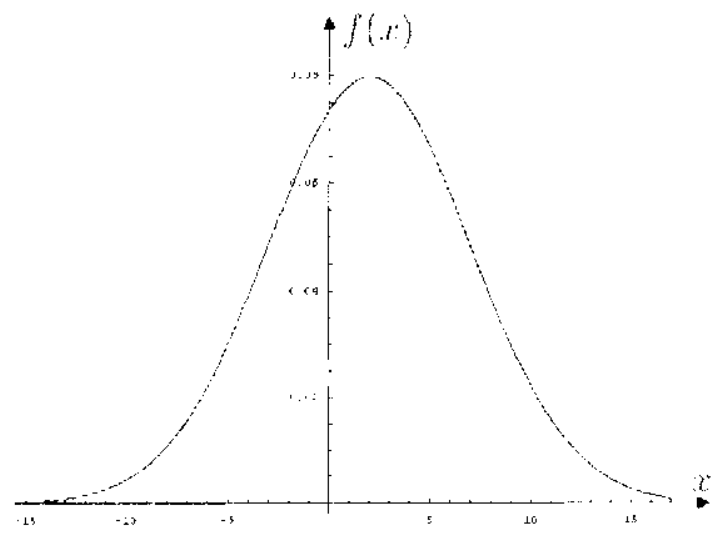

(a)

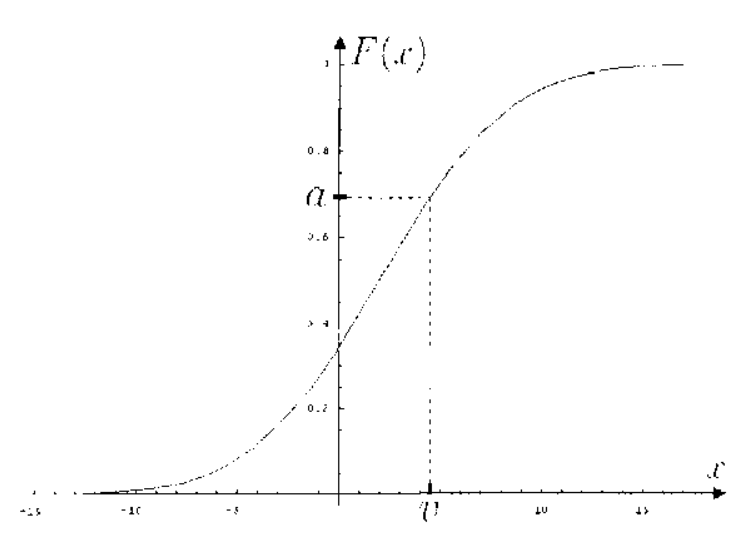

$(b)$

Figura 1.3: Geraca de una anostra e com distribuicäo nomal a partir do una anostra "

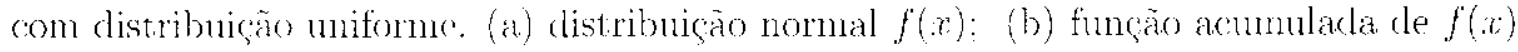


Conforme descrito na secão antrior um, des passos do algoritum Gribls Sompler consiste cm obter uma amostra da distribuicão condicional $p\left(X_{y^{\dagger}}=k \mid Y=y \cdot X_{r}=x_{r}, r \in \mathcal{G}_{s}, \theta\right)$. gue corresponde à probabilidade da variável $I_{\text {qt }}$ assmunir o valor $k$, dado o valor das demai

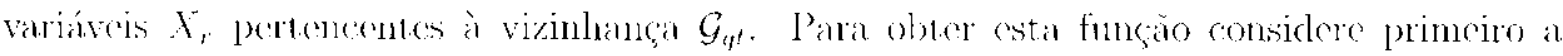
definicăo de probabilidade condicional [Dong8!. Dachos dois eventos, F e F a define-se a probabilidade de $E$ ocorrer dado que $F$ ocorren da seguinte forma:

$$
I^{\prime}(E \mid F)=\frac{P(E F)}{P(F)}
$$

Considere agora os seguintes eventos: (a) mam determinada variável aloatória $X_{a t}$ assumir o valor $k$, ou seja, $X_{q l}=k ; 0$ (b) as demais variveis assumirem valores quaisquer $\left(X_{r}=\right.$

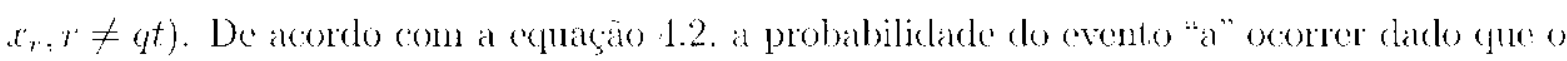
(vento "l)" ororren é dada por:

$$
p\left(X_{q^{\dagger}}=k \mid X_{r}-x_{r}, r+q l\right)-\frac{p\left(X_{q t}=k_{1} X_{r}-x_{r} r \neq q t\right)}{p\left(X_{r}=x_{r}, r \neq q t\right)}
$$

onde $p\left(X_{r}=x_{r}, r \neq q t\right)=\sum_{k=1}^{\prime} p\left(X_{t t}=k, X_{r}=x_{r}, r \neq q t\right)$.

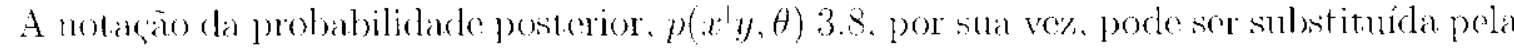
notaçäo correspondente $p\left(X_{q t}=k, X_{r} \cdot x_{r}, \neq q t Y_{0}\right.$, . Sendo assim, á possível encontrar a probabilidade eondicional descjada, utilizando a equaça 3.8 , a partir do soguinte desenvolvinento:

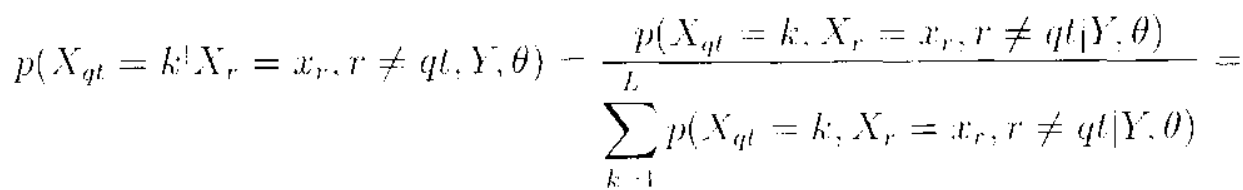

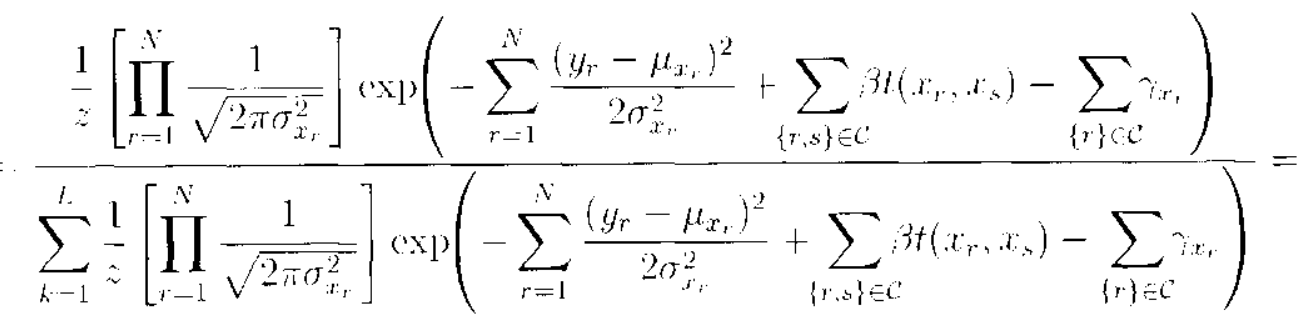




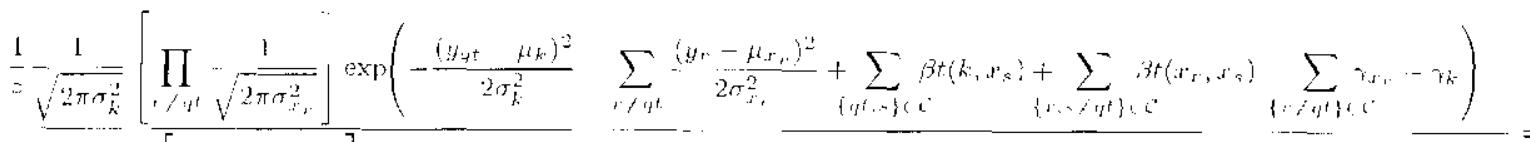

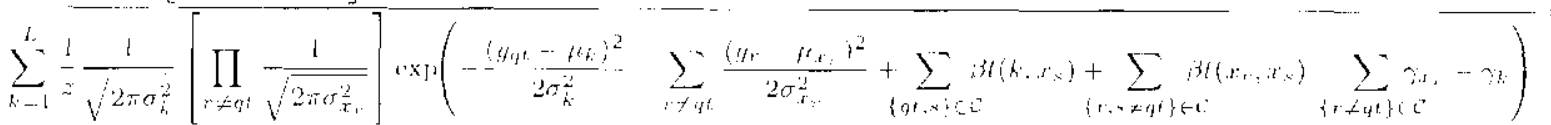

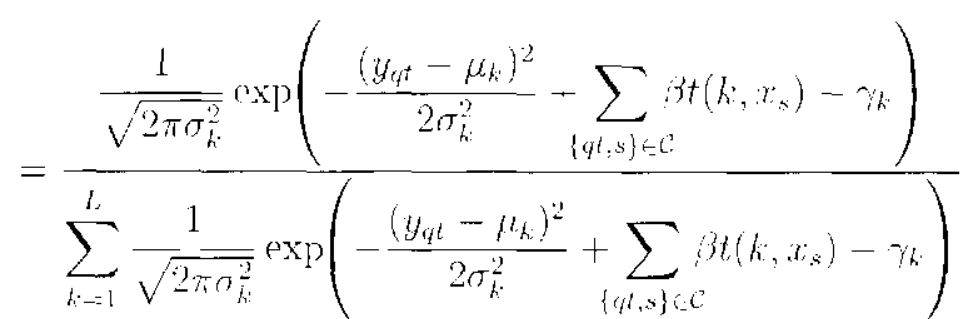

onde

$$
t\left(k, x_{s}\right)= \begin{cases}0, & \text { se } x_{s}=k \\ 1, & \text { se } x_{s}=k\end{cases}
$$

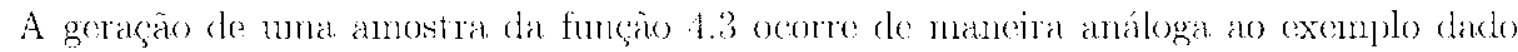

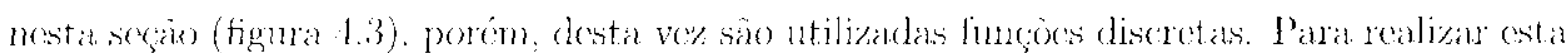

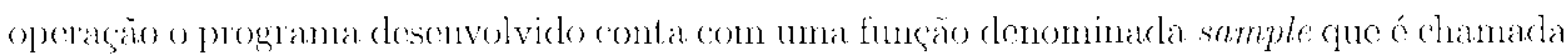
toda vez que um determinalo pixel é visitado pelo algoriumo Gibbs Sampler. Através da funçăo 4.3 a rotina sample calcula, para cada classe, a probabilidade dela ocorrer. dado os valones dos parânetres narpuele nomento. Constrói-se entào um vetor V de probabilidarles

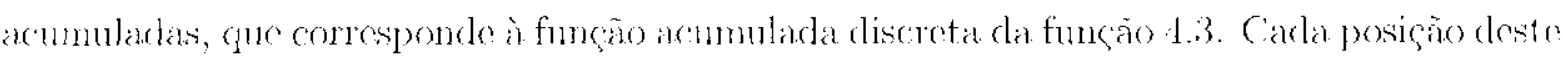
vetor corrosponde a uma classe armazena para ela o valor cla funçáo acumulada. A seguir

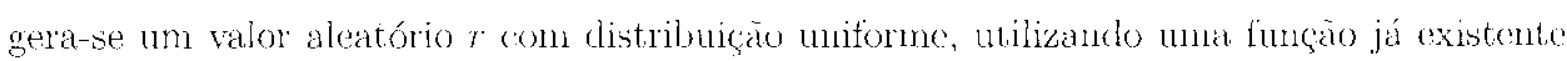

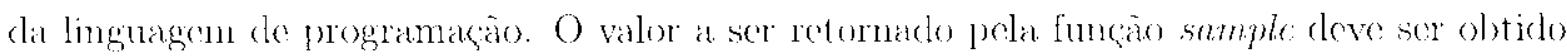

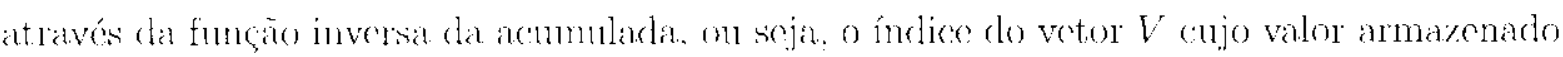
mais so aproxina ro valor aleatório $r$. Para isso, a funçio sumple simplesmente percorrer o vetor $V$ até encontrar um valor maior que $r$, retornado assin o indice da posiçăo anterior.

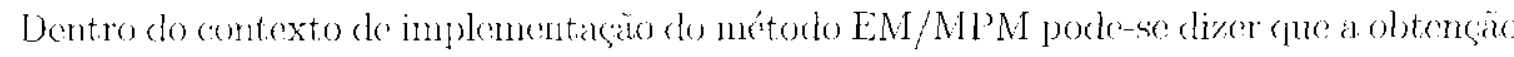
de una amostra da funçä 1.3. (onstitui uma operaça chave para o processo como um todo. Uma rápida análise da função sample nos permite ter uma loo icléia do esforço computacional

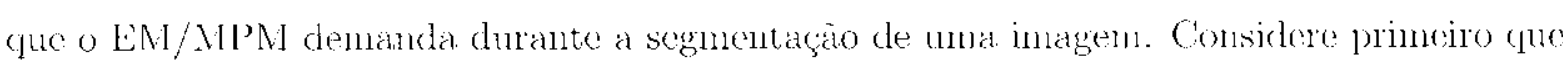
nma inagem de tamanho $N \times M$ venha a ser segmentala. Suponlat gue este processo seja

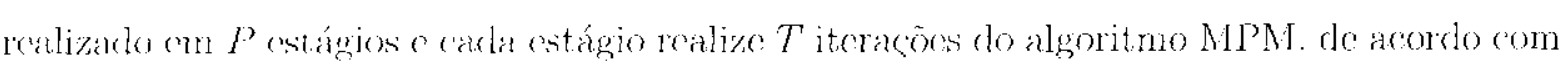


algoritmo apresentado na seç̃o 4.1. Deste modo a função sample será executada $N \times M \times$ $T \times P$ vezes durante a segmentação. O que representa un número razoavelmente grande de chamadas. Considerando agora as diversas operacoens realizadas pela funcäo sample ó

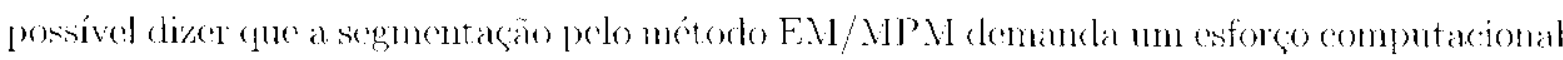
significativo.

Dentre as tarefas da função sample, sem dúvida a mais custosa corresponde à execucão da função exponencial. Para suprimir o efeito de sobrecarga causado pela ativaçio conseculiva

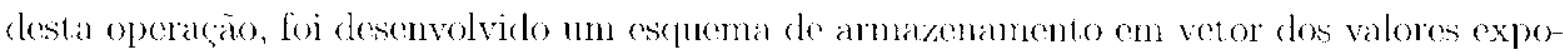

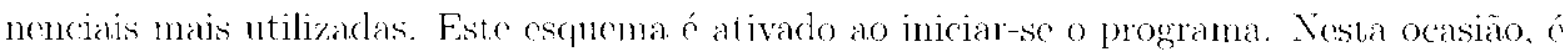
alocado um vetor de valores reais com milhares de posigoes e em seguida, saio calculadas o armazenadas neste vetor as exponenciais do uma anpla faixa de valores pre-definidos. Con-

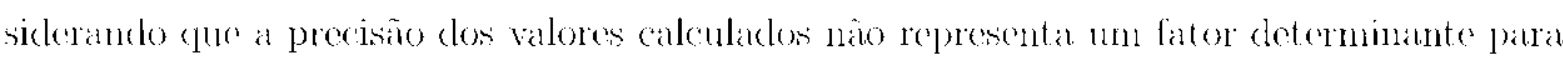
o hom descmpenho do processo, năo se faz nocessário calcular a exponencial para valores reais com muitas casas de precisăo, o que torna possível a utilização de um vetor menor, de tamanho razoável, sem comprometer a qualidade final dos resultados gerados. Ioste modo.

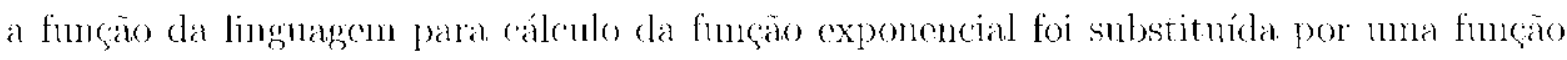

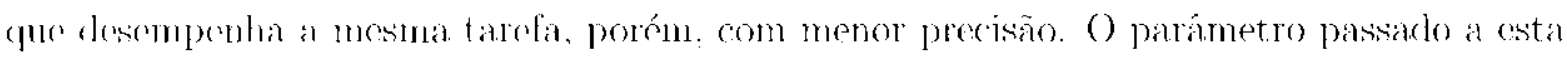
funçăo serve como índice para o vetor de exponenciais. () valor oncontraklo nanducla posiça ¿ retornado como senclo o valor exponencial desejado.

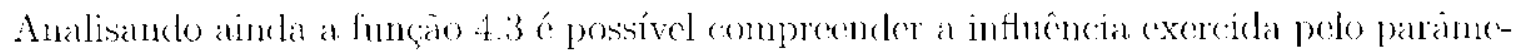

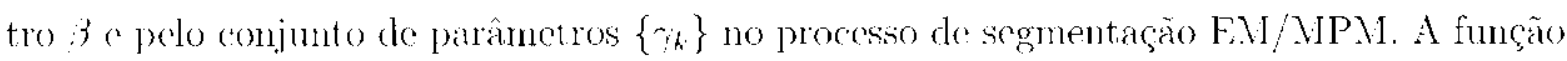
$t\left(k\right.$. $\left.x_{s}\right)$, cm ontras palavas contabiliza a quantidade de pixels vizinhos ao pixel ql que pertencem a classo $k$. Considerando que o sistema de virinhanga utilizato nesta implementaçäo

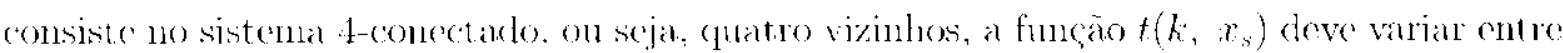
valores de 0 a 4 . Quanto maior for o valor desta funçäo, isto 6 equanto majs vizinhos do pixel qt pertencerem a classe $h$, maior será o valor da exponencial da funcáo e, conscqücntenente. maior scrá a probabilidade do pixel qt ser classiticardo como sendo também da classe ha Como

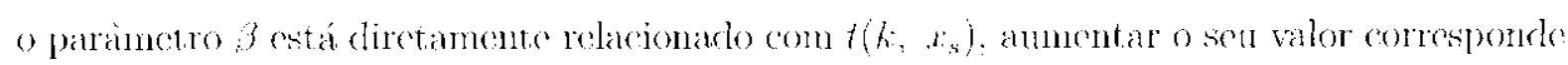
a aumentar proporcionalmente a influchcia guce os pixels vizinhos exercem na classificacaro do pixel qt. Por outro lado, diminuir 3 implica en igual diminução desta influencia. Senclo assim. o parametro is é denominado o parametro de interaço espactal.

Conforme já mencionado na seçäo 3.1.1 o parametro w. define, em temos práticos, uma stimativa de custo para o surgimento de regióes da classe $k$. Sendo assim. quanto maior for o valor de $\gamma_{k}$, menor será a probabiliclade do pixel qt ser classificado conno sendo pertencente a classe $h$. lsto ocorre porque o parannetro in influeneia de maneira negativa o valor da

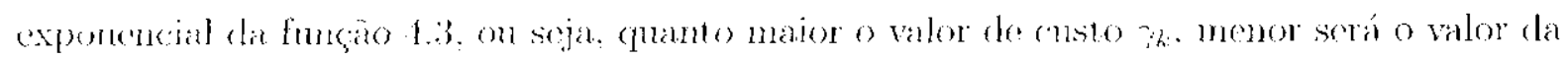


exponencial c, consequicntenente menor será o valor cla probabilidale $p\left(X_{t l}=k, X_{r}=x_{r}, r \neq\right.$ (t. Y.A). A utilização deste conjunto de parànetros de custo é rescrvada para aplicaçöes que possuem una informaça a priori sobre o lanamho relativo das diversas regiós gue

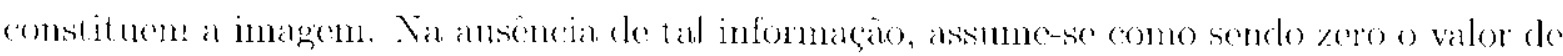
ik para cada classe $k$.

\subsubsection{Abordagem Multiresolução}

A dilerença na suavidade das diversas textumas dos objotos que compöen uma inagen constitui $13 n$ assunto do grande relevancia no processo de segmentaça bascado on textura. Ina mesma imagem pode conter regioes de texturas mais suaves o ontras de textumas mais grosisciras. A rapacidade que um determinado método tem de lidar com texturas mai grossciras irá, definitivaneme. influenciar na gerage de um resultado que mais so aproxime da segmentagio verdacteira

A delinitagão re regiones realizada apenas pela análise da textura pode, a partir de uma mesma imagem, gerar resultados diferentes. Para visualizar esta situaçào, considere uma região de textura ben grosseira. Se observatmos de perto esta regiáo iremos encontra sub-regioes de texturas mais suaves, a assim. o result ado da segmentação poderia ser tanto aquele constitúclo por uma única regiäo de textura grosseira. quanto outro formado por regions monores de toxturas mais suaves. A imagen de una parede de tijolos, por exemplo. poderia ser representada por una ínica regian, que conprendesse toda a parede, on por

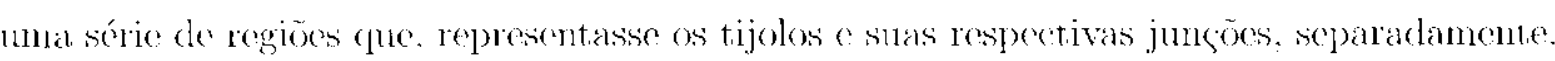

Dentro deste contexto, surge de imediato a seguinte questão: até que ponto, uma região do lextura grosseira, deve ser delimitada como uma única regiăo polo processo de segmentaça? A resposta desta questán ná é simples do ponto de vista compulacional. Cada regia on objeto da imagem possui um significalo aja análise csiá alóm dos limites do processo de segmentaça Para deterninadas imagens a consideração do texturas mais grossciras podo representar una boa opgào, enquanto que para outras isto pode causar o desaparecimento de pequenas regioes que serian relevantes no resultado final da segmentacäio. Sendo assim.

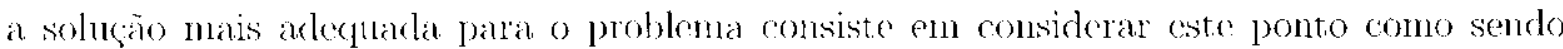
un paranctuo intrínseco do algoritmo de segmentação e ajustá-lo de acordo com o tipo de inagom que so pretende segmentar.

() sistema de vizinhanga arlotado para un determinarlo mótodo está diretamente relaciomado com a capacidade pue de tem de delimitar regioes de texturas mais grosseiras on mais sunves. A nuelicla que vizinhancas mais abrangentes são utilizadas, regioes de texturas mais grosseiras tendem a aparecer com maior freqü̈ncia ao final da segmentaçäo, e: por outro lato, a utilizagöo de vizinhanças pecpuenas anmenta a ocorencia de regions de texturas mais 
suaves. Sendo assinn, ó possivel dizer que a variagão do sistema de vizinhança constitui una altemativa viável para tormar o método mais on menos sensivel as texturas grosseiras.

Porćn, man ontra alternativa para se variar o parametro em questao tem sido claborada

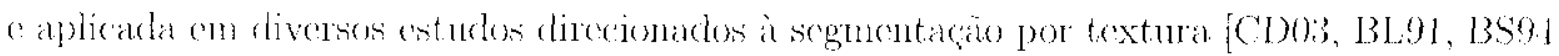
NLI93, M.J92]. Trata-se do um tócuica enja abordagem consiste, basiononte, om combina. com o processo de segmentaçào uma análise conjunta de diversas resoluçōes ${ }^{1}$ dá imagem.

De fato, a suavidade é una característica da textura gue varia proporeionalnente com o escalonannento da imagem, on seja, no varianos a cscala da imangem, anmentando on diminuindo, estaremos alterando proporcionalmente a suavidade das texturas das región que a compón. A figura 4.4 nos permite visualizar esta característica. Percebe-se que

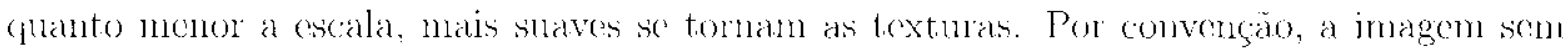

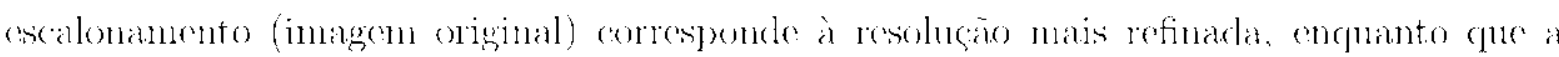

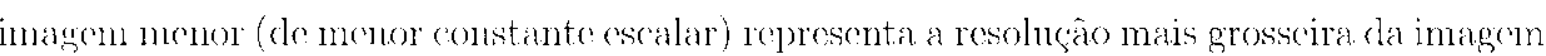

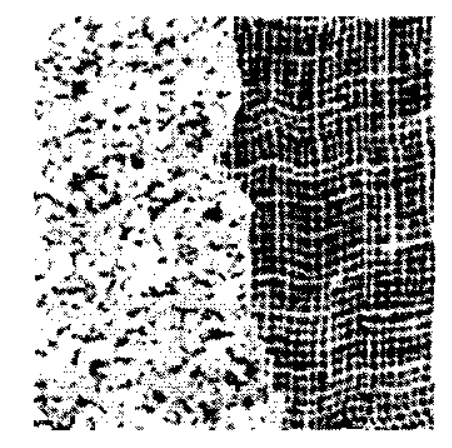

(a)

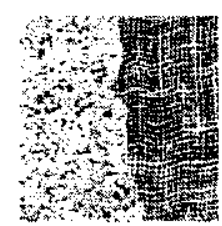

(b)

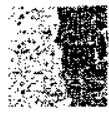

(c)

Figura 4.4: Fscalonamento de uma imagenn com duas regiões de texturas distintats (a) Imatgem original (b) Constante escalar $=0.5$ (b) Constante escalar $=0.25$

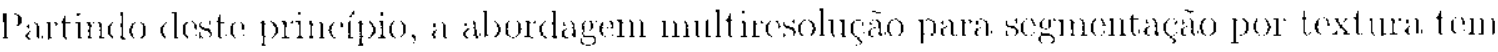
como objutivo obter a segnentaça de diversas resolucoues da imagem e combinar estas inLormações de tal modo que a segmentação final se aproxime mais do resultado verdadeiro esperado. Esta estratégia garante que regióes de texturas malis grossciras possann ser delimi-

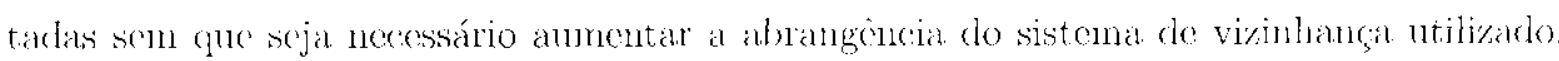
Isto: por sta ve\%. (onstitui uma vantagem já que a utilizaça de uma vizinhança major proporciona um anmento de complexidade do algoritmo de segmentaçäo [CDOB3]. Também, outra caracteristica vantajosa consiste no fato de que a maior parte do trabalho do segunentaga

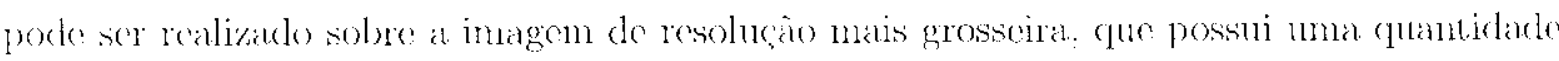

\footnotetext{
Cópia ciscalontarla.
} 
significativanemule menor de pixels.

Conforme já mencionado. o métodlo FM/MPM implementado neste estudo utiliza un sistema de vizinhança do tipo 4-conectado. on seja, quatro vizinhos em forma de cruz. Com

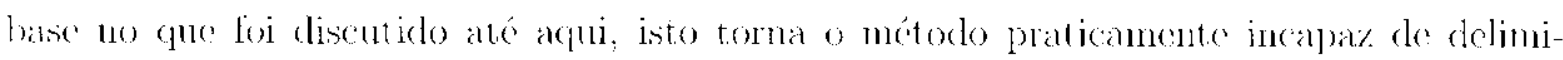
tar regiones de textmats mais grosseiras. Por se tratar da soluga mais vantajosa para este problema, a abordagem multiresolução foi incorporada ao método tornando-o mais flexível e ayaz do gerar resultados mais coerentes ma segmentação de imagens com regioes de texturas mais grosseirits.

A arlaptagão necessária para ineorporar esta abordagem ó relativanente simples. Primejramente foi implementak um algorit mo de escalonamento para gerar imagens con a metade da resolugão original. A técnica utilizada é a mais simples e consiste em substituir um conjunto de quat ro pixels por um único pixel cuja intensidade enresponde à média aritmótica da intensidade dos outros quatro. Gera-se então, ao incio do processo de segnentação, um vetor de imagens cujo primeiro elemento corresponde à imagen original; o segunclo elemento contém uma inagem com a netade da resoluça da primeira: o terceiro contém numa ima-

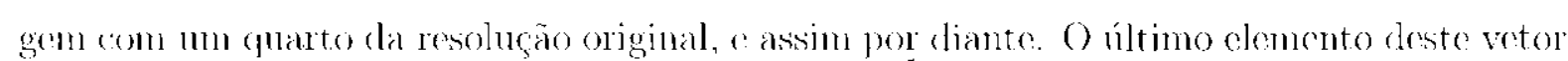

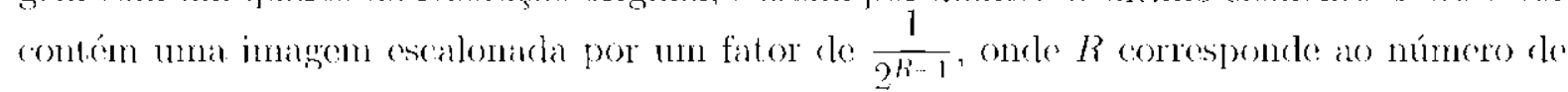

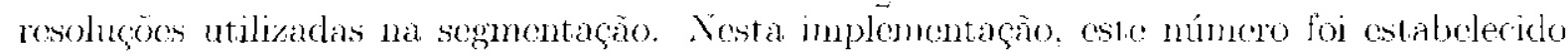
cono scredo un paranetro ajustável do precesso. Através da intenfaco do prograna é pos-

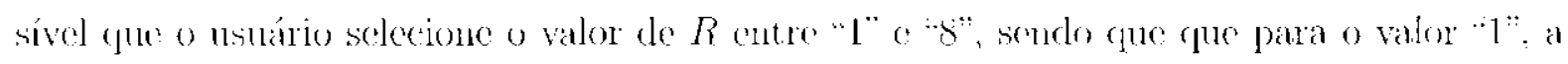
seguncutaça é realizada pelo método E.M/ MP M simples, sem abordagem multi-resoluçào.

Após ter sirlo montarlo. o vetor de imagens possui uma estrutura que se assemelha a una pirâmide, sendo a base constitúda pela magem original a o topo constitúdo pela imagem de resolugăo mais grosseira. De forma resumida o nowo algoritmo irá segmentar as imagens desta piramide separadamente, começando pelo topo e teminando en sua base. O resultado oblido em cacla etapa deste processo é ntilizada para auxiliar a segmentação da próxina inagem da piramide até que o resultado final da segmentação seja alcanģado.

$\triangle$ inaggen do topo da pirande é segmentada inicialmente com o algoritmo FM/ MPM sem altraçös. O número de estágios clesta etapa é um parâmetro que deve ser definido pelo usuário, bem como o parâmetro 3 que define a interaçào espacial de um pixel com os sens respectivos vizinhos. A partir de então, inicia-se uma nova lase do algoritmo que irá segmentar o restante das imagens da piramide ulilizando uma versăo 1 m ponco modificada do F.M/MPM. Para esta fase novos valores para o múmero de estágios c para o paranetro 3 devem ser introduzidos a partir da interface do programa. Alóm (lisso, ontro novo parânetio, a, fue será discutido adiante, também deve ser infomado pelo usmário.

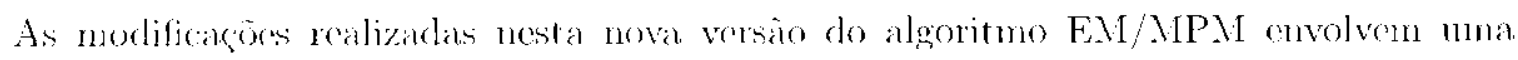


alteraça estrutural do modelo ntilizado para o mépa de classies $X$. No modelo anterier, $X$ cra definido sobre um ('sjaço bidimensional $S$, conforme as notaçós apresentadas na seçào

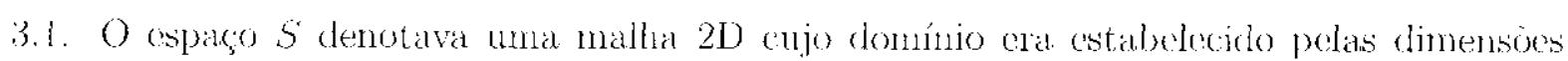
da imagem olservada $Y$. Para este novo modclo, tanto $Y$ quanto $X$ siáo definidos $\mathrm{cm}$ um novo espaço triclimentional que corresponde ao cerpeço formado pelo conjunto do imagens de diversas resoluçōes en formato de pirâmide. Para se referir a este espaço, a mosma notação $S t$ será utilizada sendo que os planos dia pirâmide correspondem a $S^{0}, S^{1}, \ldots, S^{\prime h}$. A figura 4.5 ilustra un exemplo de piràmide constituída por três níveis de resoluçäo.

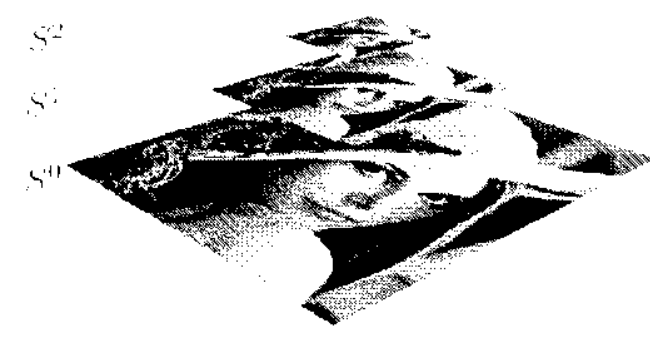

(a)

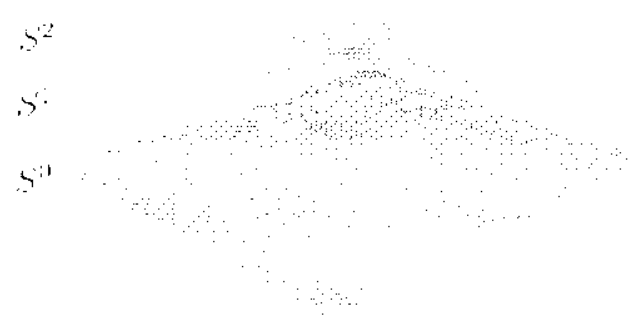

(b)

Figma 4.5: Espace 31), denotado por $S$, onde a imagem obscrvada $Y$ o o mapa de chasse $X$ estrio definidos (a) Pirănide da imagem obscrvada $Y$ (b) Espaço do mapa de classes $X$

O novo modelo atribuílo aro mapa de classeses $X$ constitui un modelo multi-resolugáo e por isso passa a se chamar MMRF (Mulliresolution Markov Random Field). A probabilidade conjunta $p(x)$, atribuída ao modelo de resoluçáo única, deve, portanto, ser reformuladia para

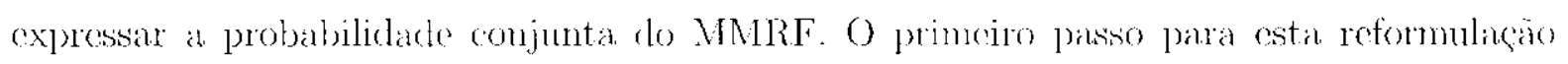
consiste mu tever a concrito de cliques, introdurido na seçäo 3.1.1.

Para lembrar. $1 \mathrm{~m}$ clique ó um conjunto de pixels onde cada pixel é vizinho de todos os outros pixels do conjunto. Para o modelo original (NRF), considerando una vizinhangar

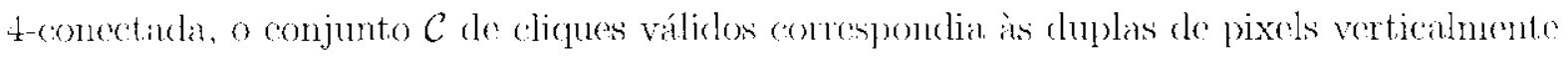
arljacentes, mais as duplas de pixcls horizontalmente adjacentes. conforme ilustrado na figura 3.2. Para o novo modelo, o conjunto $\mathcal{C}$ continua a ser válido, mas passa a constituir o conjunto de elicues do tipo 1 , denotado por $\mathcal{C}_{1}$. Uma nova relação de vizinłhanģa, que surge da relaçăo entre planos adjarentes no espaço $S$, vem definir mu novo conjunto de dirques: o conjunto de (licpues do tipo 2, denotado por $\mathcal{C}_{2}$, gue comresponde an conjunto de duplas de pixels do tipo "pai-filho"? O conjunto de pixols individuais também constitui um tipo válido de cliquues. Eles săo denoninados diques do tipo $3\left(\mathcal{C}_{3}\right)$. As figuras 1.6 e 4.7 ilustram, rejpectivamente

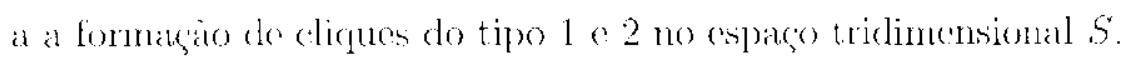

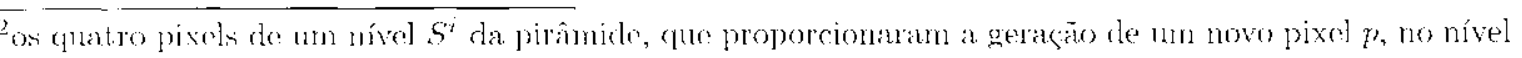

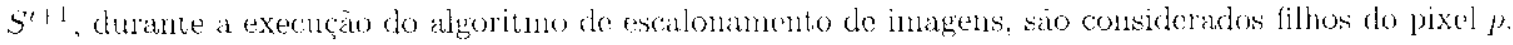


Após ter definido o escluema de clicpues para o modelo multi-resolnçào do mapa de classos $X$ é preciso reformular a probabilidade conjunta $p\left(X_{1}=x_{1}, X_{2}=x_{2}, \ldots, X_{N}=x_{N}\right)$, ou simplesmente $p(x)$. (que corresponcle a probabilidade préva (prior probability). Suguindo 0

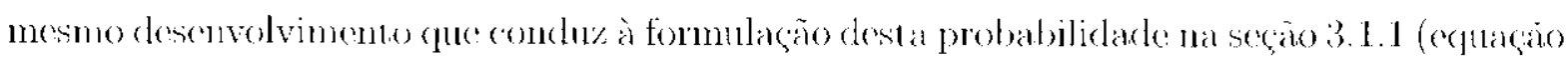
3.5), aqui vamos simplesmente mostrar a sua forma final, conformo segur:

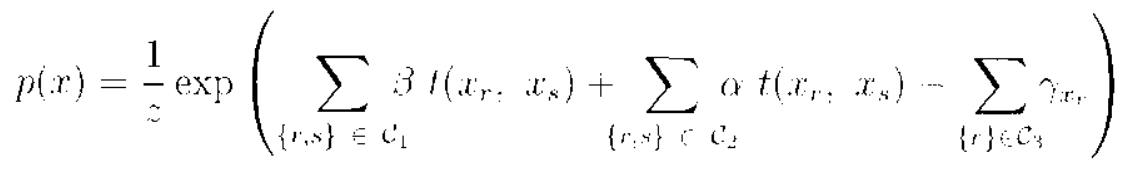

onde

$$
t\left(x, x_{s}\right)= \begin{cases}0, & \text { se } x_{r}-x_{s} \\ 1, & \text { se } x, \neq x_{s}\end{cases}
$$
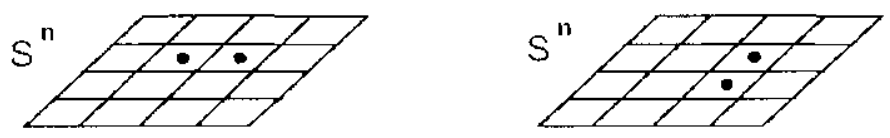

Figura 4.6: Fxomplos do dois clicpues do tipo 1 definidos ems.
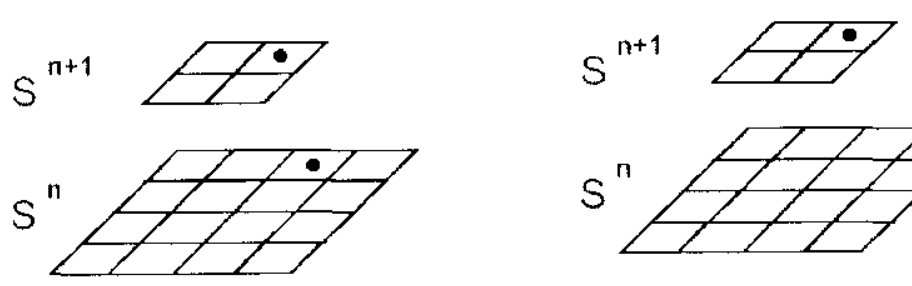

$\mathrm{s}^{\mathrm{n}}$
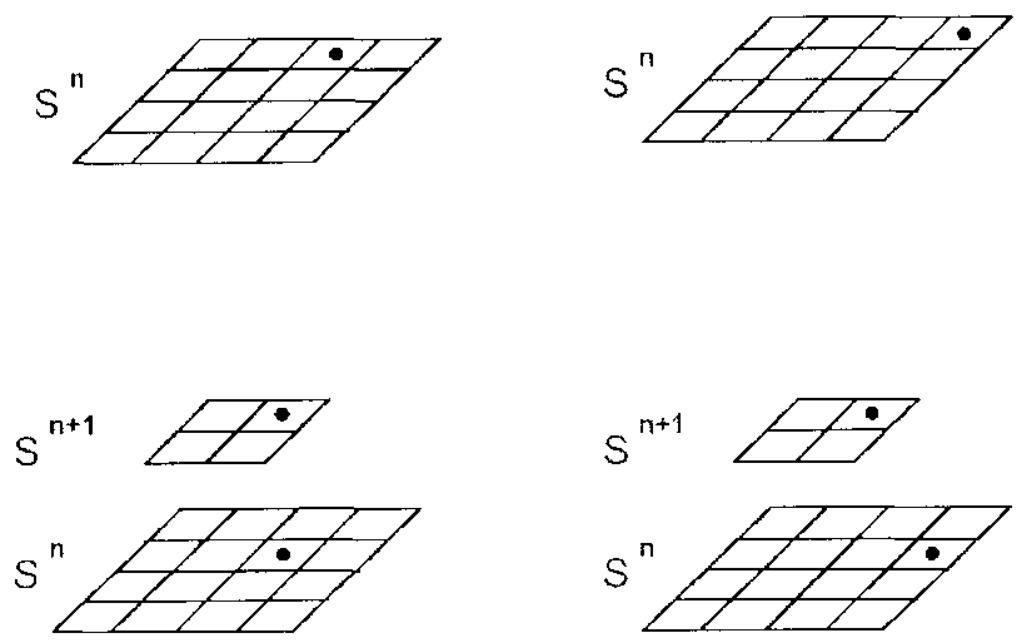

Kigura 4.7: Exemplos de quatero diefues do lipo 2 definiclos en $\mathrm{S}$.

Embora tanto o mapa de classes $X$ quanto o modelo da imagem observado $Y$ tenlam sido definidos em un novo espaço trielimensional para a incorporaça da abordagem multi- 


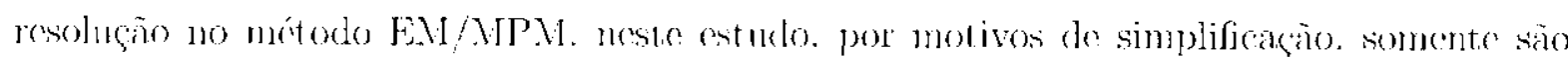
offetuadas modificaçoes no modelo utilizado para $X$. De fato. os resultados obtidos com esta implementagão se assemelham muito aos resularalos apresentados no estudo realizado

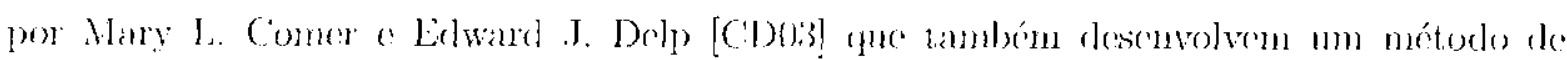
regmentação multi-resoluçäo utilizando modelos estocásticos. Lsto nos leva a percober gue tal simplificaçào nào constitui, de maneira geral, uma falta significativa para a abotdagem multi-resoluçäo implenentada.

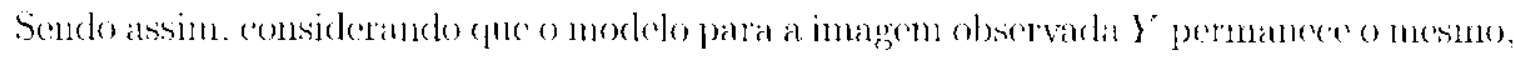

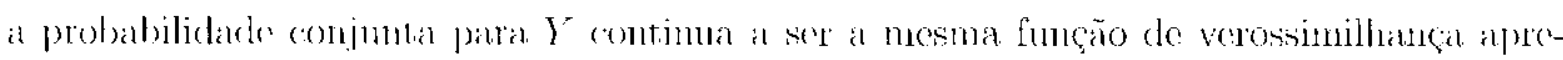

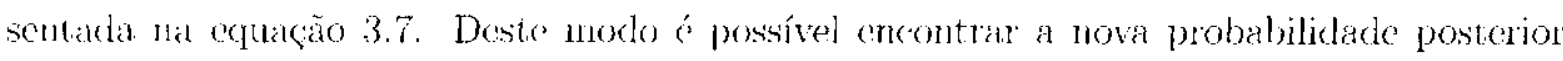
$p(x, y, \theta)$. utilizando a regra de Bayes [Leegi].

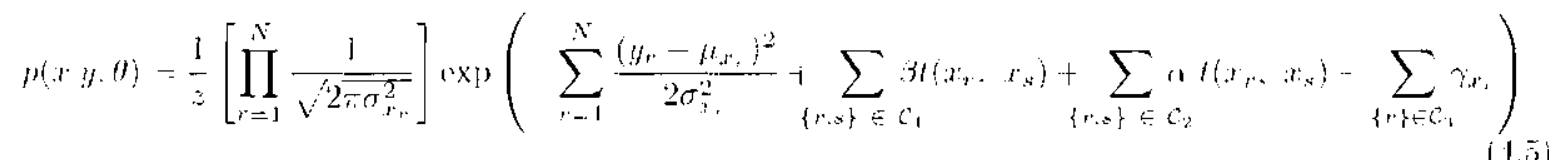

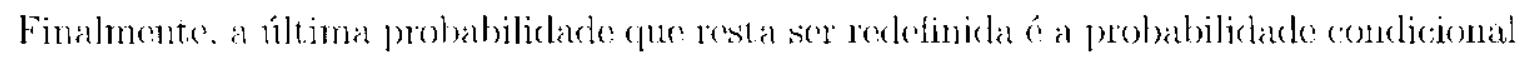
$p\left(X_{q !} \cdots h_{!} Y=y, X_{r}=x_{y} . r \in \mathcal{G}_{*}(\theta)\right.$. Vale lembrar que uma amostra reciracla desta

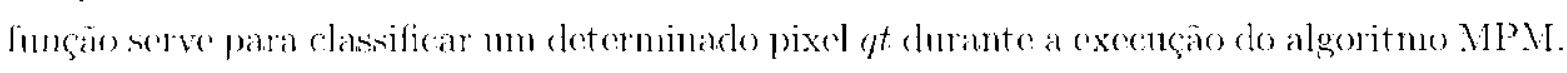

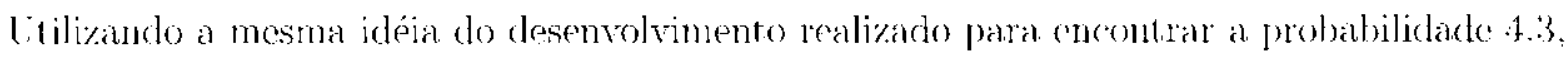
temos a seguinte nova probabilidarle:

$$
\begin{aligned}
& p\left(X_{q t}-k ! Y \quad=y_{1} X_{r} \quad x_{r}, r \in \mathcal{G}_{s} \theta\right)-
\end{aligned}
$$

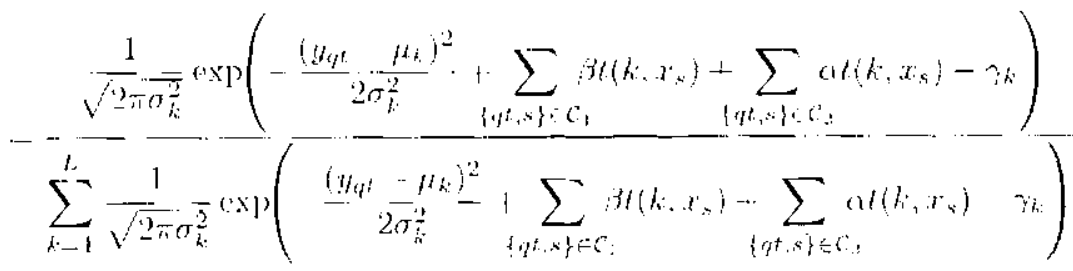

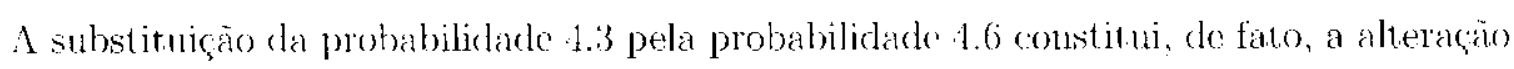

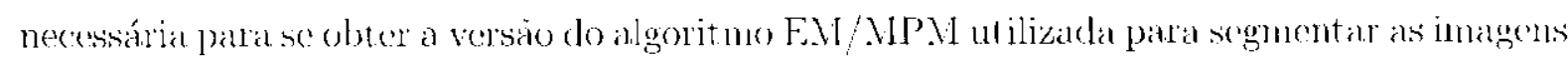

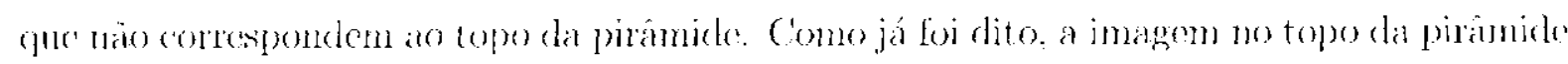

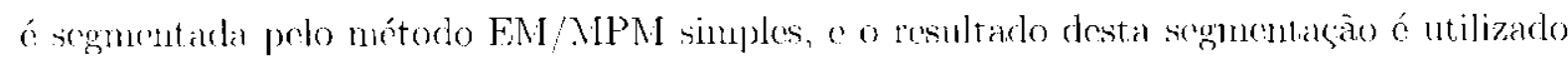
para segmentiar os clemais níveis.

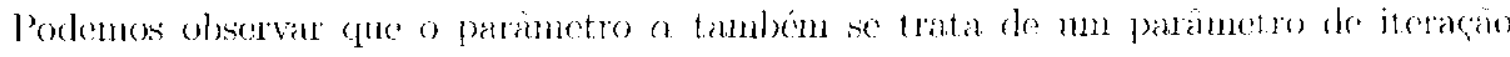

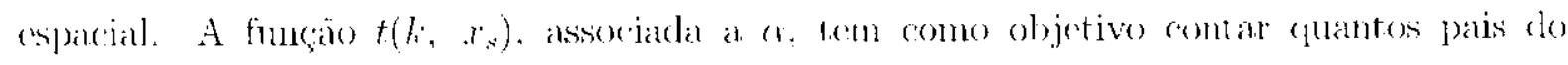


pixel filho of foram elassificarlos como sendo da classo he Como um pixel filho pode ter apenas um pixel pai. o valor desta funçăo deve variar entre 0 o 1 . Sendo assim, o valor do parametro a representa a influencia exercirla pela classilicaça pixel pai na classificagäo do

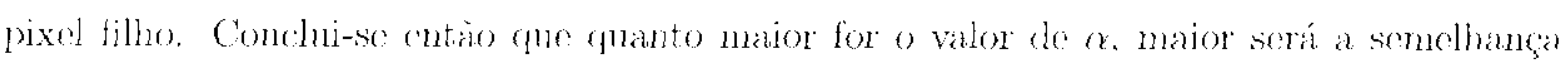
entre os resultarlos da segmentacào de mívois adjacentes na pirànide.

\subsubsection{Annealing}

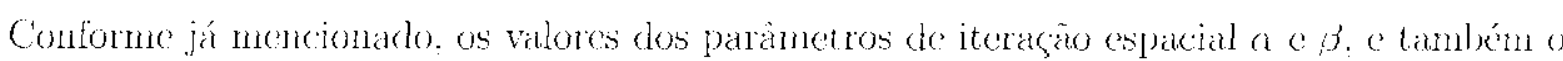

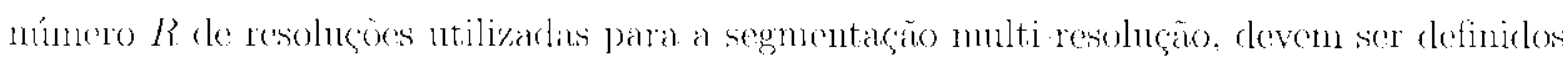
pelo usuário antes do incício do processo de segmentação. A escolha correta dest es paràmetros infuenciann diretamento na geraçüo de um resultado que mais so aproxime da scgmentaça verdaxleira da jmangern.

O ajuste de $\beta$ corresponde de fato ao ajuste madis crítico do processo. Valores muites baixos para oste parametro não são interessantes, visto que eles diminuem a correlação cxistente crstre pixels vizinhos, ocasionando a geraço de um resultado ruidoso, on seja, uma imagem composta por vários pixols isolados classificardos de mancira errata. Valores mais

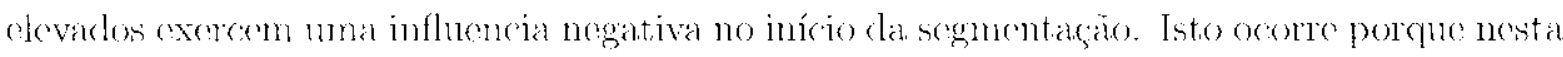
ocasião, a maioria dos pixels se encontram elassificados erroneamente, on seja, o resultado cncontra-so dinda distante da segmentação vercladeira. Se a correlaçäo entre pixels vizinhos

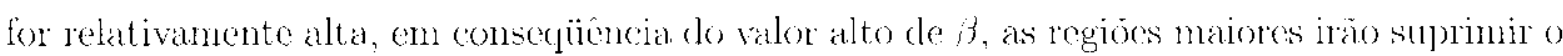

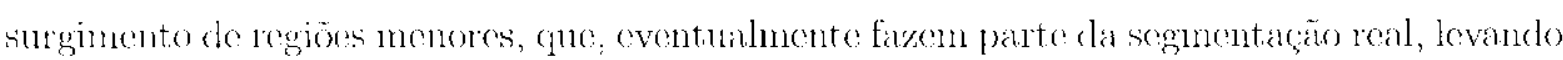
o processo a convergir para a geragäo de um resultado completamente incoreto.

Uma alternativa interossante para so diminuir a responsabilidade do usmário do programa na escolba do parametro 3 a ajudar o método EN/ MPM a produrir resultados mais coc-

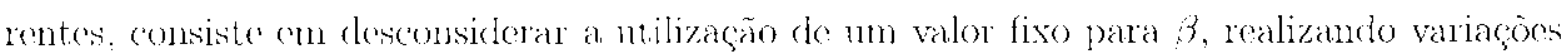
sistemáticas deste valor ao longo do processo. Esta técnica é conhecida na literatura como nome de Annealing, ou Simulated Annealing, que significa enrijecinento, on o ato de tomperar $u m$ eleteminado tipo de metal através de uma variaga brusca de temperatura, o gue proporciona un rearanjo cotrutural de suas molénlas de nodo a tomáto mais rígido. O motivo desta denominação provém do fato de que, comumente. por motivos de convençăo, aplicaçoes que se utilizam do mesmo modolo de Markov utilizado neste estudo, referent-so ao

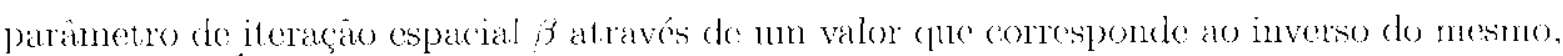

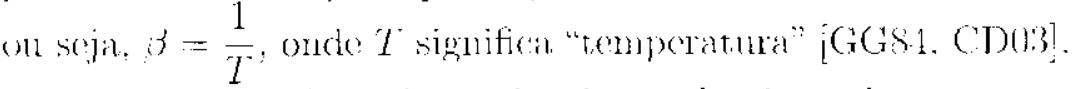

A técnica cle Amnealing aplicada ao algoritmo de segnentaçän EM/MPM foi implementada de foma a anmentar gradativamente o valor de $\beta$ durante a sognentaça do uma imagem. A interface do programa pernite (une o usuário ajuste o valor inicial de $\beta$ o 0 
valor de um incremento que sutilizarlo para atualizar itcrativamente este parâmetro. Esta atualizaçào ó feila de modo lincar. on soja a cada estágio $P$ do processo é adicionado a 3 um valor constanto que corresponde ao incremento estabeleciclo. Para melhor compreensào

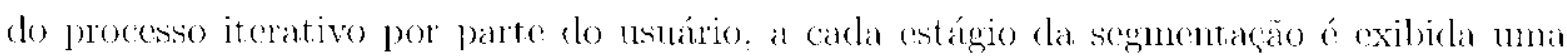
imagen que corresponde a situagào atural do mapa de classe. Un valor perpueno para is no início da segmentaço laz com que a elassificaçäo dos pixels no mapa do classes ocorra de maneira mais dinänica (as inagens exibidas iterativanente variam bastante de cotágio para entágio), proporcionando maior velocidade na convergencia do método. Nesta fase inicial. os pixels encontram-se ponco correlacionados, constituindo um mapa de classes ruidoso e inconstante. que pode ser comparado a uma chapa metálica em alta temperatura, cujas noléculas se encontram en intensa movimentagão. O anmento gradual do paranctro de

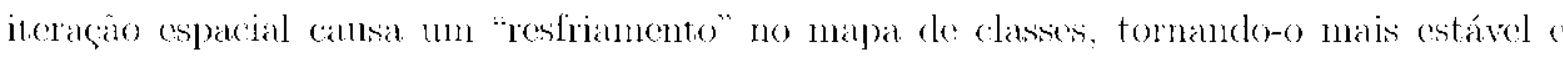
constante, proporcionando assim um resultado sem ruídos.

\subsection{Contagem de Regiões}

A contagen de regiões é uma operação que tem como objotivo verificar o número de regiões conexas obticlas, para cacla classe ao final da scgmentação. Para realizar ssta contagen foi implenemtadlo um método itcrativo que utiliza. como auxiliar. o algoritmo de preenchinuento

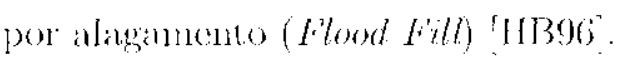

De maneira informal, uma região conexa de classe $k$ corresponde a um conjunto de pixels.

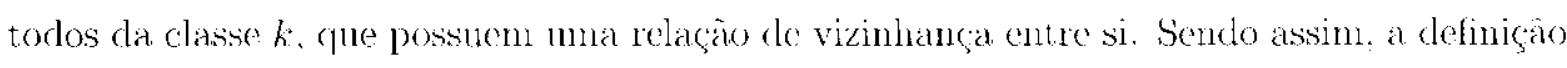
de $m$ sistema de vizinhanga constitui un fator importante para se deterninar o múmero

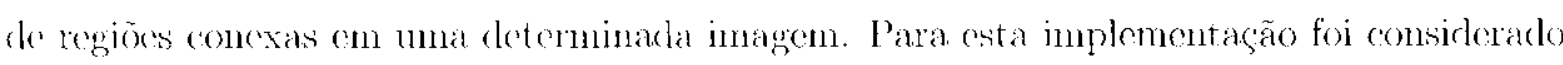
novamente $u m$ sistema de 1 vizinhos para cada pixel, on seja, o sistema t-conectado. A figura 4.8 ilustra a diferença entre a utilizaça de um sistema 8 -conectado para um sistema 1-conectado pala a contagenn de regions conexas. Com o prineiro sistema, ó possivel contan duas regiòes, R1 e R2, cunquanto que para o segundo, quatro regioes concxas foran formadas: R1. R2, R3 P R1.

A idéia básica do algoritno de contagen de regióes consiste em observar as regiós co-

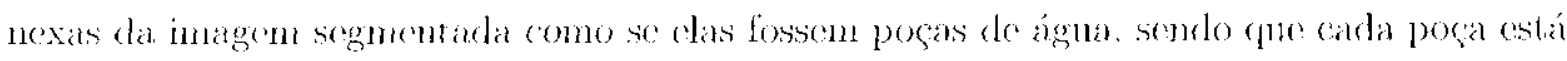
associada a ma classe $h$, e para cada classe $k$ existe $u$ contador para almazenar o múmero do poças (regiones) daquela classe que existem na imagem. Inicialmente todas as poças se encontram vazias e todos os contadores amazenann o valor zero. Ao longo do processo ats

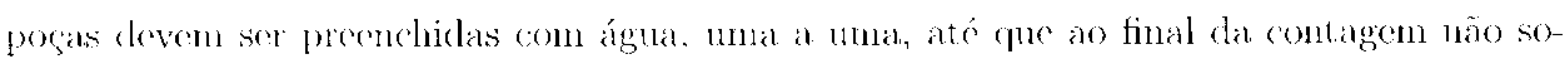
bre nemhuma poga varia. A medida que uma poga é presnchida, verifica-se qual classe está 


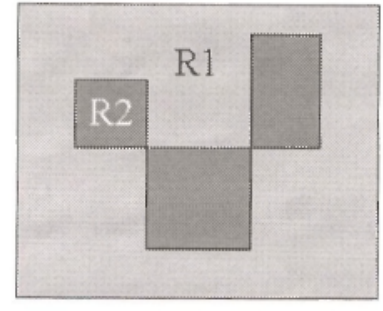

(a)

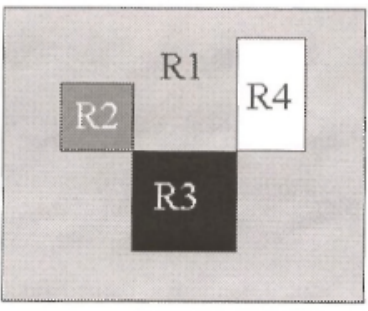

(b)

Figura 4.8: Utilização dos sistemas 8-conectado e 4-conectado para a contagem de regiões conexas (a) Sistema 8-conectado; (b) Sistema 4-conectado

associada a ela, e incrementa-se o contador de regiões associada àquela classe. Sendo assim, o número de regiões de classe $k$ existentes na imagem corresponde ao número de vezes que o procedimento de preenchimento foi executado para preencher uma poça daquela mesma classe.

Foram utilizadas duas estruturas na implementação: um vetor $V$ de contadores de regiões; e uma matriz bidimencional $M$, de valores inteiros, do tamanho da imagem segmentada. Inicialmente todas as posições do vetor $V$ são "zeradas" e a matriz $M$ recebe integralmente os valores contidos na imagem segmentada, ou seja, cada posição de $M$ representa um pixel e armazena o número da classe daquele pixel. Esta matriz $M$ atua, praticamente, como um "mapa do terreno" que serve para indicar qual a situação das "poças" em relação ao seu preenchimento (preenchida ou não preenchida). A posição de $M$ que representa um pixel de uma região que já foi preenchida recebe um valor negativo. Neste caso, considera-se que este pixel já tenha sido "visitado" pelo algoritmo de contagem.

Após a iniciação do vetor $V$ e da matriz $M$ o algoritmo percorre $M$ sequencialmente, linha por linha, a procura de um pixel que ainda não tenha sido visitado. Ao encontrar este pixel, verifica-se a qual classe ele pertence e incrementa-se o contador correspondente àquela classe. Logo após, o algoritmo de preenchimento por alagamento é chamado para que a região que compreende aquele pixel seja completamente preenchida. Isto significa que o algoritmo de preenchimento irá percorrer todos os pixels desta região marcando-os como "visitados".

Em seguida, um novo pixel que ainda não tenha sido visitado é selecionado seqüencialmente e, novamente, é incrementado o contador correspondente a sua classe e chamado o procedimento de preenchimento. Este processo continua até que todas as posições da matriz $M$ tenham sido marcadas como "visitadas". Nesta ocasião, o vetor $V$ irá conter o resultado final da contagem de regiões conexas da imagem segmentada. Resumido, o algoritmo de contagem consiste nos seguintes passos: 
1. Iniciar o votor de contadores $V$ o a matriz mapa $M$;

2. Selecionar um pixed pur ainda não tenha sirlo visitado

3. Incrementar o entialor correspondente à clasise deste pixel

4. Marcar o pixel p (onno "visitarlo";

5. Channar o algoritno de preenchinento por alagamento (Flood Fill) para prencher a regiäo conexa gue compresede p:

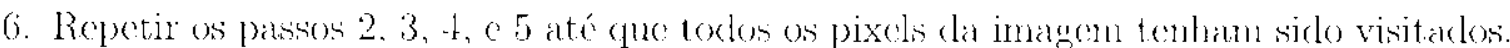

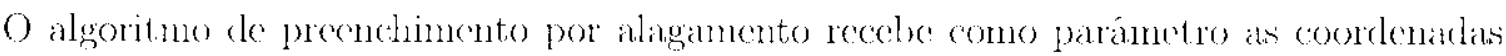

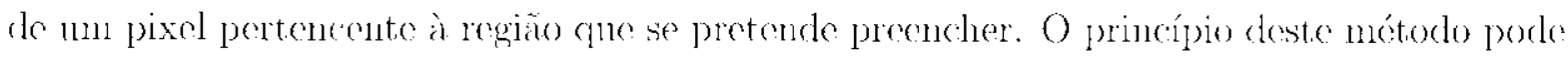
ser facilmente comprecndido através de uma definçào recursiva. A idécia do algoritno ó verificar: inicialmente, se o pixel $p$, cujas coordenadas foram passadas como parànetro, já foi

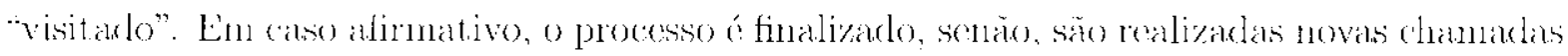
rectusivas do proecelimento, wna para cada vizinho do pixel $p$.

Embora simples de se implementar, esta versão recursiva do algoritmo cle preenchinento näo representar una altemativa adequada para o prenchimento do grandes regiojes conexas.

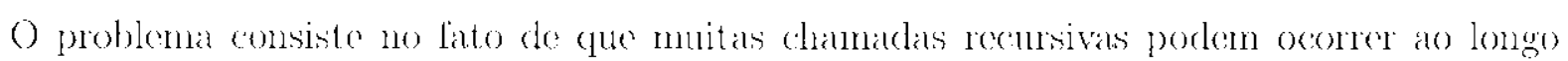
do procosso, ocasionakdo un estouro da pilla do programa (Stack: Oucrfiow). Veste caso, foi implementarla una versäo iterativa deste mosno algorituno. Para isto foi preciso inmplementar una estrutura do tipo pilha que pudesso simular as chandalas recursivas de procedimentos.

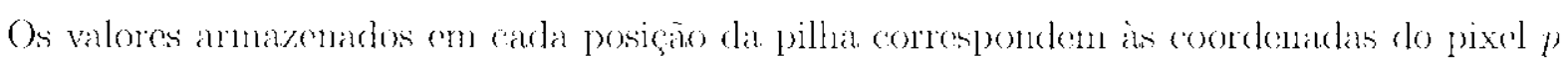
que cran passadas como parametro para o procedimento de versão recursiva. O algoritno iterativo porle ser resumido da seguinte forma:

1. Empilhar as coordenadas do pixel cuja regiăo se deseja preencher;

2. Descmpilhar as coordenadas do min ponto p, no topo da pilha;

3. Marcar o ponto p como "visitado":

4. Fmpilhar as coordenadas do vizinho acima de $l$. se ole ainda näo tiver sido visitado;

5. Enpilhar as coordenadas do vizinho abaxo do $p$, se ele anda näo tiver siclo visitado;

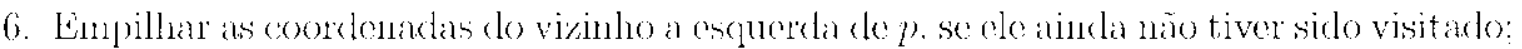

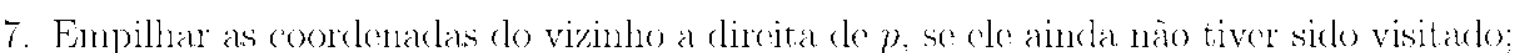

8. Executar os passon 2, 3, 1, 5, 6 a 7 ate (fue a pilha so esvazie por completo. 


\subsection{Considerações finais}

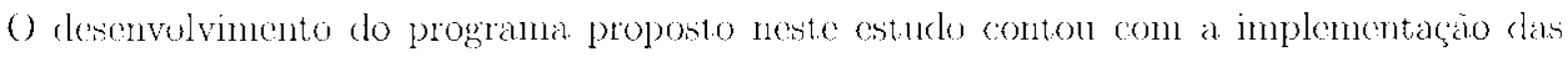

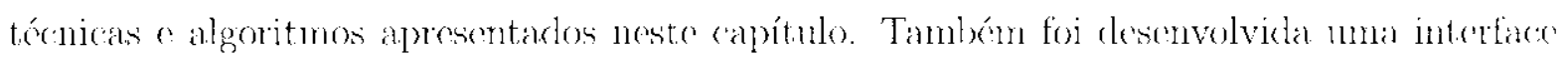
para o usuário que proporciona a configuragăo do conjunto de parâmetros dos métodos bem cono uma apresentaçäo adequada dos resultados parciais e findis do processo do segmentacăo

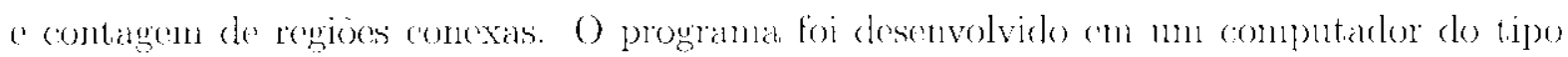
P(: com sistemat operacional Winclows 2000 utilizando-se o compilador Delphi da Borlankl, versĩo 6.0. Para a segmentagão o programa trabalha apenas com imagens en escalas de cinza (256 tons - 8 bits per pixcl) do tipo bitmap (.bmp). A inagen segmentada também é do tipo bitmap 8bpp.

Un esturlo sobre a comvergencia do mótodo EM/MPM porle sere encontrade no artimo cscrito por Mary L. Comer e Edward Delp CDo(o)]. Fsse estuclo garmente, a partir de teoremas e formulaçocs matcmáticas, a convergencia tanto ro algoritmo EM quanto alo algoritmo MPM. 


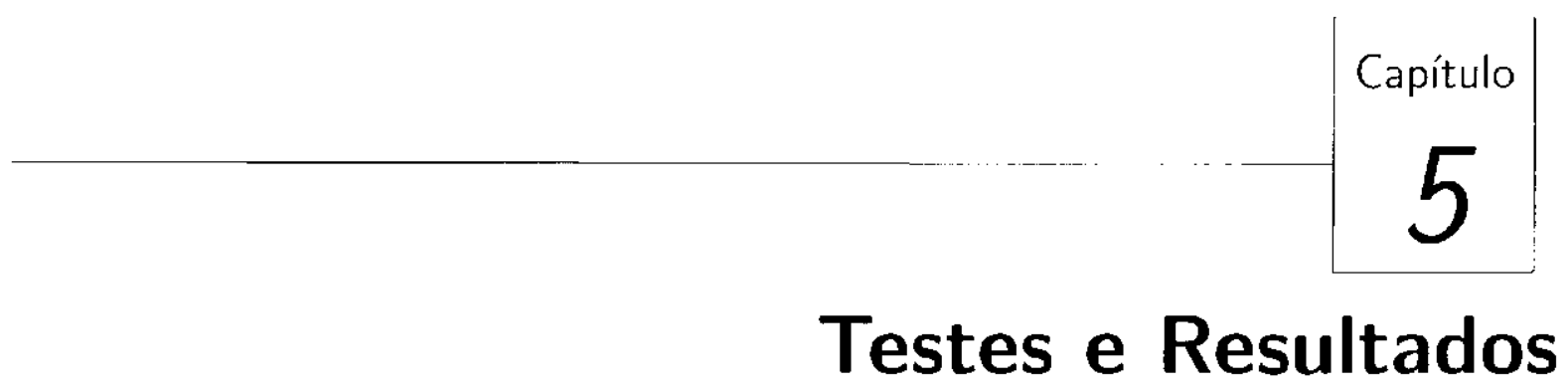

Este capítulo tom como objetivo apresentar os principais resultados obticlos com o programa de segmentaçäo de imagens e contagem de regiôs implementado. Os testes form aplicarlos em três conjuntos de imagens: imagens sintéticats, mamografias o imagens de ninhais.

$\Lambda$ análise de desompenlo do método de segmentacăo levou em consideração aspectos de qualidade dos resultarlos obtidos e critérios de convergencia. O primeiro diz respeito à capacidade do método em identificar todas, on a maioria das regioes/objetos relevantes na cella. () scegundo, consiste nat análise do múmero de estágios necessários para que o processo se estintilize.

Entonde-se por sstabilidade a ocasião cm cue não mais se observa uma mudança significativa do mapa de classes cntre estágios consecutivos do processo. Durante a fase de testes foi descobcrto que o processo se torna estável praticamente ao mesmo tempo en que o algoritmo de estimação de parâmetros (EM) atinge o ponto de convergência, ou seja, quando os valores do velor $\theta$ (média e variância para carla classe) deixan de sofrer alterações significantes. Sendo assim: en termos práticos; a convergència do método EM pode refletir diretamente o ponto do estathiliclade do processo.

A interface do programa foi adaptadla para exibir, em foma de gráficos, a evolução dos valores dos parâmetros do vetor $\theta$ em relação ao estágio $p$, ao longo processo. Dois gráficos são atualizados iterativamente, un para os valores de média clas regiöes e outro para os valores de variancia. A cor de cadla série de valores (cenva do gráfico) indican a qual classe esse conjunto so refere. Neste cupítulo, para alguns dos testes realizados, esses gráficos são apresentados juntamente com o resultado da scgmentação, com o objetivo de ilustrar a convergencial dos processios. 
Para lodos os testes realizados, o valor utilizado do parannetro $\beta$ foi ajustado de modo a se obter o melhor resultado de segmentação. De fato, o ajuste adequado deste paràmetro influencia dirctamente na qualidade do resultado bem como na velocidade de convergencia do processo. Para a segmentaçào de imagens com a utilizaçăo da abordagom multiresolugão $(R>1)$ foram utilizados dois valores do $\beta$ : 1 m valor para a segnentaca do da imagem topo da pirâninide (nível superior) o outro valor para os demais níveis. Para todos os testes oncle $R>1$, o valor deste último parâmetro foi definido como sondo 5 , o o valor do parámetro $\alpha$ como sendo 6. Sendo assim, a notaçãe 3 será ndilizada aponas para so referir ao parâmetro de iteraga espacial do nível superior da pirânide, para $R>1$.

A utilização da técnica de Annealing, que consiste em variar iterativamente o valor de $\beta$, nảo apresenton resultados interessantes na segmentaçào de inagens com regiöes do tamanho relativamente pequeno. Foi observalo que, ao longo do processo, tais regiones desaparecian do mapa de classes, sendo englobadas pelas regiós nuaiores. Deste modo, esta técnica näo foi aplicada na segmentaçâo de tais imagens: como é o caso das magens do ninhais, onde as aves se apresentan em tamanho bastante reduzido. Para a segmentação multiresoluçào, a técnica de Annealing bambém foi utilizadia apenas para segmentar a imagem lopo da pirâmide, visto que a segmentacia dos demais níveis bascia-se fortemente no primeiro resultado obtido. Ao

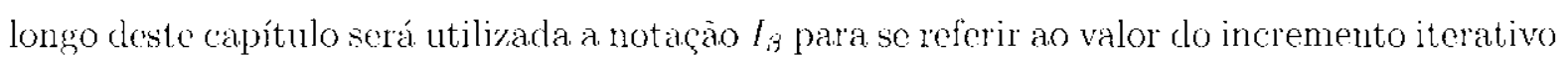
utilizado pela ténnica de Annealing.

As estimativas iniciais para a média o valiancia das chasses (vetor $\theta$ ) foram obtidas utilizando-se $\mu_{k}(0)-\frac{128}{L}+\frac{255 k}{L}$ para as médias e definindo a variancia para cada classe em 100 , ou seja, $\sigma_{k}^{2}(0)=100$. Fsta estimação se mostrou adcquada para a segmentação da maioria das imagens utilizadas para testes, porim, para algumas imagens estes valores inicias fazom, simplesmente, con que o algoritmo EM convirja para valores de média e variâneia que não são interessantes para o processo. Ern decorrencia disto a inagem segmentada acaba se distanciando muito da segmentaçäo ideal.

Para contomar este problema, foi adaptada à interface do programa una funcionalidade que pernute ao ustário definir us valores iniciais de média e mánecia para o vetor $\theta$, a partir da delimitação de regiões retangulares dentro do espaço que comprecnde a inagem original. Mais especificamente, o nsuário aponta com o mouse dois pontos sobre a imagem a ser segmentada, que definem uma regiào retanghular. Nesta ocasiäo, uma função é chamada para calcular a média e a varianeía dos pixels internos àcuele retângulo o estes valores sorvem como estinativa para a classe que o usurário escolher

Para cada pixel s, pertencente ao espaço $S$. a estimativa de sua classificação inicial foi escolhida para sor um valor aleatório com distribuição uniforme sobre todas as classes o inderpendente da estimativa inicial dos demais pixels. 
O custo relativo de ocorrência de uma determinada classe $k$, ou seja, o parâmetro $\gamma_{k}$, foi definido como sendo zero para todas as classes, na maioria dos testes realizados. Porém, para algumas imagens, a incorporação desta informação a priori pode auxiliar o algoritmo de segmentação a obter melhores resultados. Isto acontece, na maioria das vezes, quando a imagem possui regiões cujos tamanhos diferem muito uns dos outros, ou seja, quando regiões que ocupam uma área relativamente pequena se encontram difundidas em regiões que ocupam uma área bem maior. Esta situação ocorre, tipicamente, em imagens de ninhais, onde o percentual da área correspondente às aves é bem menor que, por exemplo, a área ocupada pela vegetação de fundo. Para todos os testes realizados, o número de iterações do algoritmo MPM foi definido como sendo 5. Isto significa que cada pixel da imagem é visitado cinco vezes durante a execução desse algoritmo.

\subsection{Imagens sintéticas}

A primeira imagem teste apresentada (figura 5.1(a)) é uma composição de dois tipos de texturas encontradas no livro de P. Brodatz [Bro66]: madeira e grama. A segmentação foi realizada em uma única resolução $(R=1)$ pois pode-se observar que as regiões da imagens são constituídas por texturas bem refinadas. Para o parâmetro $L$, ou seja, o número de classes, foi utilizado o valor 2. O parâmetro $\beta$ foi definido como sendo 2 e o valor de seu incremento $I_{\beta}$ para Annealing como sendo $\frac{3}{P}$, onde $P$ representa o número de estágios do processo utilizados para a segmentação. As figuras 5.1(b) e (c), ilustram, respectivamente, a situação do mapa de classes nos estágios 10 e 100. Os gráficos de médias e variâncias são ilustrados pelas figuras $5.2(\mathrm{a})$ e $5.2(\mathrm{~b})$.

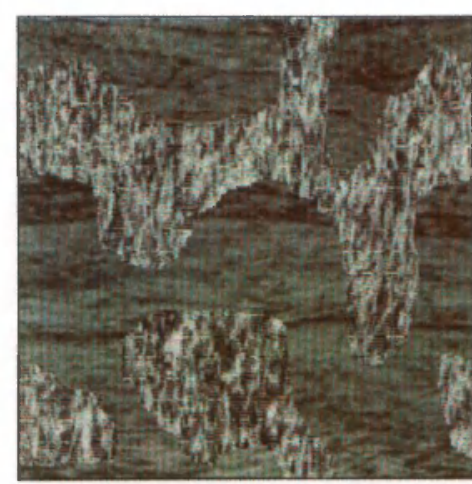

(a)

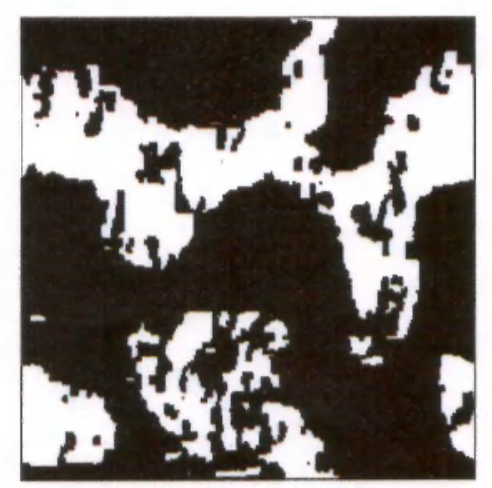

(b)

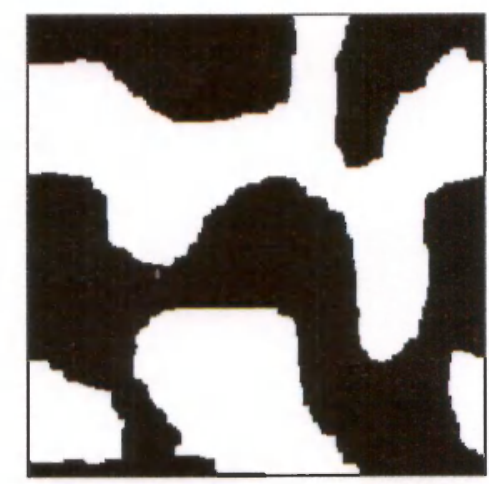

(c)

Figura 5.1: Segmentação de uma imagem teste sintética utilizando $L=2, R=1$ e $P=100$ (a) Imagem original $(274 \times 276$ pixels); (b) Mapa de classes com 10 estágios; (c) Mapa de classes com 100 estágios. 


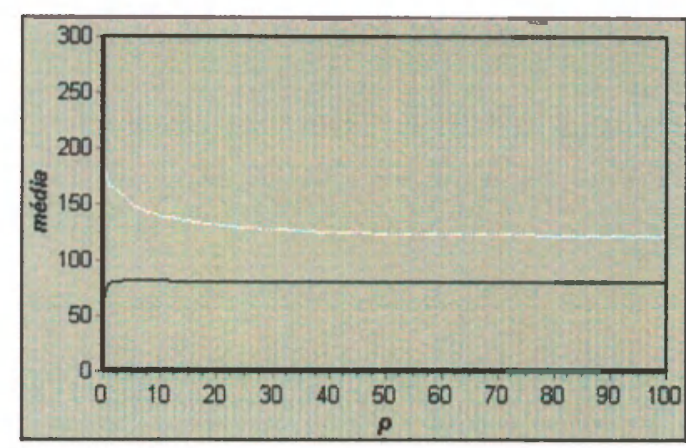

(a)

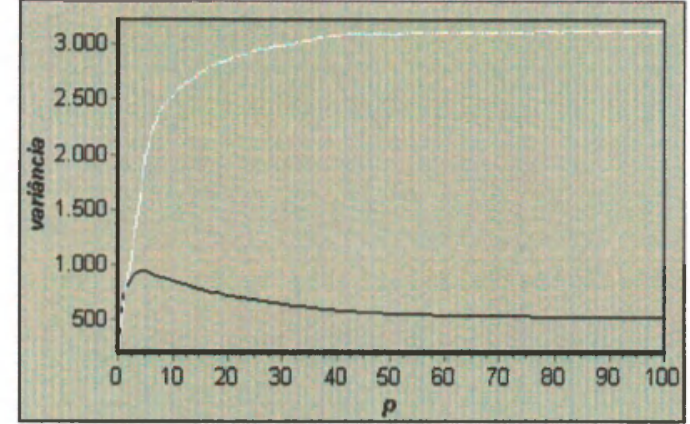

(b)

Figura 5.2: Gráficos dos valores de média e variância do processo de segmentação da figura 5.1 (a) Gráfico das médias; (b) Gráfico das variâncias.

Pode-se observar, a partir dos gráficos que a convergência do processo ocorreu próximo ao estágio 80. Após este ponto o mapa de classes torna-se praticamente inalterável até o fim da segmentação, o que representa a estabilização do processo.

A segunda imagem teste (figura 5.3(a)) é uma composição de outras duas texturas do livro de Brodatz: couro e cortiça.

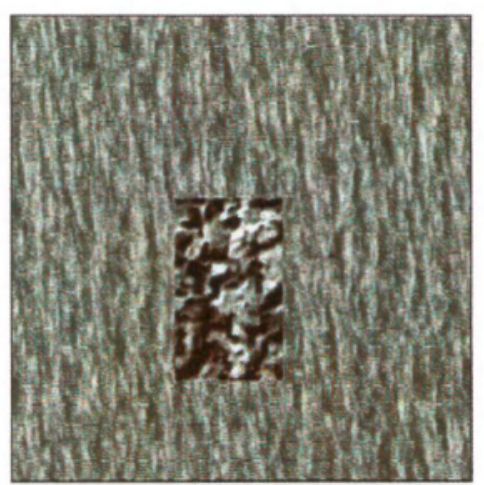

(a)

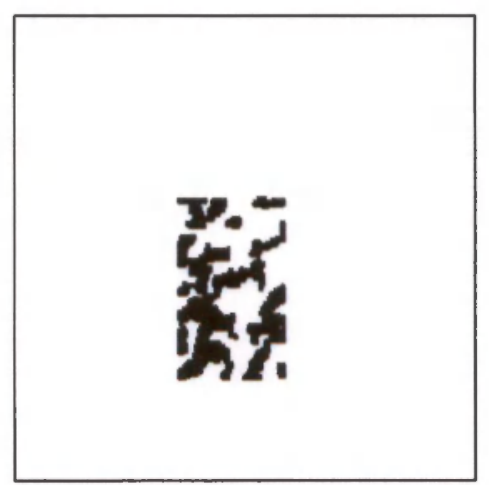

(b)

Figura 5.3: Segmentação de uma imagem sintética utilizando $L=2$ (a) Imagem original $\left(277 \times 277\right.$ pixels); (b) Segmentação em 150 estágios com $R=1, \beta=1$ e $I_{\beta}=3$.

A figura 5.3(b) ilustra a segmentação realizada em uma única resolução $(R=1)$. Os valores dos parâmetros utilizados na segmentação encontram-se na legenda da figura correspondente. Percebe-se que o algoritmo não conseguiu classificar corretamente o retângulo interno da imagem que corresponde à região cuja textura é a cortiça. Conforme apresentado na seção 4.1.3, isto ocorre porque o sistema de vizinhança utilizado não é grande o suficiente para possibilitar a classificação de texturas mais grosseiras. Para segmentar corretamente 
esta imagem foi preciso utilizar três níveis de resolução (figura 5.4). As figuras 5.4(b), (c) e (d) apresentam, respectivamente, a segmentação dos níveis 2, 1, e, 0 da pirâmide multiresolução. Para o nível 2 (topo da pirâmide) a segmentação foi realizada em 100 estágios, enquanto que para os níveis seguintes (1 e 0), 50 estágios foram executados.

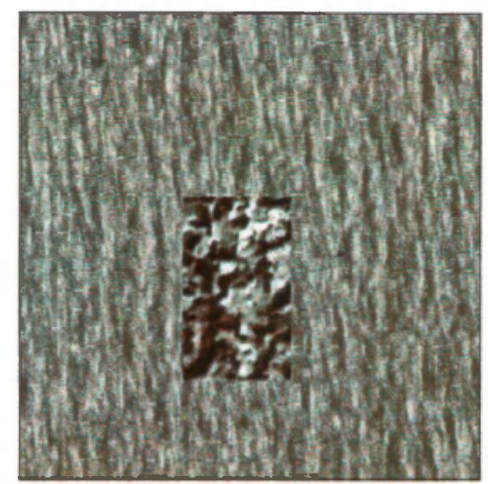

(a)

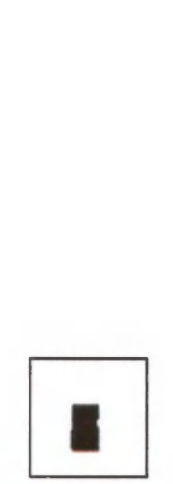

(b)

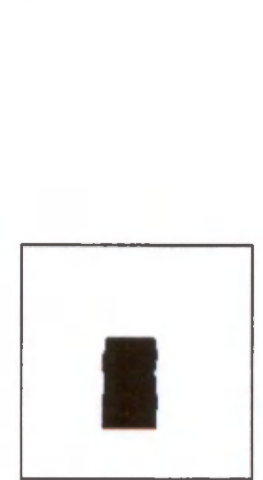

(c)

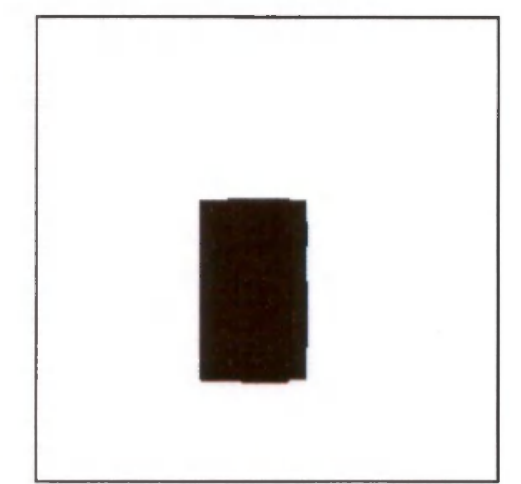

(d)

Figura 5.4: Segmentação multiresolução: $L=2$ e $R=3$ (a) Imagem original $(277 \times 277$ pixels); (b) Segmentação do nível 2 da pirâmide em 100 estágios: $\beta=1$ e $I_{\beta}=3$; (c) Segmentação do nível 1 da pirâmide em 50 estágios; (d) Segmentação do nível 0 em 50 estágios.

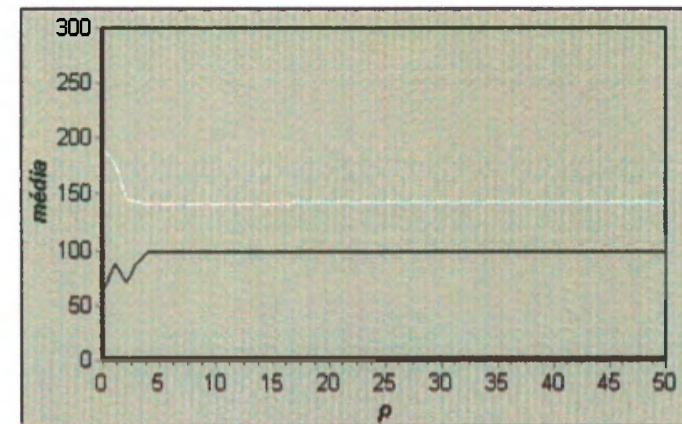

(a)

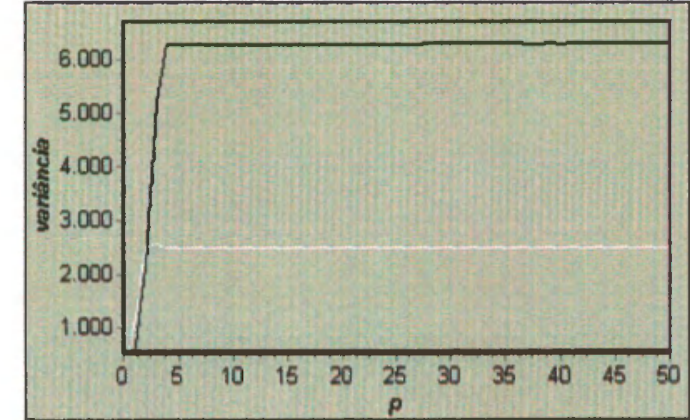

(b)

Figura 5.5: Gráficos dos valores de média e variância do processo de segmentação da figura 5.4 (a) Gráfico das médias; (b) Gráfico das variâncias.

As figuras 5.5(a) e 5.5(b) ilustram os gráficos de média e variância obtidos durante a segmentação do último nível de resolução da pirâmide, ou seja, a base da pirâmide. A partir destes gráficos observa-se que o processo converge antes mesmo do vigésimo estágio, o que representa, em comparação ao processo de segmentação da primeira imagem teste (figura 5.1(a)), uma convergência bem mais rápida. Isto deve-se ao fato de que boa parte do 
trabalho de segmentação já foi realizado durante a segmentação da imagem que representa o topo da pirâmide. Conforme já mencionado, o tamanho reduzido desta imagem proporciona ao processo atingir a convergência em uma velocidade bem maior. Deste modo, combinandose a velocidade de convergência da segmentação da imagem topo da pirâmide com o número reduzido de estágios necessários para a convergência do processo nos níveis seguintes, é possível obter um desempenho bem maior do método de segmentação em relação à velocidade de processamento.

Porém, vale lembrar que a utilização da abordagem multiresolução não representa uma opção adequada para todos os tipos de imagens. Isto ocorre na ocasião em que existem regiões muito pequenas na imagem e que são relevantes para o resultado final da segmentação. A utilização de mais de um nível de resolução $(R>1)$ pode fazer, simplesmente, com que estas pequenas regiões não apareçam no mapa de classes ao final do processo, gerando assim um resultado incorreto. Neste caso, pode-se dizer que o ajuste do valor de $R$ para a segmentação de uma determinada imagem depende, basicamente, da percepção que o usuário tem daquela imagem. Um ajuste ideal também pode ser alcançado após a realização de alguns testes, com valores diferentes de $R$, para a mesma imagem.

A figura 5.6 ilustra mais um exemplo de segmentação de imagem sintética. Desta vez a imagem é composta de três regiões de texturas distintas: madeira, couro e grama.

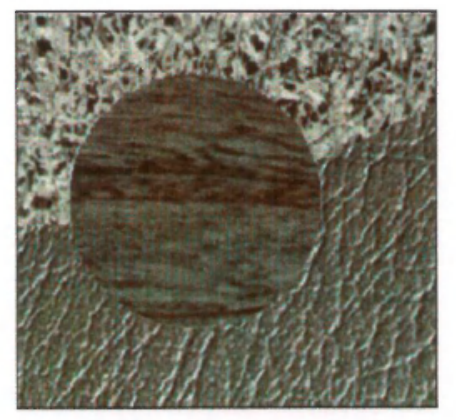

(a)

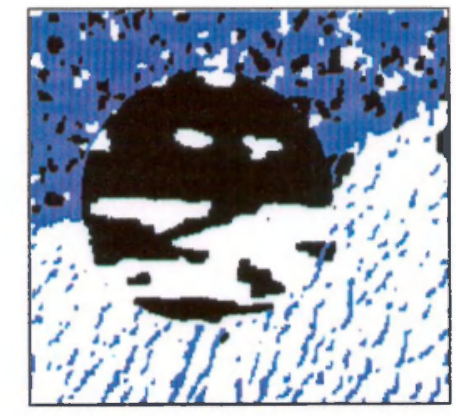

(b)

Figura 5.6: Segmentação de uma imagem sintética utilizando $L=2$ (a) Imagem original $\left(253 \times 236\right.$ pixels); (b) Segmentação com $R=1$ em 150 estágios: $\beta=1$ e $I_{\beta}=3$.

Novamente é apresentada a segmentação com apenas um nível de resolução (figura 5.6(b)). Observa-se, mais uma vez, que o algoritmo não consegue classificar corretamente nenhuma das regiões. A figura 5.7 ilustra a segmentação da imagem em três níveis de resolução. Nota-se que a segmentação final (figura 5.7(d)) aproxima-se bastante da segmentação ideal.

Os gráficos das figuras 5.8(f) e 5.8(g) também apresentam a evolução dos valores do vetor $\theta$ durante a segmentação da imagem que representa a base da pirâmide multiresolução. 


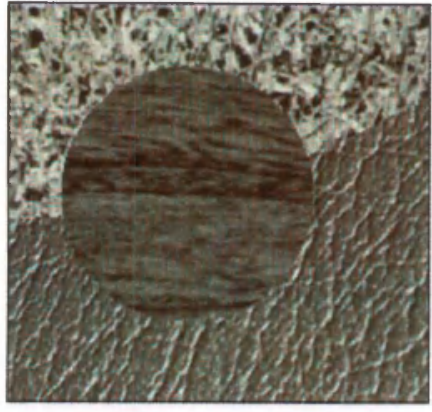

(a)

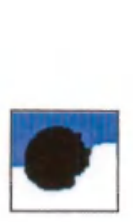

(b)

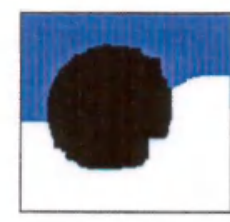

(c)

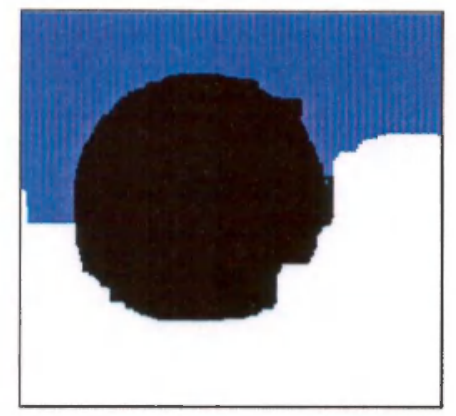

(d)

Figura 5.7: Segmentação multiresolução: $L=2$ e $R=3$ (a) Imagem original $(253 \times 236)$;

(b) Segmentação do nível 2 da pirâmide em 100 estágios: $\beta=1$ e $I_{\beta}=3$; (c) Segmentação do nível 1 da pirâmide em 50 estágios; (d) Segmentação do nível 0 em 50 estágios.

Novamente, a convergência do processo ocorre rapidamente, entre os estágios 10 e 20 .

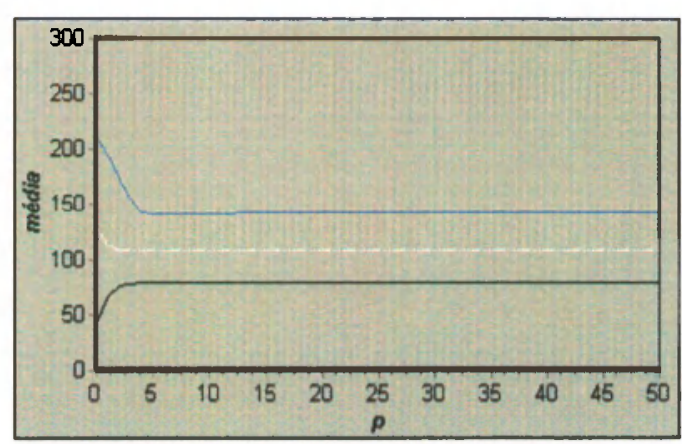

(a)

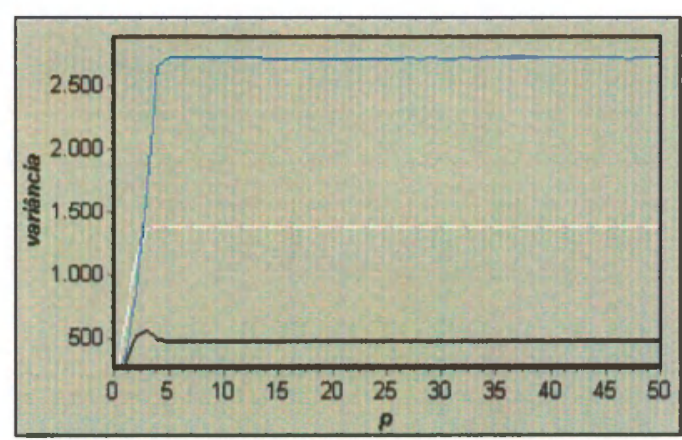

(b)

Figura 5.8: Gráficos dos valores de média e variância do processo de segmentação da figura 5.7 (a) Gráfico das médias; (b) Gráfico das variâncias.

Para os próximos testes realizados com imagens sintéticas (figuras 5.9, 5.10, 5.11 e 5.12) são apresentadas apenas a imagem original e o resultado da segmentação. O objetivo é demonstrar a capacidade do método em segmentar esse tipo de imagem aproximando-se ao máximo do resultado correspondente à segmentação ideal. Para todos os testes os valores dos parâmetros utilizados foram $\beta=1, I_{\beta}=3$ e $R \geq 3$. A convergência destes processos ocorreu de modo parecido com os exemplos das figuras 5.3 e 5.6, ou seja, entre os estágios 10 e 20. Para segmentar o nível topo da pirâmide e os demais níveis, foram utilizados, respectivamente, 100 e 30 estágios. 


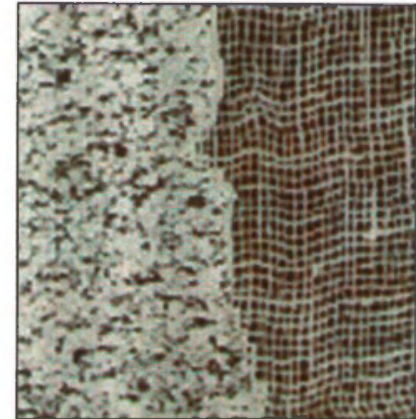

(a)

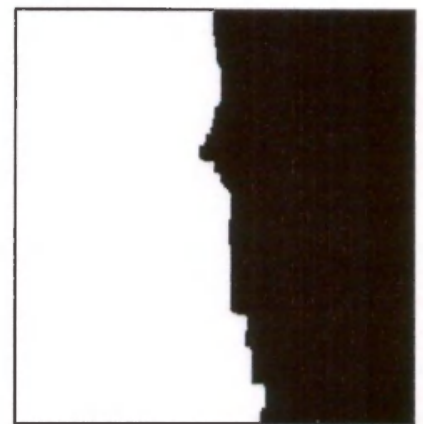

(b)

Figura 5.9: Segmentação de uma imagem sintética: $L=2, R=3$ (a) Imagem original $(240 \times 246$ pixels $)$; (b) Imagem segmentada

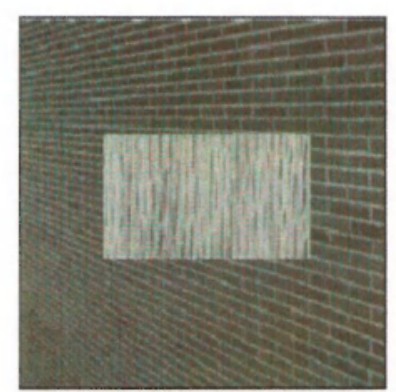

(a)

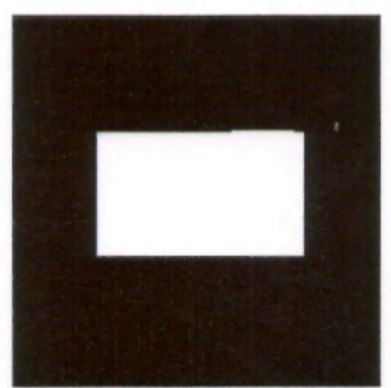

(b)

Figura 5.10: Segmentação de uma imagem sintética: $L=2, R=3$ (a) Imagem original $(200 \times 200$ pixels $)$; (b) Imagem segmentada

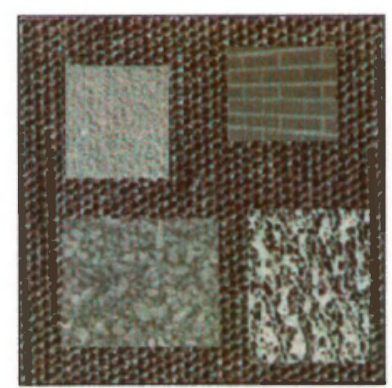

(a)

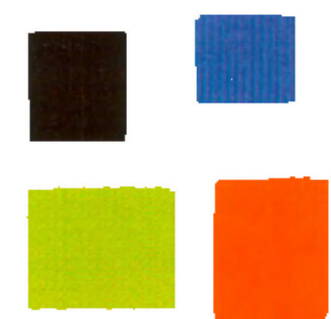

(b)

Figura 5.11: Segmentação de uma imagem sintética: $L=5, R=3$. A estimação dos valores iniciais de média e variância das classes foi feita através do esquema de delimitação de regiões retangulares mencionado neste capítulo (a) Imagem original (200 $\times 200$ pixels); (b) Imagem segmentada 


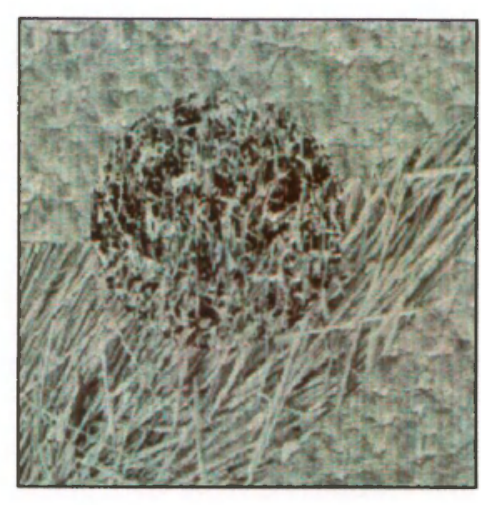

(a)

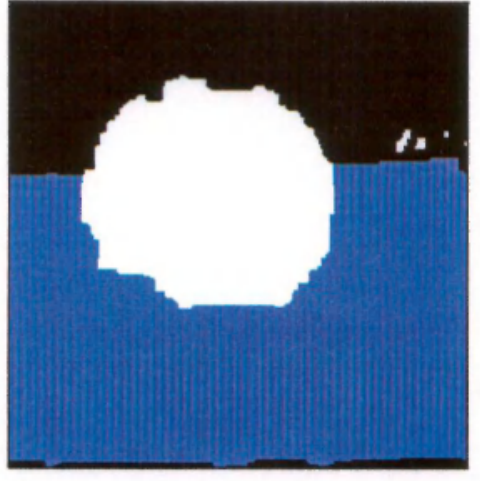

(b)

Figura 5.12: Segmentação de uma imagem sintética: $L=3, R=5$. Estimação dos valores iniciais de média e variância das classes feita através do esquema de delimitação de regiões retangulares sobre a imagem original (a) Imagem original $(200 \times 200$ pixels); (b) Imagem segmentada

\subsection{Mamografias}

Esta seção apresenta os resultados da segmentação de duas imagens de mamografias. O objetivo destes testes consiste em verificar o desempenho do método de segmentação implementado em segmentar imagens reais, especificamente de uma modalidade médica (mamografias), identificando três classes distintas $(L=3)$ : plano de fundo (background), tecido normal e tumor.

Para estes testes a segmentação foi realizada em um único nível de resolução $(R=1)$, por se tratar de imagens cujas regiões são formadas por texturas bem refinadas. $\mathrm{O}$ valor do parâmetro $\beta$ foi definido como sendo 1 , e o valor do incremento iterativo $I_{\beta}$ como sendo $\frac{2}{P}$. Também foi utilizado o conhecimento a priori de que a área ocupada pelo tumor é, na maioria das vezes, bem menor em relação à area ocupada pelas demais classes. Esta informação foi incorporada ao modelo do mapa de classes utilizando um valor de custo $\left(\gamma_{k}\right)$ não nulo para a classe que representa o tumor. Neste caso, para ambos os testes os valores de custo foram definidos como sendo 2, para a classe que representa o tumor, e nulo para as outras duas classes. Tais valores foram definidos empiricamente. As estimativas iniciais de média e variância das classes foram obtidas a partir do método de delimitação de regiões retangulares, por parte do usuário, sobre a área ocupada pela imagem original.

Em ambos os resultados ilustrados nas figuras 5.13(b) e 5.14(b), nota-se que o o algoritmo foi capaz de segmentar bem a imagem separando a região que corresponde ao tecido normal (classe branca) do plano de fundo (classe preta) e da região do tumor (classe azul). 


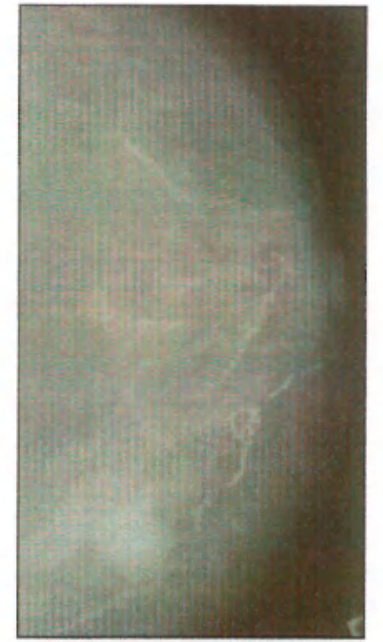

(a)

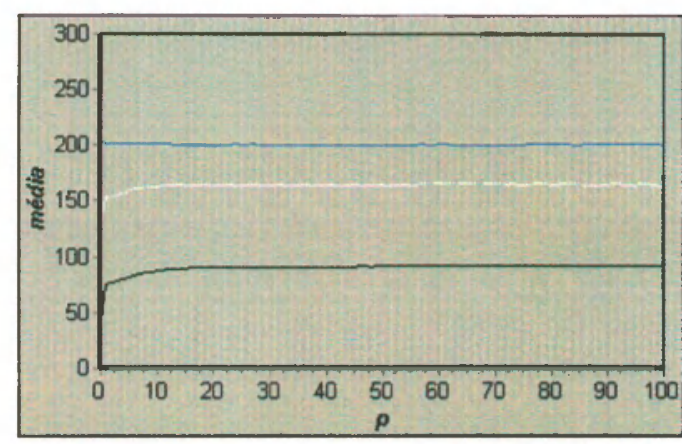

(c)

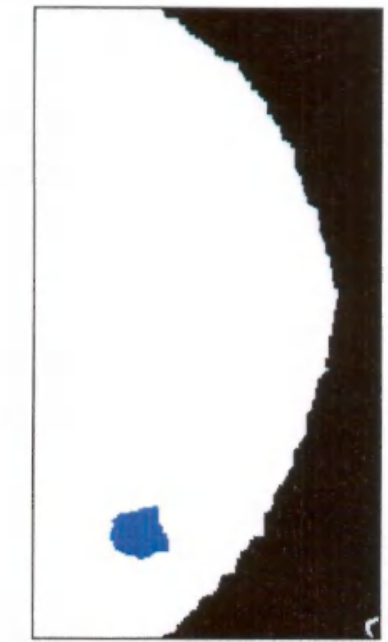

(b)

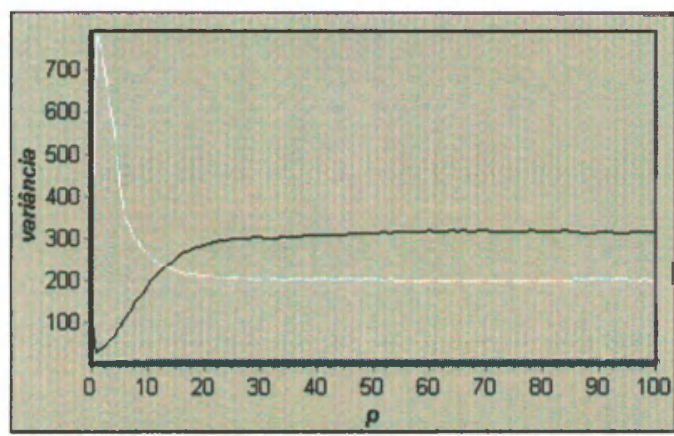

(d)

Figura 5.13: Segmentação de mamografia: $L-3, R=1$ (a) Imagem original $(190 \times 341$ pixels); (b) Imagem segmentada com 100 estágios; (c) Gráfico das médias; (d) Gráfico das variâncias.

Observa-se a partir dos gráficos das figuras $5.13(\mathrm{c})(\mathrm{d})$ e 5.14 (c)(d) que, embora a segmentação tenha sido realizada em um única resolução, a convergência dos processos ocorre de forma relativamente rápida, em torno do trigésimo estágio.

\subsection{Imagens de ninhais}

Nesta seção são apresentados os resultados obtidos com a segmentação de imagens aéreas de ninhais. O conjunto de imagens é composto por uma série de fotografias aéreas retiradas de um ninhal localizado às margens da represa Billings (região sul de São Paulo). A aquisição dessas imagens ocorreu durante uma excursão para aquela região, realizada no dia 11 de 


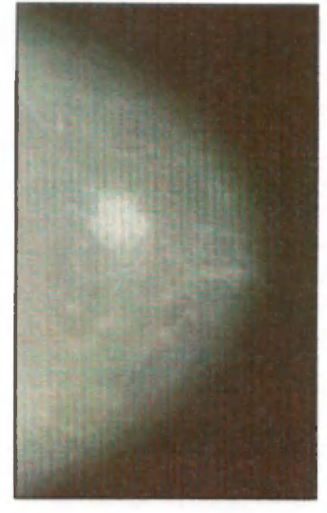

(a)

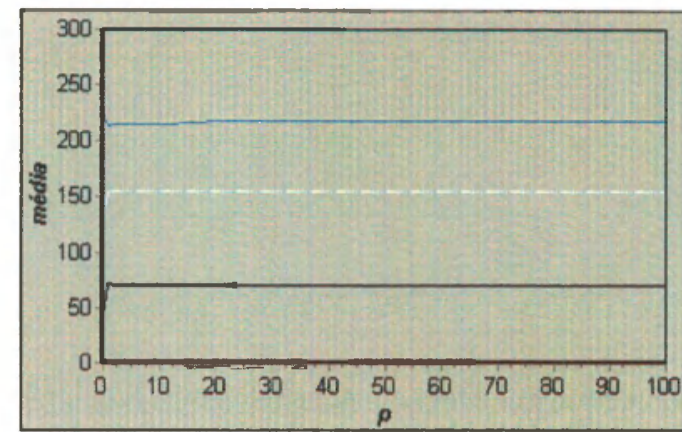

(c)

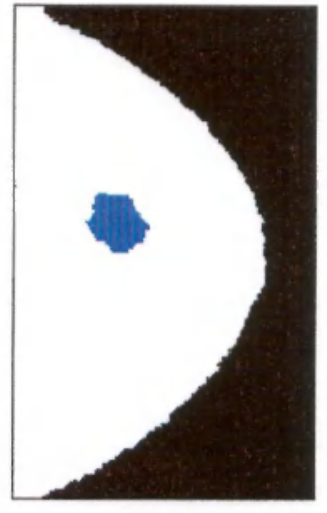

(b)

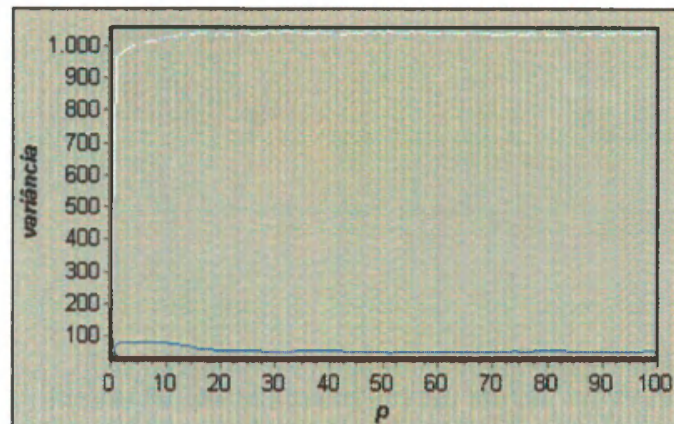

(d)

Figura 5.14: Segmentação de mamografia: $L=3, R=1$ (a) Imagem original $(165 \times 266$ pixels); (b) Imagem segmentada com 100 estágios; (c) Gráfico das médias; (d) Gráfico das variâncias.

março de 2002, que contou com a presença dos professores João do Espírito Santo Batista Neto e Onofre Trindade Junior, do aluno de doutorado Lúcio André de Castro Jorge e do aluno de mestrado André Guilherme Ribeiro Balan.

As fotografias foram obtidas utilizando-se um aeromodelo controlado por rádio que, além dos equipamentos básicos para o vôo, também contava com uma câmera fotográfica química (de acionamento controlado por rádio), uma mini-câmera de vídeo e um transmissor de UHF para acompanhamento do vôo a partir de um pequeno monitor de TV.

As aves pertencentes a este ninhal fazem parte da família das garças e socós (família Ardeidae). Elas são denominada "garças brancas grandes" por sua cor predominante e o seu tamanho relativamente avantajado (em média $88 \mathrm{~cm}$ ). Estas aves costumam migrar sazonalmente procurando sempre as regiões mais quentes. $\mathrm{O}$ pico no número de indivíduos desta espécie encontrados na região onde foram obtidas as fotos acontece entre os meses de 
janeiro e fevereiro, sendo que em março (ao fim do verão) das, pouco a pouco, comegan a migrar novamonte para regióes mais quentes. Deste modo, pode se notar um número reduzido do indivíduos nas fotos apresentadas a seguir. Una outra característica está no

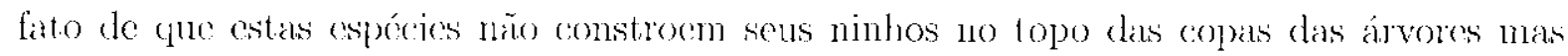
sim no interior delas. Senclo assim, este conjumto de exemplos nào conta com a imagrm dos ninhos, de modo que para a segnuentagào, apenas duas classes deven sor lovadas em consideraça: a cobertura florestal o os prissaros.

Os resultados apresentarlos nesta segà foram obtidos a partir da segmentagão das inagens em um único nível de rosolução, on soja, $R=1$. Tambím foram realizados testes com outros valores de $R$, porém, foi observado que as segmentaçós resultantes apresentavam un número bem nenor de regioes cuja classe representa os pássiaros. Isto ocome porque regioes relativanente perguenas tendem a se tomar menos pereptiveis com o encolnimente) da imagem, cm virtude da utilizaçan da abordagem multiresolucão. Sendo assim, tais regiös simplesmento desaparecem ao longo do processo do segmentação. Conformo mencionado no início deste capítulo, o mesmo acontece con a ulizaçăo da técnica de Annealing e, por csto motivo, esta técnica tambén näo foi utilizada para a segmentação deste tipo de imaggens. Para todos os testes realizados com as imagens aéreas as segmentaçoes foram realizadas em 100 estágios co valor do parametro 3 loi definido como sendo 2.

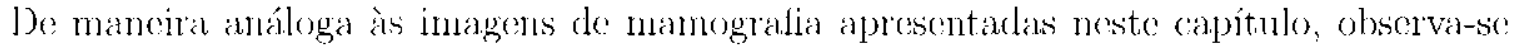
que a regiäo cuja classe representa os pássiros ocupa uma área reduzida em relaço à área ocupada pela classe de cobertura florestal. Sendo assim, também foi utilizado um valor de custo näo nulo apenas para a classe dos pássaros. Para todos os testes este valor foj definiclo cono sendo 2.5. Para a estimagào inicial dos parâmetros de nédia o variancia das

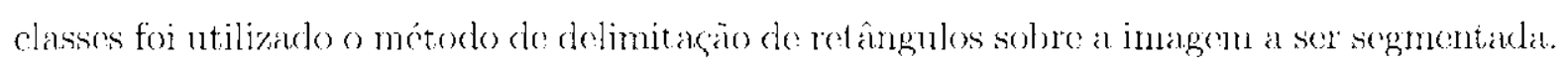
Para cada teste sũo apmentadas a imagem original, a segrnentação com doas classes e a sogmentaçăo com três classes. Os gráficos dos valores de média e variancia revelaram que torlos os processos deste conjunto de testes tendem a convergir entre o vigésinno e o trigésimo estágio. Devido à semelhanga entre os gráficos, são exibidos nesta segão aponas os gráficos referentes ao processo de sermentação dos dois primeiros testes (figuras 5.15 o 5.16 ). Conforme proposto neste estudo, o algoritmo de contagem de regiöes conexas foi aplicado

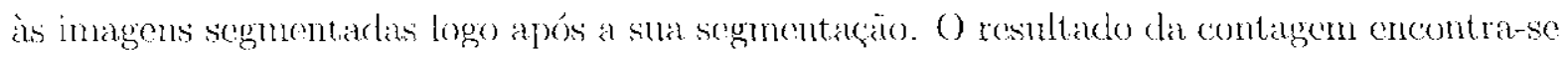
na. legenda do caula figura.

Os resultados apresentados de segmentação com duas classes demonstram a capacidade do método EM/MPM em delinitall as regioes cuja classe corresponde à classe dos pássaros, separando-as da regiäo de cobertura florestal. Vota-se que os erros cometidos pelo algoritmo, gue orasionam uma contagem de indivíduos diferente da contagem real, são derivaros, basi- 
(ammente, das segunintes ocasiōes:

- A ocorrencia de $u m$ on mais indivídnos muito próximos uns dos ontros: a algoritmo classifica o conjunto em uma única região:

- A ocorrência de regioes da área de cobertura florestal que possinem a mesma textura da classe dos pássaros: o algoritmo classifica erronémente aquela regiăo, como sendo pertencente à classe dos pássaros. Isto pode ocorrer quando verifica-se que, realmente, existem olmemtos la regia do cobertura florestal, como folhas on chareiras, cuja textura possa sere confundida com a textura de um pássaro: ou quando a luz captada pola. câmera fotográfica prodız pontos luminosos muito fortes na imagem (superexposição), que tambóm so assemelham aos pássaros.

Tais crros cometidos pelo algoritmo näo constituem, de fato. una falla intrínseca do método de segmentagăo. mas sim una linitagào ocasionada por aracterísticas próprias das imagens utilizadas. Sendo assim, é natural que na ocomencia das situagões que foram citadas o algoritmo não realize a classificação de forma correta. Observa-sc, porém. que tais situações nào ocorrem de maneira predominante na maioria das inagens observadas. Deste modó possivel dizer que a contagem de indivíduos apresentarla pelo sistema implementarlo constitui uma estimativa vátida para o valor real de número de pássaros.

As segmentaçoes roalizadas com a utilização de três classes ilustram a separação da ároa do cobertura florestal em duas regiōes de texturas distintas: uma região de vegetação mais densa (toxtura mais refinada) e uma area de vegetaga mais esparsa (textura mas grosseira). Nota-se que a classificaño das regiôes cuja classe corresponde aos pássaros permance praticamente idêntica d̀ classificação apresentada pela segmentação com duas classes. Deste modo: verifica-se que a contagem de indivíduos para ambos os resultados são praticamente equivalentes.

Nesta sção também são apresentados os testes realizados com outras duas imagens de fotografias tiradas de um pequeno açude ocupado por um bando de garģas. As fotografias foram cedidas pela professora Silvia Del Lamma, da Universidade Federal do São Carlos.

Nessas imangens observa-se pelo menos 4 regiöen de texturas diferentes: águla, céu, vegotação o pássaros. A segmentação foi realizada levando-se em consideraçâo cinco classes ( $L$ :-..5) devido a existência de um outro tipo de pássaro negro na imagem. Para o parâmetro $\beta$ foi definido o valor 2. O custo relativo $\%$ das classes dos pássaros foi definido en 1 . Para as demais classes foram utilizados custos nulos. As segmentacenes foran realizadas utilizando-se: 100 estágios.

Observa-se, a partir dos resultados, que o algoritmo classifica corretamente a maioria dos pássaros brancos encontrados na figura. Tota-se que os reflexos dessas aves lla água 
poderiam ter sido confundidos, e classificados também como sendo pássaros. No entanto, uma pequena diferença na textura dessas regiões foi o suficiente para que o algoritmo não classificasse os reflexos dos pássaros como sendo, de fato, pássaros. O algoritmo também classificou corretamente pequenas aves que se encontram nos galhos das árvores, ao fundo da imagem. Não foi possível, porém, a classificação correta dos pássaros negros que se encontram às margens do espelho d'água. Isto deve-se ao fato da existência de regiões da área de vegetação cuja textura e cor muito se assemelham à textura e cor daqueles pássaros. As figuras 5.20 (c)(d) e 5.21 (c)(d) ilustram os gráficos de evolução dos valores de médias e variâncias dos processos de segmentação das duas imagens.

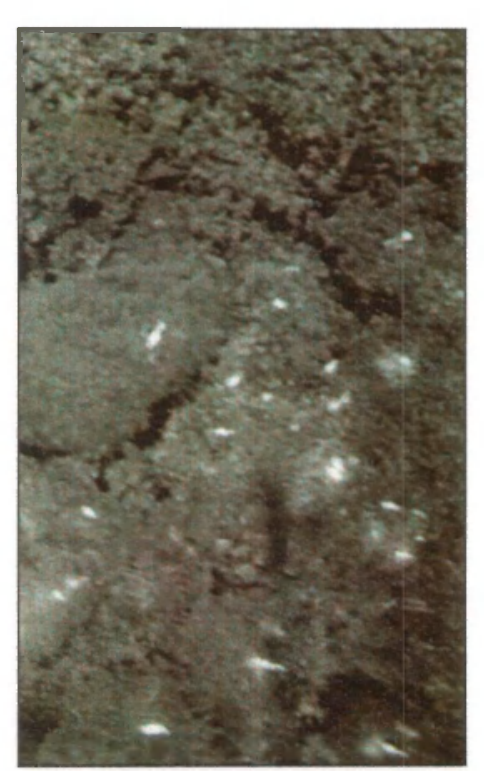

(a)

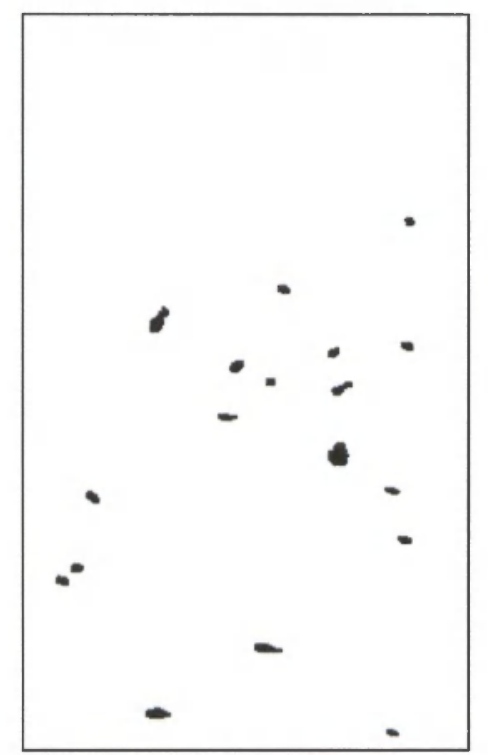

(b)

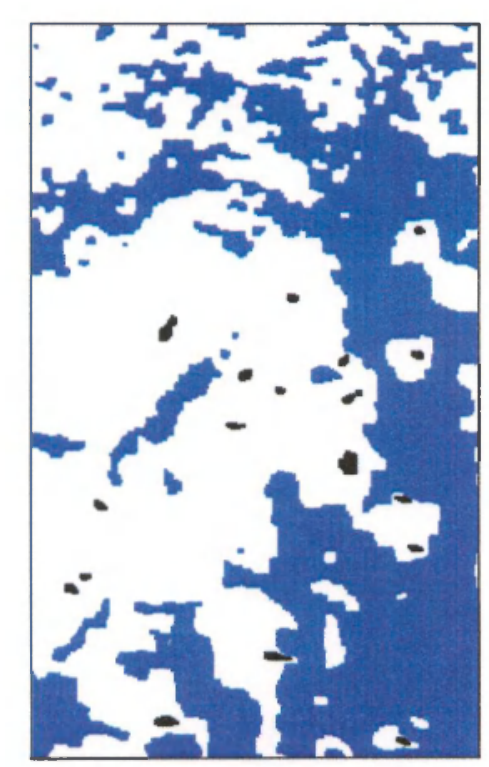

(c)

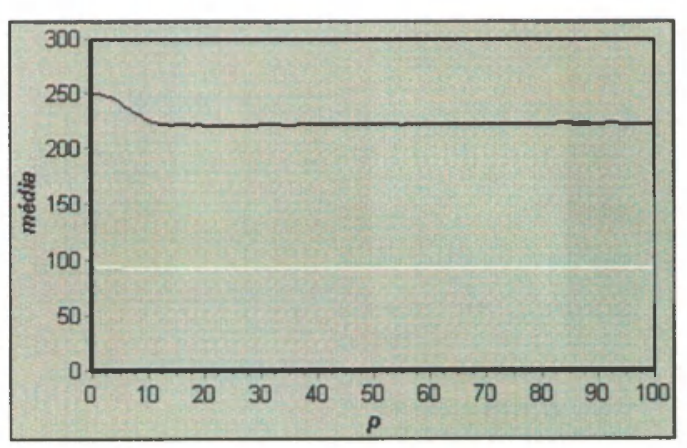

(d)

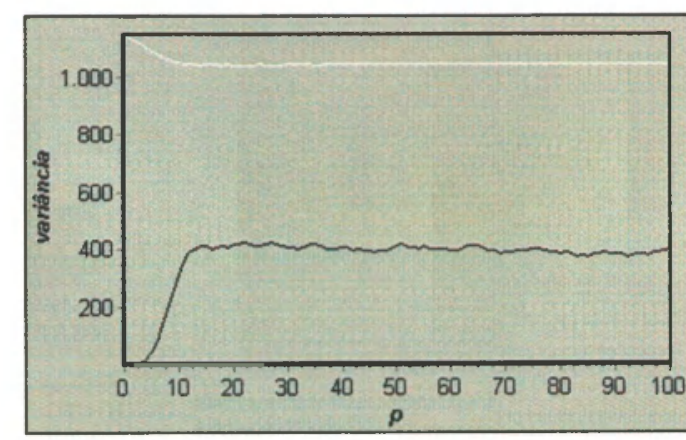

$(\mathrm{e})$

Figura 5.15: Segmentação de uma imagem aérea de ninhal (a) Imagem original $(269 \times 439)$; (b) Segmentação em 100 estágios: $L=2$ (contagem: 18 pássaros); (c) Segmentação em 100 estágios: $L=3$ (contagem: 18 pássaros); (d) Gráfico das Médias; (e) Gráfico das variâncias. 


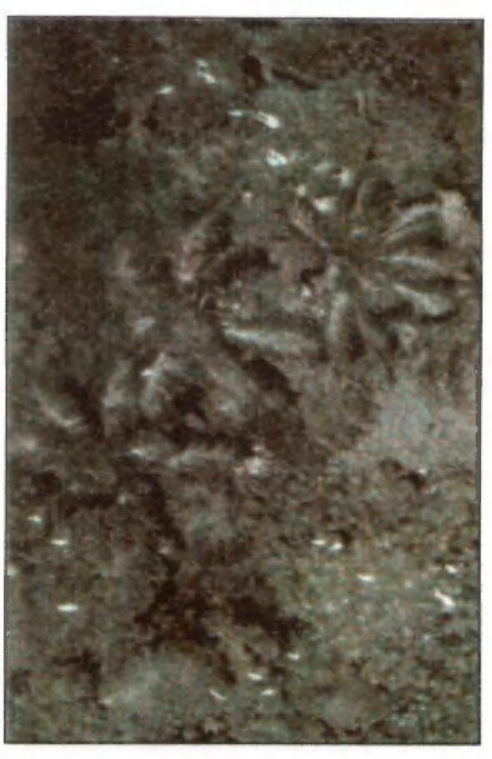

(a)

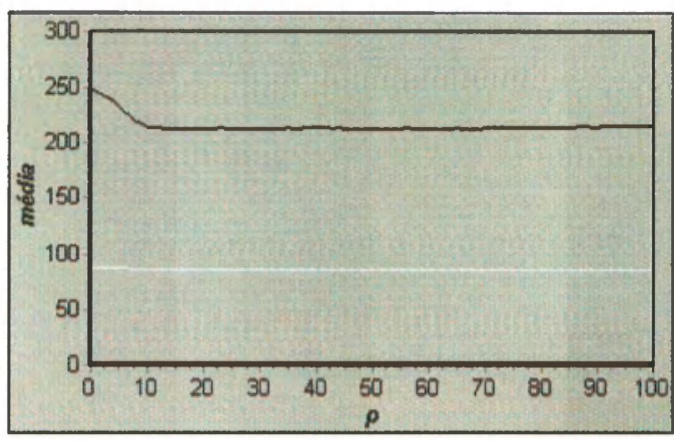

(d)

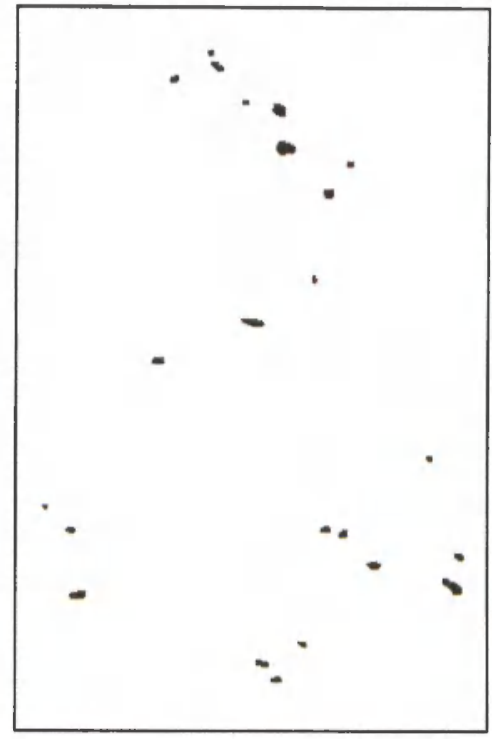

(b)

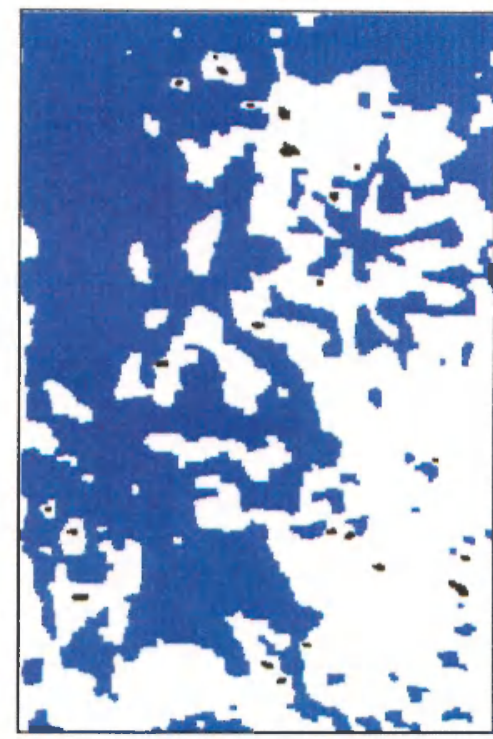

(c)

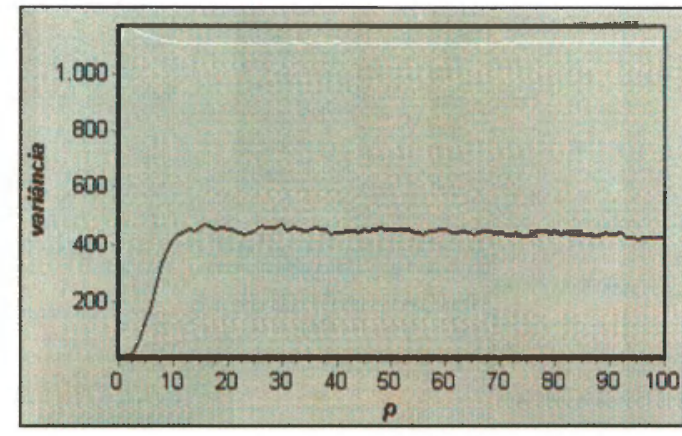

(e)

Figura 5.16: Segmentação de uma imagem aérea de ninhal (a) Imagem original $(285 \times 430$ pixels); (b) Segmentação realizada em 100 estágios: $L=2$ (contagem: 23 pássaros); (c) Segmentação realizada em 100 estágios: $L=3$ (contagem: 23 pássaros); (d) Gráfico das Médias; (e) Gráfico das variâncias. 


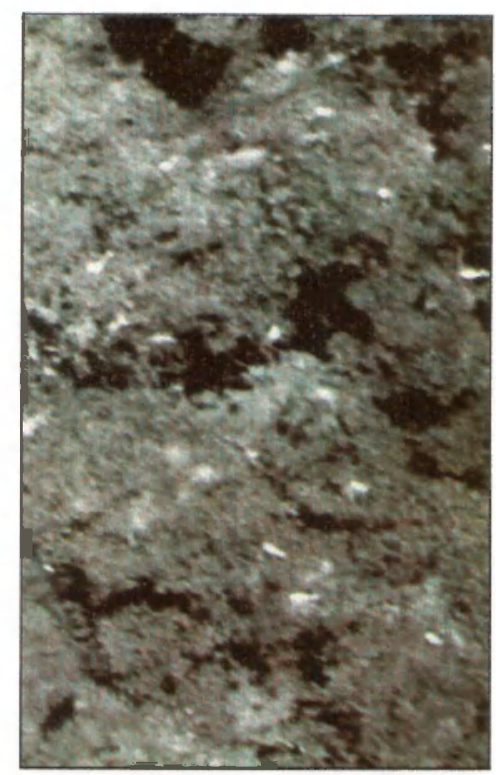

(a)

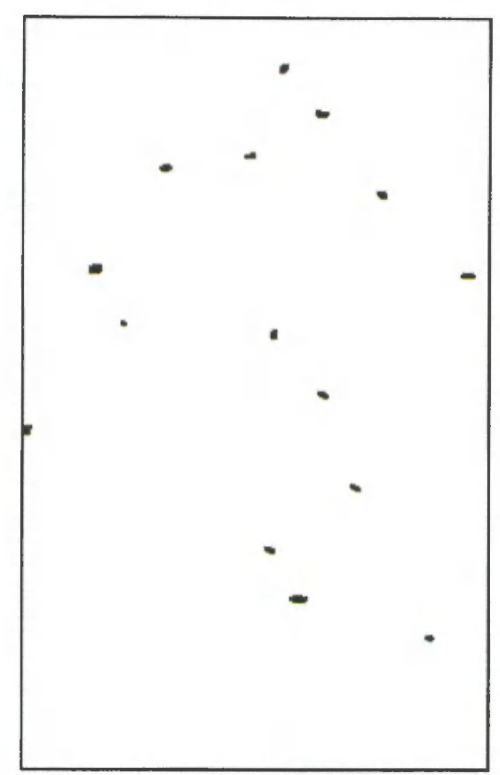

(b)

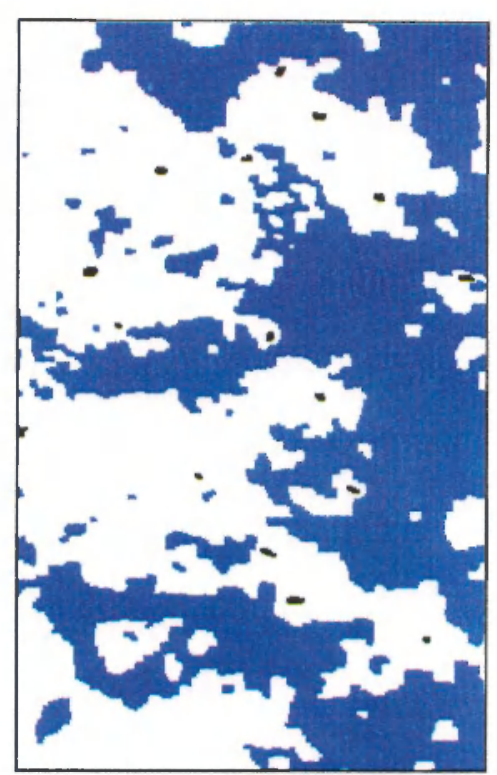

(c)

Figura 5.17: Segmentação de uma imagem aérea de ninhal (a) Imagem original $(271 \times 430$ pixels); (b) Segmentação realizada em 100 estágios: $L=2$ (contagem: 15 pássaros); (c) Segmentação realizada em 100 estágios: $L=3$ (contagem: 16 pássaros).

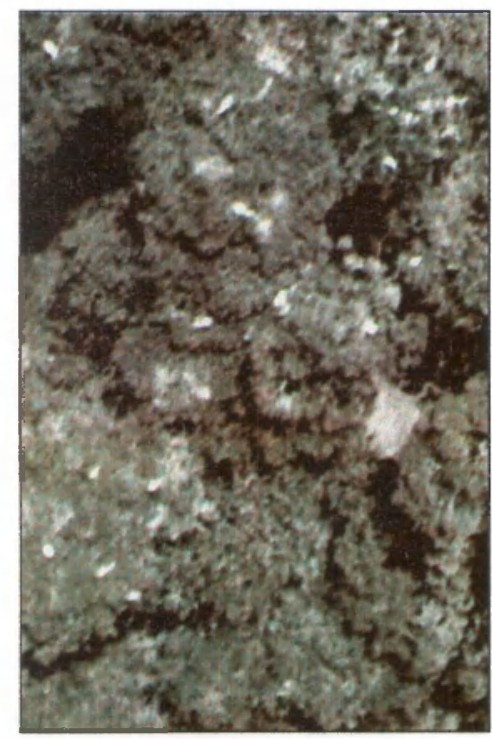

(a)

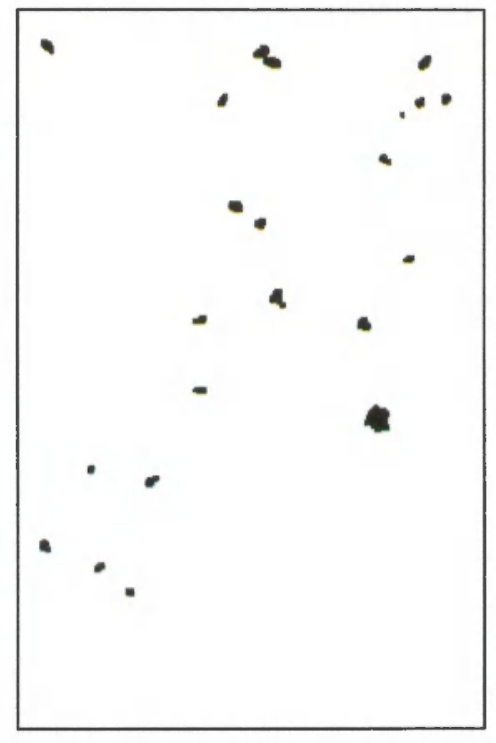

(b)

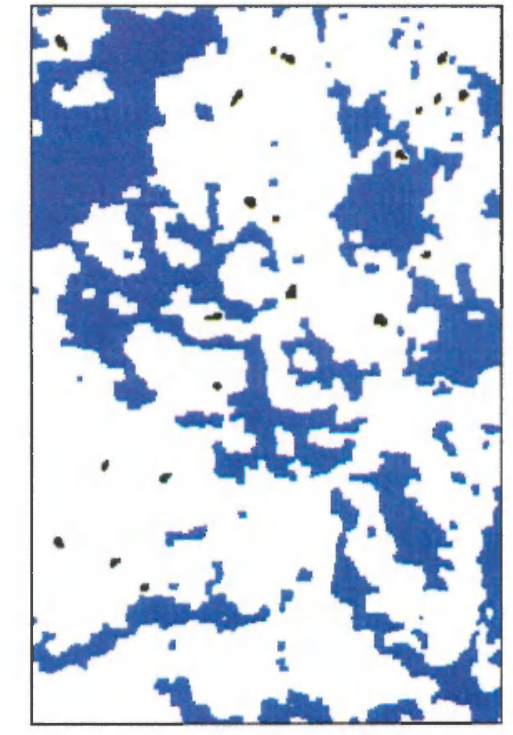

(c)

Figura 5.18: Segmentação de uma imagem aérea de ninhal (a) Imagem original $(282 \times 430$ pixels); (b) Segmentação realizada em 100 estágios: $L=2$ (contagem: 21 pássaros); (c) Segmentação realizada em 100 estágios: $L=3$ (contagem: 21 pássaros). 


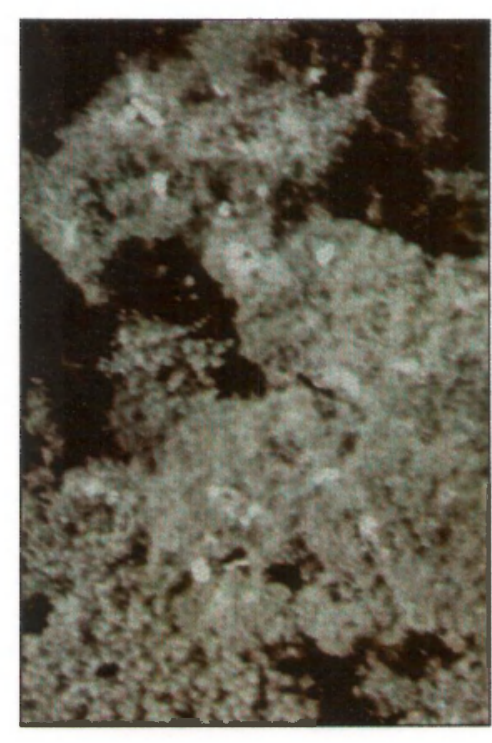

(a)

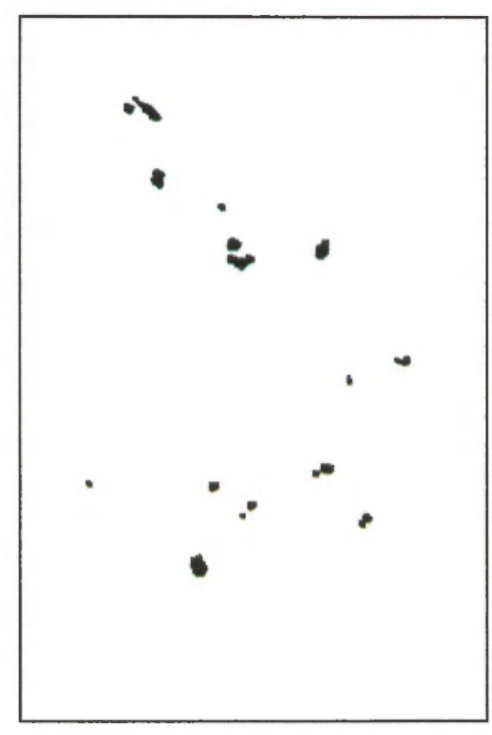

(b)

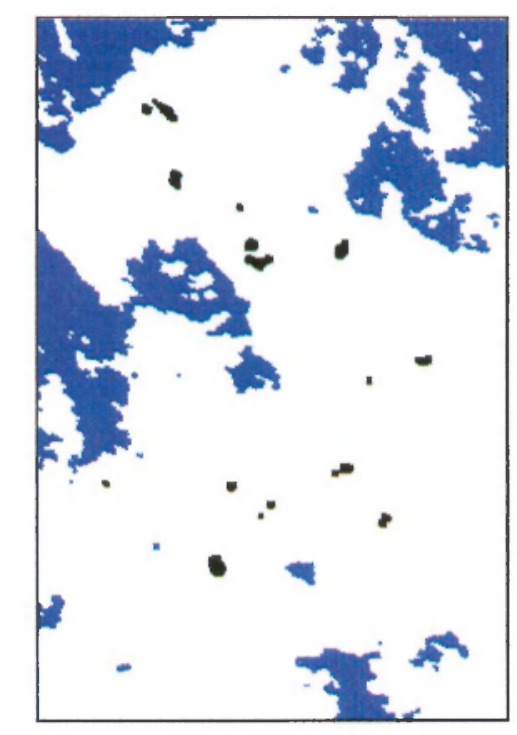

(c)

Figura 5.19: Segmentação de uma imagem aérea de ninhal (a) Imagem original $(282 \times 420$ pixels); (b) Segmentação realizada em 100 estágios (contagem: 16 pássaros); (c) Segmentação realizada em 100 estágios: $L=3$ (contagem: 16 pássaros). 


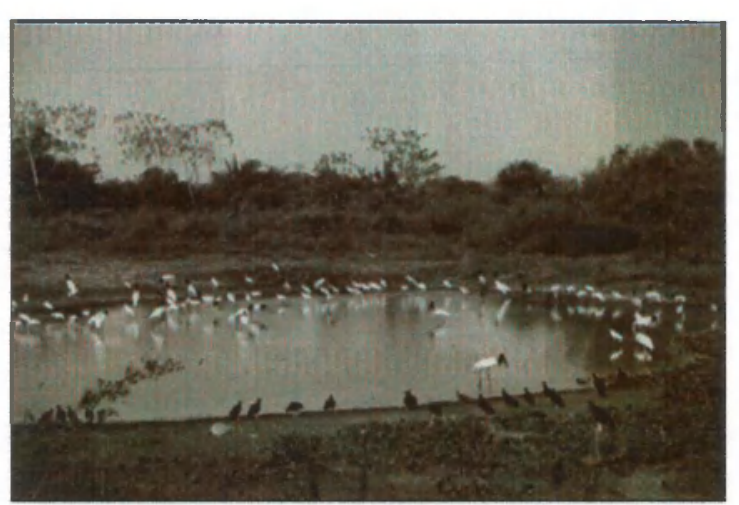

(a)

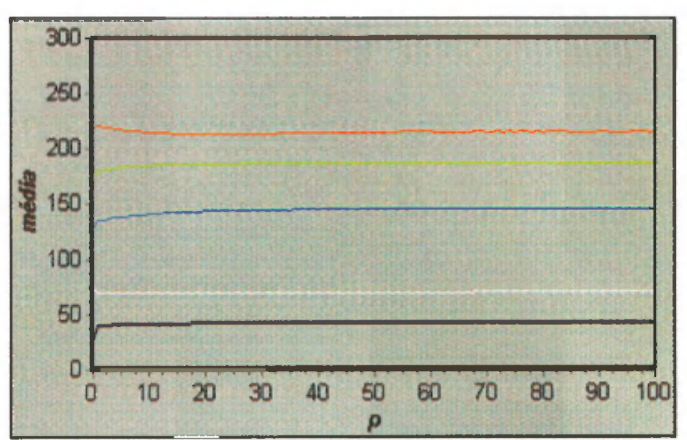

(c)

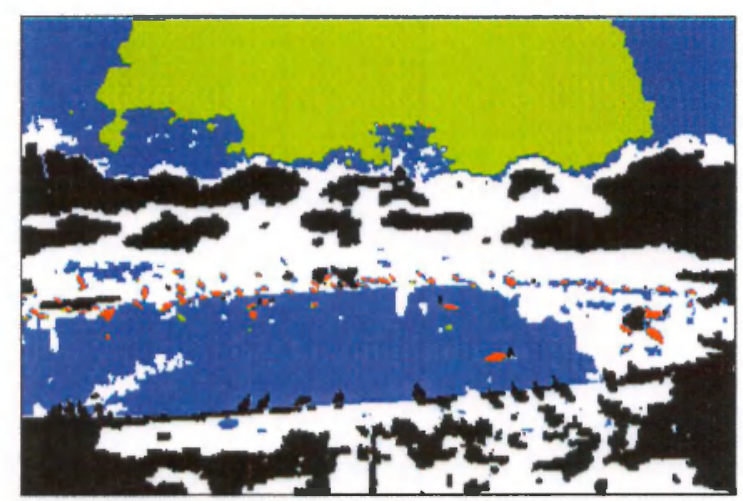

(b)

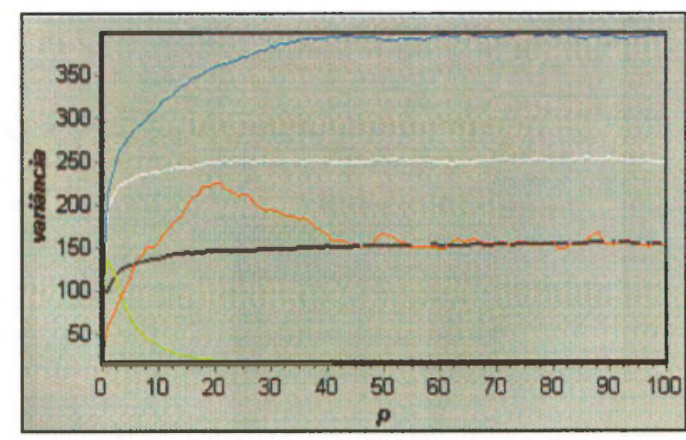

(d)

Figura 5.20: Segmentação de uma imagem de um bando de garças: $L=5$ (a) Imagem original $(430 \times 285$ pixels); (b) Segmentação realizada em 100 estágios (contagem: 75 pássaros). 


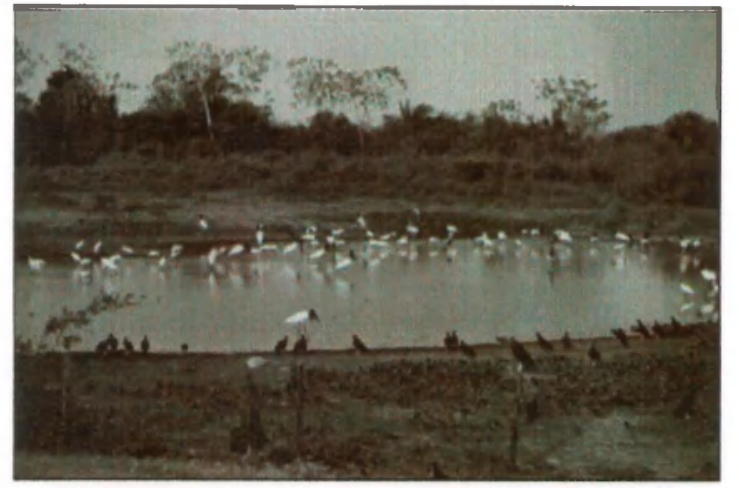

(a)

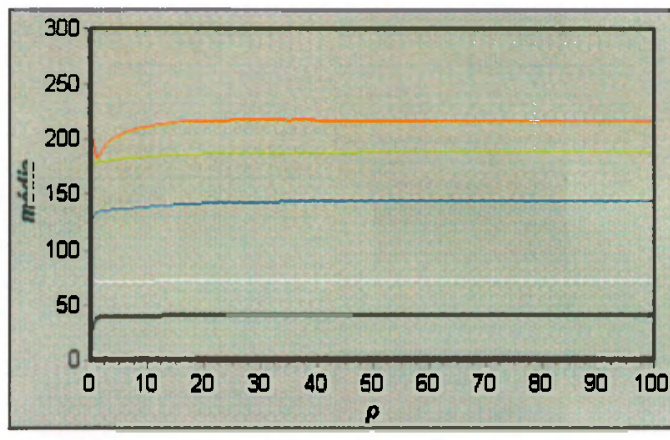

(c)

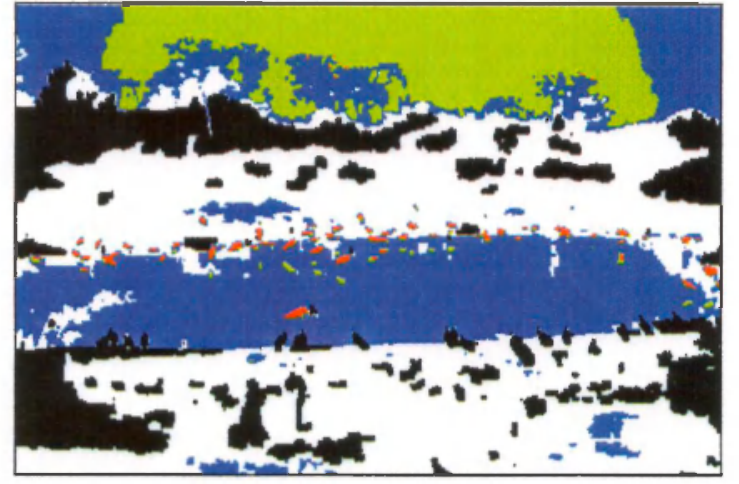

(b)

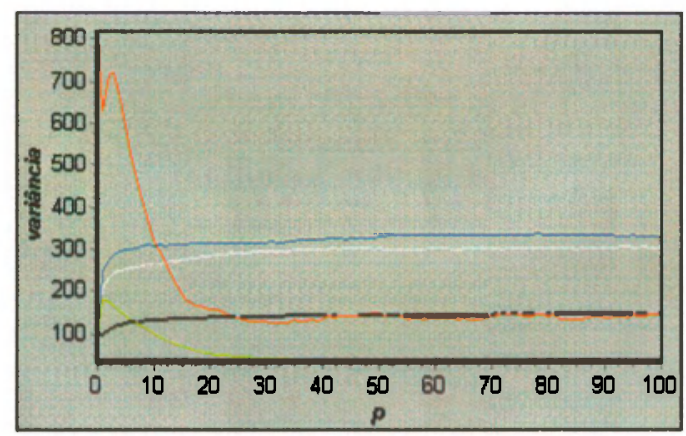

(d)

Figura 5.21: Segmentação de uma imagem de um bando de garças: $L=5$ (a) Imagem original (425 × 281 pixels); (b) Segmentação realizada em 100 estágios (contagem: 68 pássaros). 


\section{Conclusões}

Este trabalho teve como abordagem principal o estudo e a implementaçäo clo mótodo do sognentaça basoado en textura EM/MPM. O programa desenvolvido foi ntilizado para

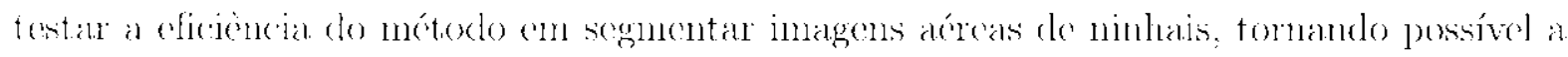
contidgem antonútica do número de individuos (aves) presentes en cada cena.

Os resultados apresentados no capítulo 5 demonstram que o método foi capaz de classifican corretanente a maioria das regiós da imagen correspondente à classe dos pássaros. As

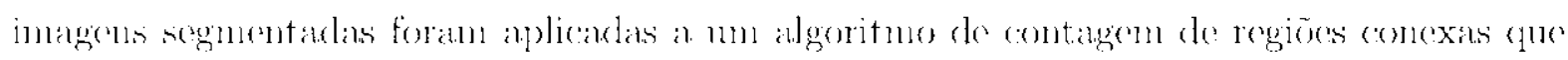
permitiu obter una costimativa válida para o múmero de indivíduos de cada inagem. Foi observado que o erro cometido pelo sistema na contagem em questäo aparece om decomencia de duas callacterísticas inerentes das imagens utilizadas: a ocorrencia de dois ou mais pássaros

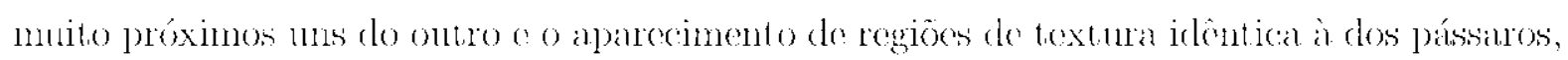
como ó o caso dos pontos da fotografia que sofreram mua superexposiçäo luminosa.

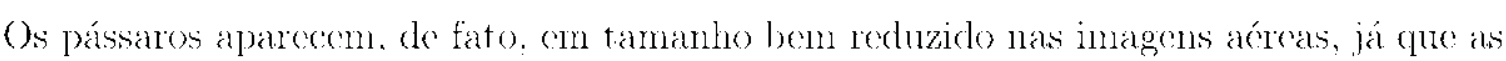
fotogratias foran tiradas com a aeronaves solorevoando o ninhlad a uma altitude aproximada de

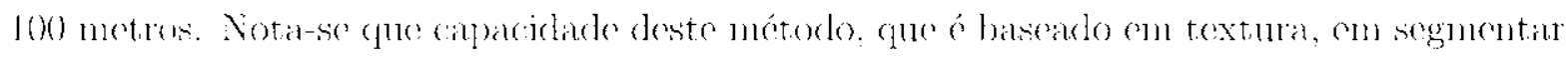

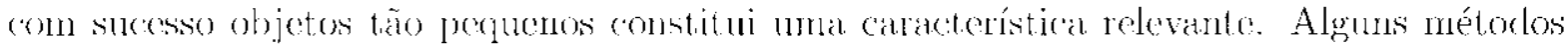
tradicionais de segmentaça por extração de características. como por exemplo os métodos bascados en matrizes do coocomoncia on primitivas run-length. não são capazes de segmentar

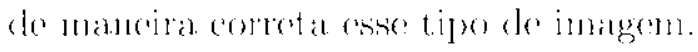

Além das imagens aéross de ninhais tambóm foram utilizados para testes um conjunto de imagens sintéticals a algumas imagens de mannografia. As inagens sintéticas são com-

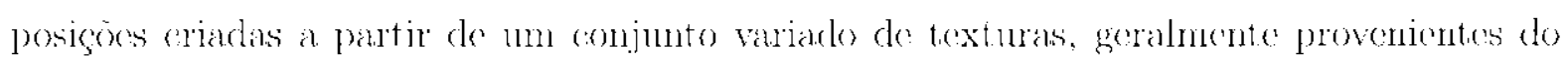


combecido állumm de Brodatz. Observa-se, que o método FN/MPM segmenta tais inagens aproximando-so bastante do resultarlo considerado, intuitivamente, como ideal. Os pixels classificades de maneira incorreta encontranu-se. na maioria das veges, próxinos às fronteiras

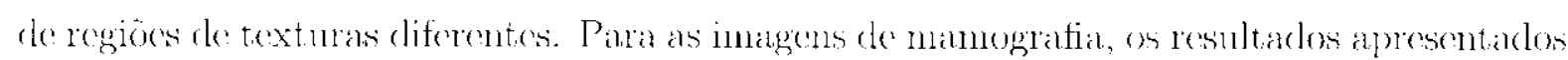

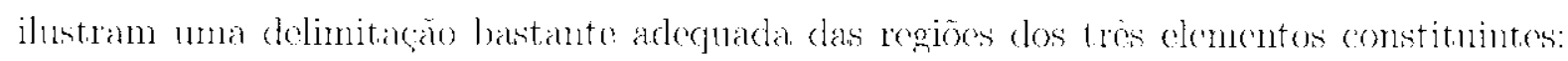
plano de fundo, tecido nomal a tumor.

Enn vista desses resultados, pode-se dizer que o nétodo de segmentadga EM/. MPM representa unn operaio interessante para o desenvolvinento de sistemas de análise de tipos variados do imagens, como por exemplo, imagens de nodalidade mérlica.

Para tormar o mótodo EM/MPM mais robusto ainda foram incorporadas outras duas

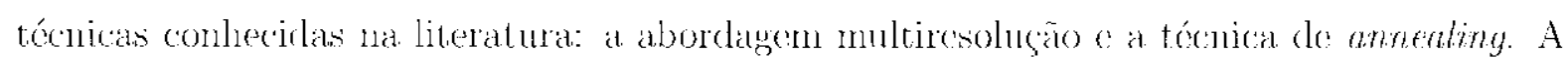

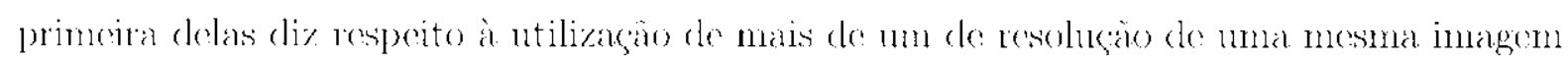
para so alcancar o resultado final do sogmentacão. A utilização desta abordagem proporeiona ao método a capacidade de segmentar regiões de texturas mais grossciras. Alóm disso, tambén foi observado que esta técnica aumenta a velocielade do métode an atingir a sognen-

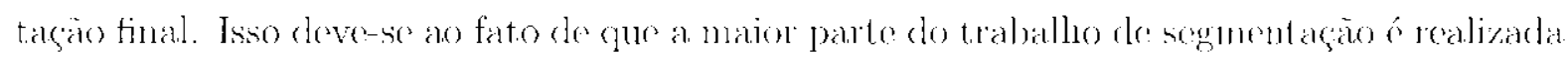
cul um nível de resoluçăo da imagem que possui um número de pixels significativanente menor que o número de pixels da resoluçào original.

l'or sur ve\%, a técuica de Anneantig: que consiste em variar iterativamente o partmetro

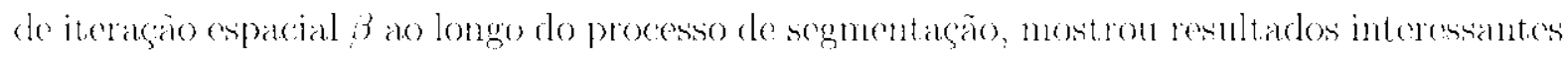
em relagão à dimimugão de rúdos na imagem segmentada e 10 aumento ra volocidarte de convergéncia do algoritmo de estimaçăo de parámetros E.M.

O programa desconvolvido cumpre a propesta de realizar a contagene antomática do nú-

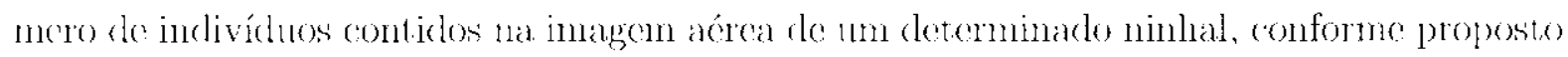
no projeto de pespuisa deste trabalho. Acredita-se que a contagem do numero de ninhos também pode ser realizada com a utilização deste mesmo sistema, levando-se cm consideragio que a textura de um ninho é diferente des texturas dos demais elementos relevantes

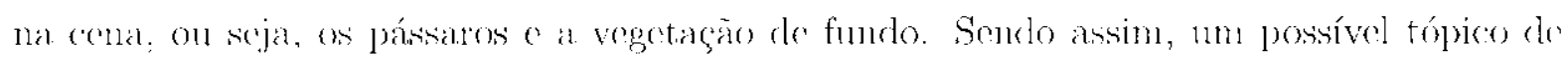
(xtensào para este traballo consiste na aquisiçäo de um novo conjunto de imagens áreas de? ninhais de uma ontra determinada espécie como por excmplo, a espécio dos "ualoças-secan". O grupo desses indivíduos ć conleceido cientifieanente com o nome de Mycteria Americanas

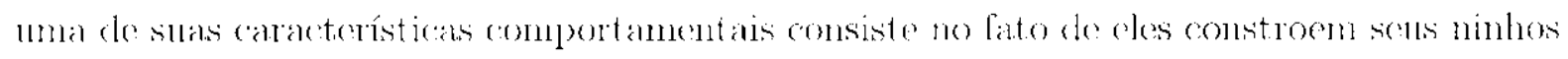
no topo das copas das árvores, e näo no interior delas. como ó o caso das garças brancas. Deste modo, an novas fotogratias arlquiridas contarian náo só com com a presença dos inclividuos da copréce, mas tabubém com as imagens de seun respectivos nimbos. 
Ontra possível extension do trabalho realizado scria a claboraço de um método antomático e dinànico para estimação inicial dos parámetros de média e variância das classesç utilizadas na segmentaçào. De fato, a escollat adeçuadla desses valores iniciais constitui um fator deteminante na obtençäo de nun resultado coerente. Foi observado que deteminades valores de estimaçio inticial fazen com cue o prowesso de segmentaçio convirjal simplesnente, para um resultado final que pouco sc aproximava da segmentaça ideal. Isto pode scr interpretado se levarmos com consideraçăo que o processo tem de convergir atingindo o mínimo local de uma deteminada funģăo multidimensional. Se a superficie desta funģăo possui mais de um ponto de mínimo, entäo o processo tem mais de uma alternativa para a situação de convergencia. Pode-se dizer, então. que o ponto inicial do processo na superfícic em culestäo, praticamente define para qual dos pontos de mínimo o processo irá convergir. 


\section{Referências Bibliográficas}

[ABML89: C. A. Ankenbrandt, B. P. Buckles, F. E. Pelry M., and Lybanon. Ocean feature recognition using genetie algorthms with fuzzy fitness functions, Proc. Thind Anmal Workshopy on Space Operations Automation and Rolotics (1989), 679 686.

[ABP90] C. A. Ankenbrandt, B. P. Buckles, and F. F. Petry, Scene recognition using genetic algorithms with semantice nets, P'attern Recognition Letters 11 (1990), 285293.

[AFIDV90] J. Albert, F. Ferri, J. Domingo, and M. Vicens, An approach to natural setene scgmentation by ments of genetic algorilhms with fuzzy data. Fourth National Sympesimm in Pattern Reregnition and Image Analysis (1990). $97 \cdot 112$.

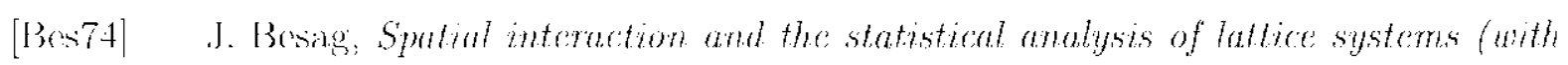
discussion), J. of Royal Statist. Sor 36 (1974), no. 2, 192326.

[Bil98] Je(f A. Bilnes, A grenle tulorial of the em alyorithm and its application to parameter cotimation for gaussian mature and hidden markiov models, Tech. report, Intcrnational Computer Science Institute. 1947 Center St., April 1998.

[B.TC9.5] Davicl A. Bader, Joseph . Jú.Já, and Rama Chellappa, Scalable data parallol atgorithrns for texture synthesis using gibbs random ficlds, IFEE Transactions on Image P'rocessing IP - 4 (1995), 14561460 .

[BL79] S. Bencher and C. Lantoéjoul, Use of watersheds in contona detection, In Proc: luternational Workshop on Inage Processing, Reral-Time Folge and Motion Detection/Extimation. Rennes (1979). 
[BL91] C. Bouman and B. Liu, Multimsolution segmentation of tertumed manges, IEEE Transactions on Pattern Analysis and Nachine Intelligence 13 (1991), no. 2. $99-113$

Bong9] S. Bonton, Ecolourism in wading bird colonies in the brazthun pantanal: biological and socioeconomice implacations. Master's thesis, University of Florida, 1999.

[BP92] J.C. Bozdek and S.K. Pal, Fuzzy models for pattern recognition, IELE (1992).

[Bro66, I'. Brodatz, Textures: a photographio allum for artists and designers, 1966, Dover, New York.

[BS94] C. Bomman and M Shapiro: A multiscale random field model for bayesian image scymentation, ILEE 'Tansaktions on Inage Processing 3 (1994), no. 2, 162177.

[Cai79] D Cains: Censusing hole-nesting auks by visual counts. Bird-Banding 50 (1979). 358364.

[CD()0] Mary L. Comer and Fidward J. Delp, The em/mpm algorithm for segmentation of texturel muges: Analysis and furthet emerimental results, IFEF Transactions on Image Processing 9 (2000), no. 10, 1731 1711.

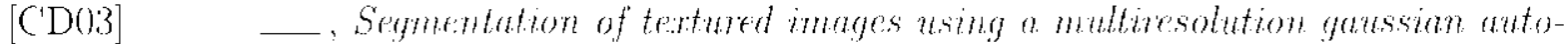
regressite model. ht.tp://citescer.nj.nec.com/14793.html, visitado em janciro de 2003.

[CG92] Goorge Casella and Edward I. George, Explaining the gibbs sampler, The American Statistioian 46 (1992). no. 3, 167-174.

[CLD96] Mary L. Comer, S. Liu, and Edward J. Delp, Statistical segmentalion of mammograms, Procecelings of the 3nd International Workshop on Digital Manmmography $(1996) \cdot 175478$

[Col97] Michene Collins, The en algorithm, September 1997

[DT,78] II. Digabel and C. Lantuójoul. Iteratine algorithms. In Actes du Second Synpesium Europén d'Analyse Quantitative des Mierostructures en Sciences des Matérianx, Biologio et Méderine, Canı (1978), 85-99.

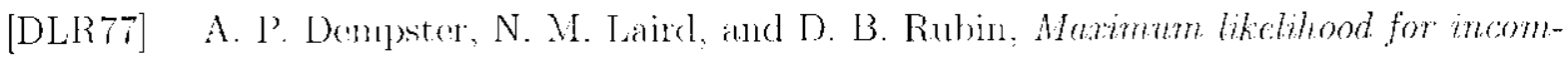
plete data wa em algorithm, J. R. Statist. Soc. B 39 (1977), 1-38. 
[Doul98] Fodward R. Doughlerty, Random processese for imaye and signal processing, IFEE Series on Imaging Science and Enginecring. SPIE/IEEE, 1998.

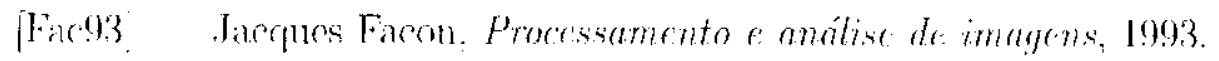

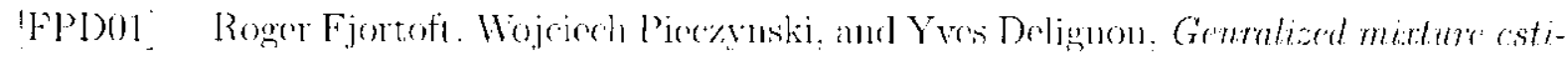
mation and unsupervised classification based on hidden markon chains and hidden matko: fields. Scandinatian Conference on Inage Analysis (2001).

[GBS90] M. Gonkale\%, D. Benitez, and C.P. Sumer, Segmentalion and recognition in visual atromatic spaces, CYBER.NETICS SYSTF.MS 21 (1990), 241247.

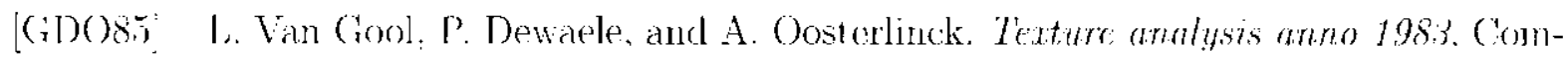
mater Vision, Graphics, and Image Processing 29 (1985). 336355.

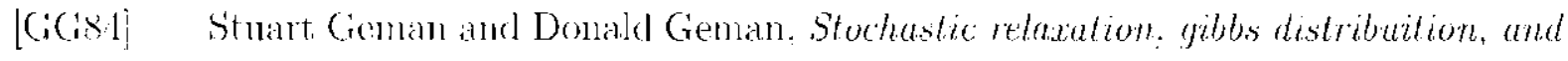

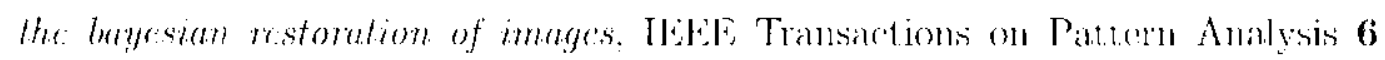
(198.1), 110. (6. 721 inl.

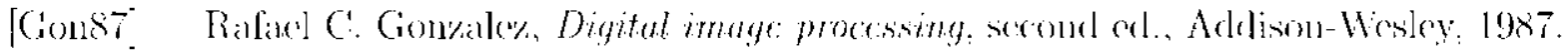

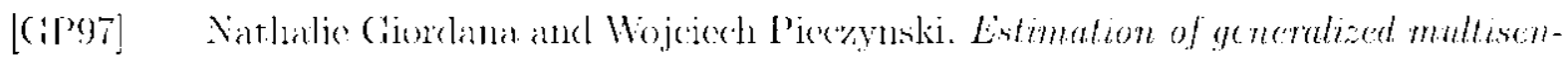

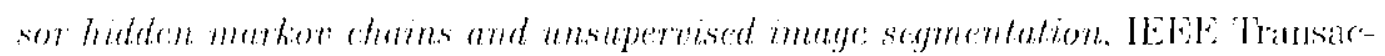
tion on Patten Analysis and Nachine Intelligence (1997), no, 5. 465) 175.

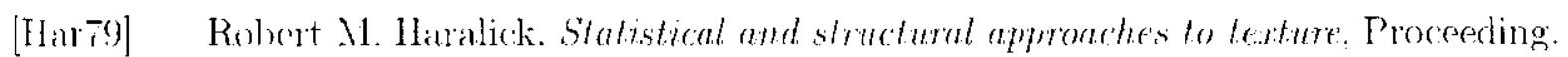
IEFE. $(1979)$, 110. $67,786604$.

[IB96] Donald Hearn and .1. Panlino Baker, Computer gruphics, Prentice Hall. 1996.

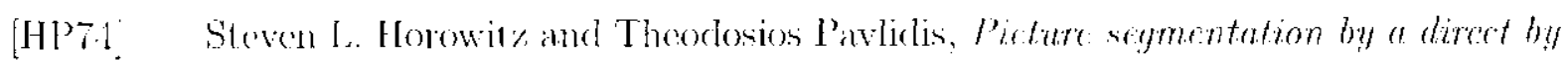
a direded split-and-merge procedure. second ed., Addison-Wosley. 1974.

[LE:OO) IEEE. Lees standard 610.4-1990 - standard glossary of image processing and patItrn recognition terminology. ILEL P'ress. 1990.

[X98] I.Nilscinemo and J. Nascimento, Databank of the birl colonies in brazil, Meeting of the colonial waterbirel socioty. Miami. Resume. $8(0)(1998)$, 55.

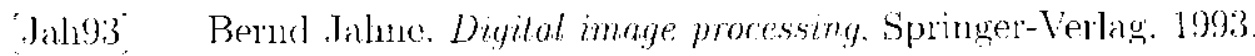

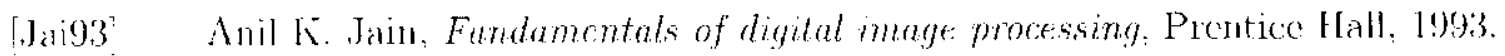




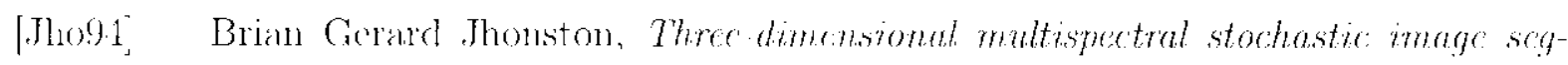
mentation, Mastor's thesis, University of British Columbia, January 1994.

[KDHs8; P. A. Kelly. H. Derin, and K. D. Hart, Adaptine segmentation of speckled images uning a herarchical random field model. IEEE Transactions on Acoustics, Speech and Signal P'rocessing 36 (1988), 16261641.

LD89] S. Iakshmanan and H. Derin, Simultaneous ponrameler estimation and segmen-

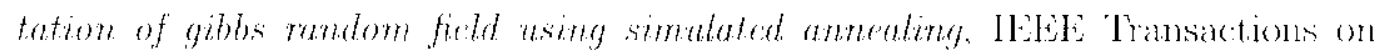
Pattern Analysis and Machine Intelligenen 11 (1989). 799 -813.

[Leng7] Peter M. Lor, Bayesian statisties: An introduction, secomd ort. Armold, 1997

[LL90) Y. W. Lin and S.U. Lee, On the color mage scgmentution algorithm bused on the thresholding and the fuzzy c-metans techniques. PIR 23 (1990), 935-952.

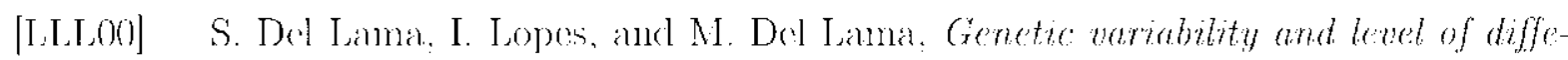
rentiation in wood stork populations., IBIS (2000).

[M.J92] .J. Mao and $\mathrm{A}$. K. Jain, Texture classification and segmentation using multiresolution shmulaneous autoregressive models. Pattern Recognition 25 (1992), no. 2, $17318 \%$

[MAL'87] J. Marroguin, S. Mitter, and T. Poggio, Probabiliste solution of illposed problems in computurional vision. The Anerican Statistician 82 (1987), 7689

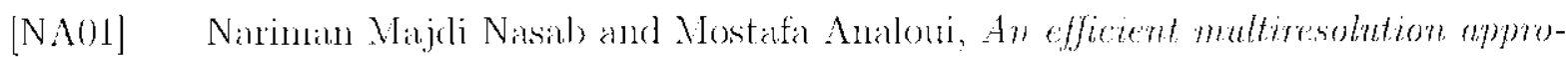
ach for mage segmentution based on mathow mondom field. Proceedings of SPIL $4322(2001), 1066-1074$.

[Nas98] I. Nascimento, Waterbirds colomes in the pantanal area whth an emphasts on then temporal and spacial scales. Meeting of the colonial waterbird society, Miani. Restuno, 80p) (1998), 2'3.

[NKI9:3] I. Ng, J. Kittler, and J. Illingworth. Superviscd segmentation using u multirsolution data represcotution. Signal Processing 31 (1993), no. 2, 133 163.

[Pa]92] T. N. Palpas, An adaptue clustering alqurithm for mage segmontation, IEEE Transactions on Signial Processing 40 (1992), 901-914

[RB93] Todel R. Reed and J. M. Hans Du Buf. A remen of recent terture segmentation. and feature extraction techniques, Image Understanding 57 (1993), no. 3, 359 372. 
[RMO0)] Jos B.T.M. Roerdink and Arnold Meijster, The watershed transform: Defmitions, algorithms and parallelization stralegies, Fundamenta Informaticae 41 (2000)). 187228 .

[Ros:97] Anders Rosholm, Statistical methods for segmentation and classification of imagrs, Ph.D. thesis, Teehnical University of Denmark, 1997.

[RW84] R. A. Redner and 11. F. Walker, Mixture densities, maximum likelihood and teh em algorithm, Soc. Ind. App)l. Math. Rev. 26 (1984), 195239.

[Son199] Millan Sonkia. Image processing. analysis and machine vision. PWS, 1999

[SsWCss, P.K. Sahoo. S. Soltani, A.K.C. Wong. and Y.C. Chen, A survey of thresholding techniques. Computer Vision. Craphices and Image Processing 41 (1988), 233 260 .

[Tan96] Martin A. 'Timmer, Tools for statistical informe: methods for the exploration. of prosterior distributions and likelihood functions, Springer scries in Statistics. Springer, 1996

[TCROO)] O. Trindade, M. Carmo, and E. Ribciro, Small aincraft for application in agricullure, Published on Anais (eletronic format) of the 2000 ASAE Amual International Meoting, Nilwakee. Wisconsin, USA, 2000.

[VS91] L. Vincent and P. Soille, Watersheds in digital spaces: an cficient algorithm based on immersiun simulations. IEEE Transactions on Pattern Analysis and Maxdine Intelligence $13(1991)$, no. 6. 5833598

[Wingos] Gorhard Winkler, Image analysis. random fields and dynamis: monte carto methods: a mathematical introduction, Applications of mathematiss, vol. 27 , Springer, 1995

[WuS3] C. F. Jeff W11, On the conmergence properties of the em algorithm, The Annals Statistics 11 (1983), no. 1, 95-103. 